\title{
Diagnostic and therapeutic guidelines for plaque psoriasis - Brazilian Society of Dermatology*
}

\author{
Marcelo Arnone ${ }^{1}$, Maria Denise Fonseca Takahashi ${ }^{1}$, André Vicente Esteves de Carvalho², Wanderley \\ Marques Bernardo ${ }^{3}$, Aline Lopes Bressan ${ }^{4}$, Andrea Machado Coelho Ramos ${ }^{5}$, Aripuanã Cobério Terena ${ }^{6}$, \\ Cacilda da Silva Souza ${ }^{7}$ Daniel Holthausen Nunes ${ }^{8}$, Maria Cecília de Carvalho Bortoletto ${ }^{9}$, Maria de \\ Fátima Santos Paim de Oliveira ${ }^{10}$, Jane Marcy Neffá ${ }^{11}$, Luciana Cristina Fieri ${ }^{12}$, Luna Azulay-Abulafia ${ }^{13,14}$, \\ Paulo Antônio Oldani Felix ${ }^{15}$, Renata Ferreira Magalhaes ${ }^{16}$, Ricardo Romiti ${ }^{1}$, Tatiana Jerez Jaime ${ }^{17}$
}

DOI: http:/ /dx.doi.org/10.1590/abd1806-4841.2019940211

\begin{abstract}
Psoriasis is a chronic inflammatory disease that affects $1.3 \%$ of the Brazilian population. The most common clinical manifestations are erythematous, scaling lesions that affect both genders and can occur on any anatomical site, preferentially involving the knees, elbows, scalp and genitals. Besides the impact on the quality of life, the systemic nature of the disease makes psoriasis an independent risk factor for cardiovascular disease, especially in young patients with severe disease. By an initiative of the Brazilian Society of Dermatology, dermatologists with renowned clinical experience in the management of psoriasis were invited to form a work group that, in a partnership with the Brazilian Medical Association, dedicated themselves to create the Plaque Psoriasis Diagnostic and Treatment Guidelines. The relevant issues for the diagnosis (evaluation of severity and comorbidities) and treatment of plaque psoriasis were defined. The issues generated a search strategy in the Medline-PubMed database up to July 2018. Subsequently, the answers to the questions of the recommendations were devised, and each reference selected presented the respective level of recommendation and strength of scientific evidence. The final recommendations for making up the final text were worded by the coordinators.
\end{abstract}

Keywords: Biological therapy; Comorbidity; Dermatology; Practice guidelines as topic; Psoriasis

Recebido 14 December 2018

Aceito 28 January 2019.

* Work conducted at the Sociedade Brasileira de Dermatologia, Rio de Janeiro (RJ), Brazil.

Financial Support: None.

Conflict of Interest: The coauthors hereby declare that they participated in meetings and talks and/or received support from the following pharmaceutical laboratories: Marcelo Arnone: Abbvie, Glenmark, Janssen, Leo Pharma, Lilly, Novartis, Pfizer, UCB Biopharma; Maria Denise Fonseca Takahashi: Abbvie, Janssen, and Pfizer; André Vicente Esteves de Carvalho: Abbvie, Janssen, Lilly, Novartis, and UCB; Biopharma; Wanderley Marques Bernardo: none; Aline Lopes Bressan: Abbvie; Andréa Machado Coelho Ramos: Abbvie, Janssen, Lilly, Novartis, Sanofi, and UCB; Biopharma; Aripuana Cobério Terena: Abbvie, Janssen, Lilly, Novartis, and Sanofi; Cacilda da Silva Souza: Abbvie, Janssen, Leo Pharma, Lilly, and Novartis; Daniel Holthausen Nunes: Abbvie, Janssen, Novartis, and Sanofi; Maria Cecília de Carvalho Bortoletto: Abbvie, Janssen, and Novartis; Maria de Fátima Santos Paim de Oliveira: Abbvie, Janssen, Leo Pharma, and Novartis; Jane Marcy Neffá: Abbvie and Pfizer; Luciana Cristina Fieri: none; Luna Azulay-Abulafia: Abbvie, Janssen, Leo Pharma, Lilly, Novartis, Pfizer, and Roche; Paulo Antônio Oldani Felix: Abbvie, Astra-Zeneca, Janssen, Leo Pharma, Lilly, Novartis, UCB Biopharma; Renata Ferreira Magalhaes: Abbvie, Janssen, Lilly, Novartis, and Pfizer Ricardo Romiti: Abbvie, Galderma, Janssen, Leo Pharma, Lilly, Novartis, Sanofi, and UCB Biopharma; Tatiana Jerez Jaime: none

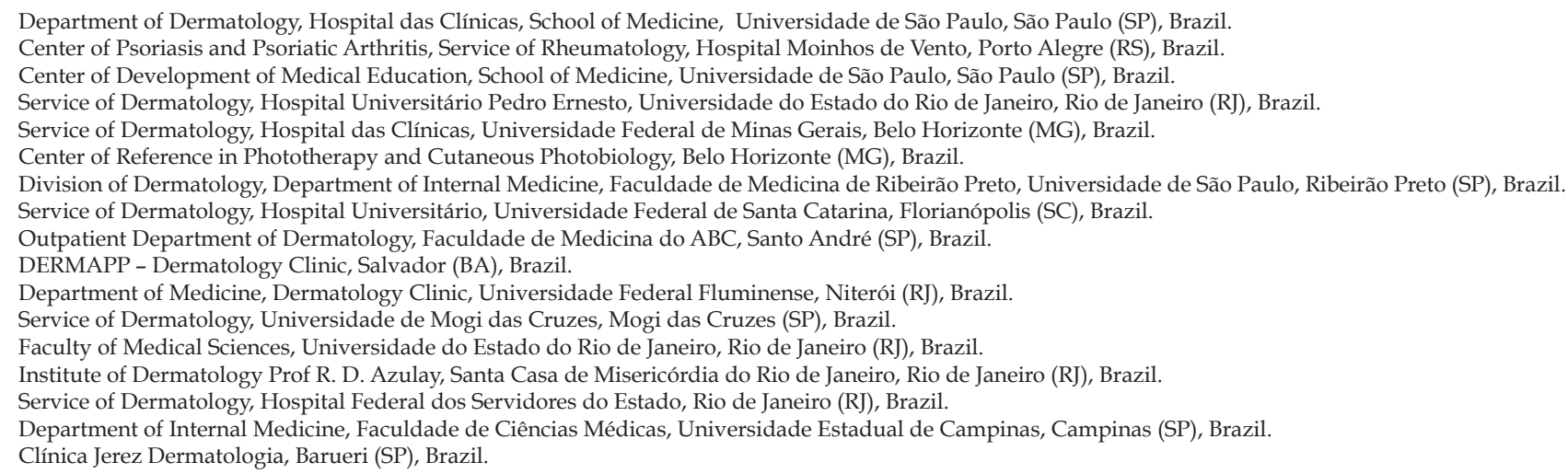

E-mail: arnones@uol.com.br 


\section{INTRODUCTION}

In an initiative of the Brazilian Society of Dermatology, dermatologists with proven practical experience in the clinical management of psoriasis were invited to be part of a work group which, in partnership with the Brazilian Medical Association, was dedicated to develop the Plaque Psoriasis Diagnostic and Treatment Guidelines. Relevant issues for the diagnosis (assessment of severity and comorbidities) and treatment of Plaque Psoriasis were defined. These issues were structured with the P.I.C.O. strategy (patient; intervention or indicators; comparison; outcome). Such strategies used Medline-PubMed database up to July 2018. The articles selected in the first search strategy were submitted to the critical evaluation of evidences using the Jadad score. Subsequently, answers were drafted to the questions of the Recommendations, with each reference selected demonstrating its respective degree of recommendation and strength of scientific evidence. The final Recommendations were drafted by the coordinators for the development of the final text. Details of the methodology as well as the complete version of these guidelines can be accessed through the link http:// diretrizes.amb.org.br/?s=psoriase ${ }^{1}$

Grade of recommendation and strength of evidence

A: Experimental and observational studies of best consistency.

B: Experimental and observational studies of lower consistency.

C: Case reports (uncontrolled studies).

D: Opinion lacking critical evaluation, based in consensus, physiological studies or animal models.

\section{OBJECTIVE}

To establish the recommendations for the diagnosis (assessment of severity and comorbidities) and the treatment of plaque psoriasis.

\section{TOOLS OF SEVERITY ASSESSMENT}

With the aim of evaluating the role of the assessment tools applied to psoriasis patients, a Medline-PubMed database search was conducted, resulting in 984 studies, of which 14 were selected to answer to the clinical question. ${ }^{2-15}$

What is the role of the assessment tools PASI, BSA, DLQI and PGA for the assessment of severity and therapeutic response of plaque psoriasis?

\subsection{PASI}

In the PASI (Psoriasis Area Severity Index) score, the evaluator should observe the erythema, thickness, scaling, and the percentage of the area affected of four regions (head/neck, trunk, lower and upper limbs) and calculate the score, which varies from 0 to $72(\mathbf{B}) .^{15}$

In the evaluation of severity in plaque psoriasis patients, the PASI tool demonstrated adequate content validity and internal consistency and moderate intraobserver variation. Despite some limitations, PASI can be recommended for the scientific evaluation of the severity of plaque psoriasis (B). ${ }^{16}$

\subsection{PGA}

This tool [Physician's Global Assesment (PGA)] only evaluates the features of the lesion, measuring the degree of erythema, scaling and thickness of psoriasis lesions of the whole body, grading in a six-point scale, ranging from 0 (no lesion) to 6 (severe); however, it does not provide information on the extension of the disease (B). ${ }^{15}$ It demonstrated adequate content validity, moderate interobserver variation and low intraobserver variation (B). ${ }^{16}$

\subsection{BSA}

BSA (Body Surface Area) was defined as the percentage of body area, where $1 \%$ corresponds to approximately the palm of the hand of the patient being assessed (B). ${ }^{15}$ It demonstrated little intraobserver variation, however, an unacceptable interobserver variation for the evaluation of the severity of disease. It is not adequate to define psoriasis severity because it does not assess the intensity of the lesion $(\mathbf{B}){ }^{16}$

\subsection{DLQI}

The Dermatology Life Quality Index (DLQI) measures the impact of the skin disease in the quality of life of the patient in the last seven days. It consists of 10 items, six dimensions and one overall summary score. Each question has four alternative answers: "not at all", "a little", "a lot" or "very much", with scores of $0,1,2$ and 3, respectively. The overall summary score aggregates the score of each item and ranges between 0 (the best score) and 30 (the worst score). (B).$^{10}$ In plaque psoriasis patients, the DLQI tool demonstrated adequate content validity, construct validity, internal consistency, replicability, acceptability and sensitivity in appropriately detecting changes in the disease $(\mathbf{B}) .{ }^{4}$ Due to its briefness and simplicity, it is useful for the clinical practice $(\mathbf{B}) .^{3}$

\subsection{NAPSI}

NAPSI (Nail Psoriasis Severity Index) is used to evaluate the severity of psoriasis in the nail bed and nail matrix. The nail plate is divided into quadrants using an imaginary longitudinal and horizontal lines. The involvement of the nail matrix and nail bed is assessed, and the score ranges from 0 to 8 per nail. The tool is replicable and the analysis is simplified (B).$^{13}$ Although it has a few limitations (B), the scoring agreement among observers was considered between good to moderate with NAPSI (B)..$^{2,9}$

\subsection{PGA X BSA (PGA multiplied by BSA)}

The instrument PGA X BSA was calculated multiplying the PGA result by BSA. When associated to BSA, a tool that evaluates the body surface area involved, PGA showed moderate to high correlation with changes in PASI (0.53-0.89) to detect disease severity (B). ${ }^{15}$ Using PGA $x$ BSA to evaluate the clinical response and define minimal disease activity, the author found a significant correlation with percentage changes in PASI $(0.915-0.943 ; \mathrm{P}<.001)$ and medium correlation compared to DLQI (0.303-0.407; P <.008), independent of the category of baseline PASI score (12-19 or higher than 20) (B). ${ }^{5}$ 


\subsection{PASI versus DLQI}

When the mean percentage of PASI improvement was compared to the mean improvement with DLQI, the value of the correlation coefficient observed was of 0.898 ( $\mathrm{p}<0.01)$, showing a high correlation between the indexes (Spearman correlation coefficient $=0.87$, where the coefficient higher than 1 demonstrates total agreement) (A). ${ }^{11}$

\subsection{PASI versus PGA}

The two instruments, PASI and PGA, when used to evaluate the PASI 75 therapeutical response $(75 \%$ or more reduction in the PASI score) e and PGA zero (no lesion) or 1 (almost no lesion), showed high correlation with each other $(\mathrm{p}<0.01)$. PGA and PASI are redundant, and the use of either PASI or PGA only is recommended (A) $\cdot{ }^{13}$ There is a high correlation between those two tools (Spearman correlation coefficient $=0.87$ ), with low intra-evaluator variation for PGA (and high variation for PASI. The inter-evaluator variation was higher with PASI when compared to PGA (B). ${ }^{7}$

\section{Recommendations:}

The instrument PASI is recommended for the evaluation of the severity of the disease and the therapeutical response. The reduction in the PASI score has a good correlation with the clinical improvement seen by the physician and with the improvement of the symptoms reported by the patients.

The instrument DLQI showed a high correlation with PASI in patients with moderate to severe psoriasis, being a useful instrument for the clinical practice due to its briefness and simplicity.

The instrument PGA, when associated to BSA, has a high correlation with the instrument PASI, and is recommended for the evaluation of disease severity. Differently to PASI, PGA has the advantage of not depending of the experience of the evaluator (low intra-evaluator variation).

NAPSI is a simple tool that can be used to evaluate nail psoriasis. It has good to moderate scoring agreement between observers.

\section{PREVALENCE OF COMORBIDITIES}

Psoriasis is a chronic inflammatory condition that has been associated to a number of comorbidities. With the aim of determining the main comorbidities associated to plaque psoriasis patients, a search was carried out in the Medline-PubMed database, resulting in 873 studies, of which 73 were selected to answer the clinical question. ${ }^{17-89}$

What are the main comorbidities associated to psoriasis? 2.1 Depression

The prevalence of depression in psoriasis patients in the random effects model is of 16\% (CI 95\%: 13.2-19.3; Figure 1).

\subsection{Anxiety}

The prevalence of anxiety disorder in psoriasis patients in the random effects model is of $15.4 \%$ (CI 95\%: 10.6-21.7; Figure 2).

\subsection{Suicide attempt}

The prevalence of suicide attempt in psoriasis patients in the random effects model is of $2.9 \%$ (CI 95\%: 1.4-5.9; Figure 3).

\subsection{Asthma or COPD}

The prevalence of asthma or chronic obstructive pulmonary disease (COPD) in psoriasis patients in the random effects model is of $2.7 \%$ (CI 95\%: 1.3-5.5; Figure 4).

\section{Depression}

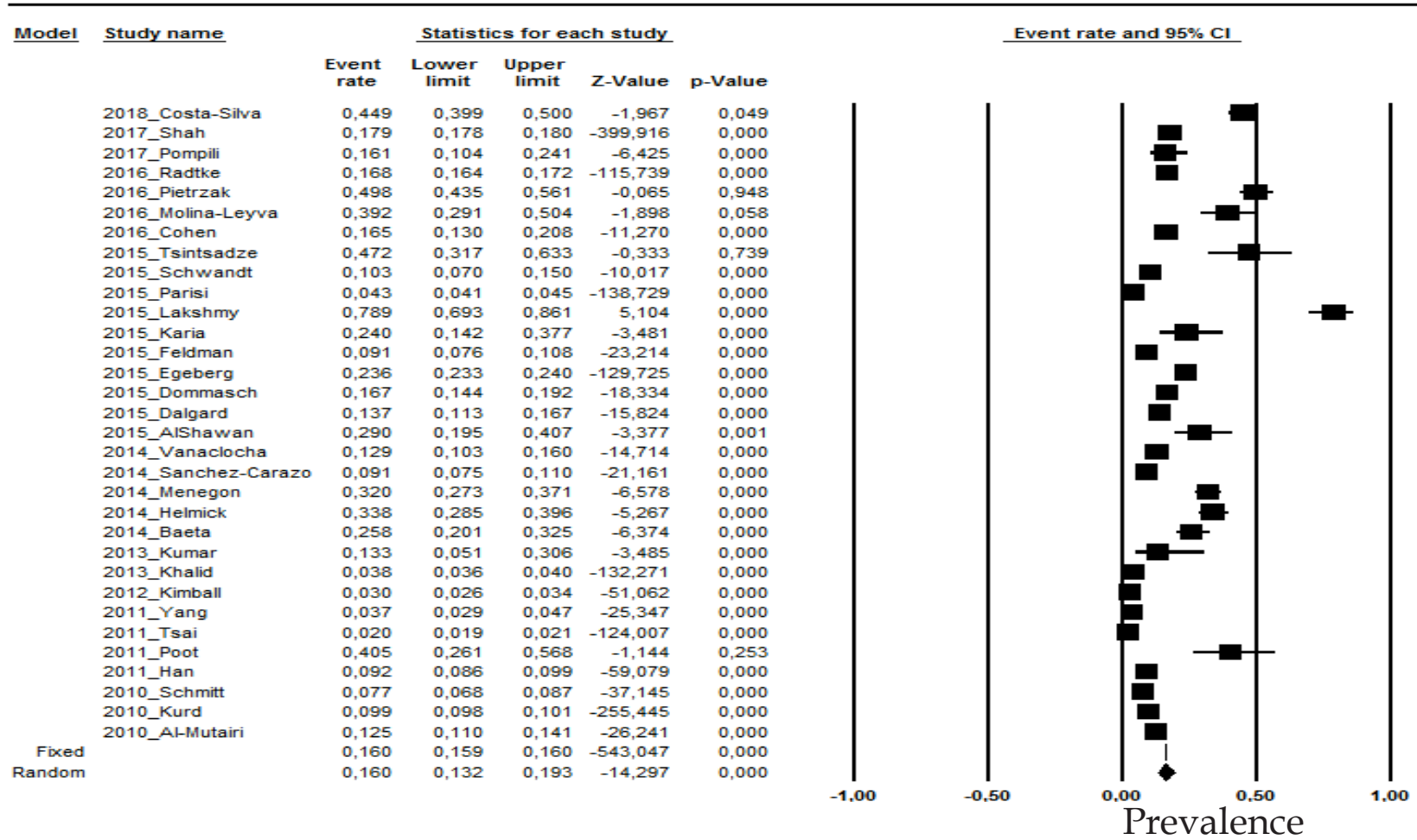

Figure 1: Prevalence of depression in moderate to severe plaque psoriasis patients 
2.5 Chronic liver disease

The prevalence of chronic liver disease in psoriasis patients in the random effects model is of $0.8 \%$ (CI 95\%: 0.1-4.9; Figure 5).

2.6 Nonalcoholic fatty liver disease

The prevalence of nonalcoholic fatty liver disease in psoriasis patients in the random effects model is of $15.3 \%$ (CI 95\%: 5.8-34.5; Figure 6).

\subsection{Obesity}

The prevalence of obesity in psoriasis patients in the random effects model is of 25.6 (CI 95\%: 22.7-28.7; Figure 7).

\subsection{Dyslipidemia}

The prevalence of dyslipidemia in psoriasis patients in the random effects model is of 20.4\% (CI 95\%:13.6-29.3; Figure 8).

\section{Añxiety}

Model Study name

Fixed

Random

2015_Karia

2012 Kimbal

2011_Han

2010_Kurd
2017_Pompili 2015_Tsintsadze

2015_Lakshmy

2015_Feldman

2015_Dalgard

2015_AlShawan

2014 Sanchez-Carazo0,159

\section{Statistics for each study}

\section{Event Lower Upper}

rate limit limit $Z$-Value $p$-Value

0,125

0,556

0,767

0,120

0,059

0,227

0,304

0,075

0,393

0,200

0,707

$0,668 \quad 0,843$

0,05

0,04

0,196

0,208

0,137

0,018

0,069

0,075

0,076

0,154

$\begin{array}{lll}0,015 & 0,021 & -45,810\end{array}$

$\begin{array}{llll}0,064 & 0,075 & -58,883\end{array}$

$0,074 \quad 0,076-256,281$

$0,074 \quad 0,077-267,408$

0,106

$0,217 \quad-7,887$
0,000

0,506

0,000

000

0,002

0,000

0,000

0,000

, 000

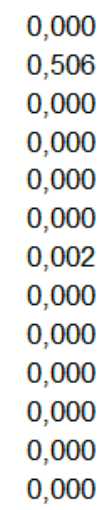

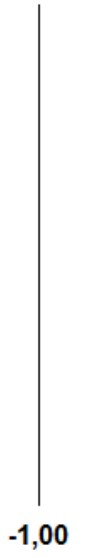

Event rate and $95 \% \mathrm{Cl}$
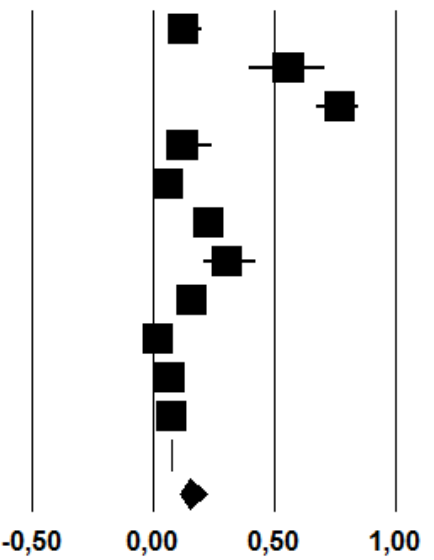

Prevalence

FIGURE 2: Prevalence of anxiety in moderate to severe plaque psoriasis patients

Suicide attempt

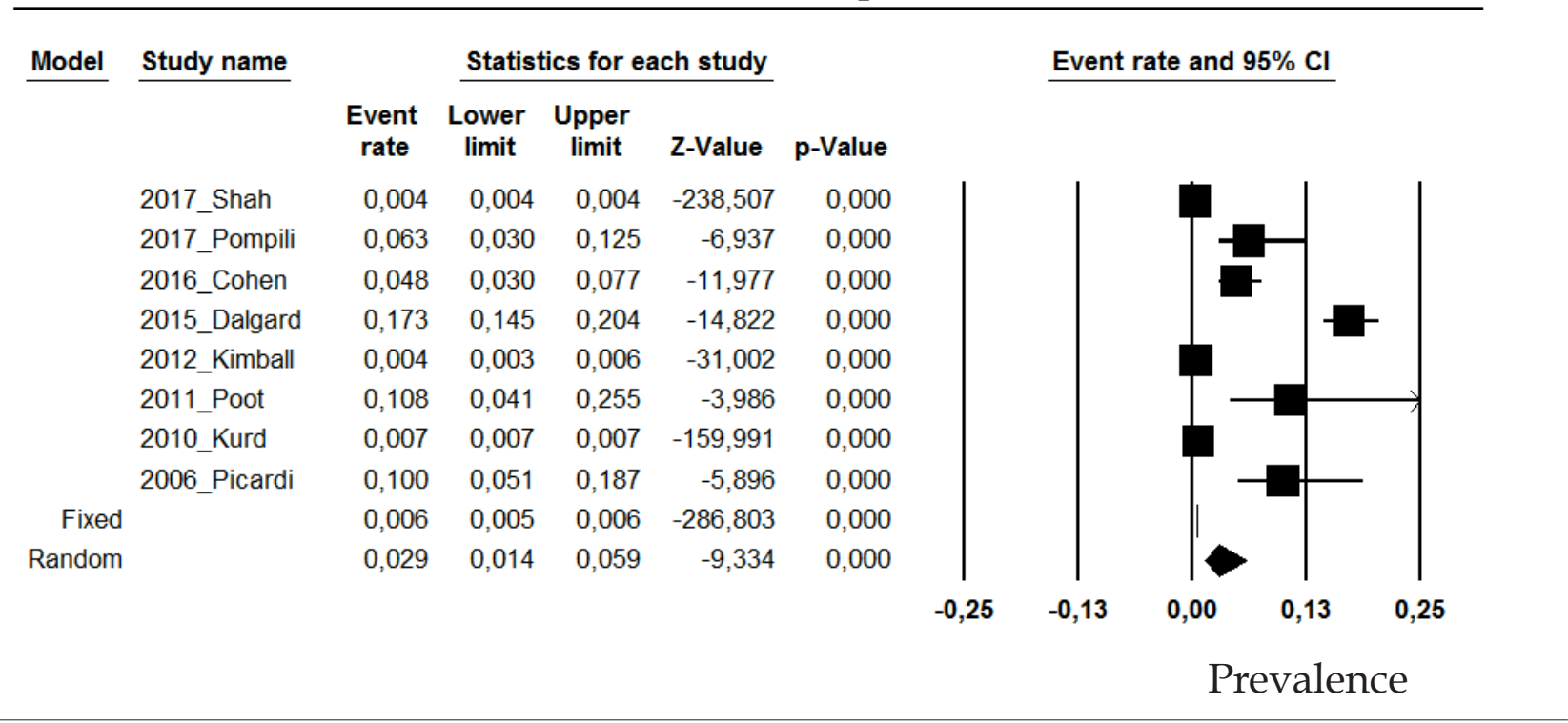

FigURE 3: Prevalence of suicide attempt in moderate to severe plaque psoriasis patients 


\subsection{Systemic hypertension}

The prevalence of systemic hypertension (SHT) in psoriasis patients in the random effects model is of $26.9 \%$ (CI 95\%: 21.5-33; Figure 9).

\subsection{Diabetes mellitus}

The prevalence of diabetes mellitus (DM) in psoriasis patients in the random effects model is of $11.7 \%$ (CI 95\%: 8.9-15.2; Figure 10).

\subsection{Coronary insufficiency}

The prevalence of ischemic cardiomyopathy or coronary insufficiency in psoriasis patients in the random effects model is of 3.4\% (CI 95\%: 2.3-5\%; Figure 11).

\subsection{Inflammatory bowel disease}

The prevalence of inflammatory bowel disease in psoriasis patients in the random effects model is of 0.9\% (CI 95\%: 0.6-1.3; Figure 12).

\subsection{Migraine}

The prevalence of migraine in psoriasis patients in the random effects model is of 15.5\% (CI 95\%: 0.3-84.8; Figure 13).

\subsection{Other comorbidities}

Other prevalent comorbidities in psoriasis patients were alexithymia; other dermatological conditions such as seborrheic dermatitis, acne, rosacea; pulmonary hypertension; and celiac disease (Table 1).

\section{Asthma/COPD}

\begin{tabular}{|c|c|c|c|c|c|c|c|c|c|c|}
\hline \multirow[t]{11}{*}{ Model } & Study name & \multicolumn{4}{|c|}{ Statistics for each study } & \multirow[b]{2}{*}{ p-Value } & \multicolumn{4}{|c|}{ Event rate and $95 \% \mathrm{Cl}$} \\
\hline & & $\begin{array}{l}\text { Event } \\
\text { rate }\end{array}$ & $\begin{array}{l}\text { Lower } \\
\text { limit }\end{array}$ & $\begin{array}{l}\text { Upper } \\
\text { limit }\end{array}$ & Z-Value & & & & & \\
\hline & 2017_Shah & 0,074 & 0,073 & 0,075 & $-453,028$ & 0,000 & & & & \\
\hline & 2015_Khalid & 0,004 & 0,003 & 0,004 & $-89,483$ & 0,000 & & & & \\
\hline & 2015_Egeberg & 0,003 & 0,003 & 0,003 & $-82,773$ & 0,000 & & & & \\
\hline & 2014_Vanaclocha & 0,047 & 0,032 & 0,069 & $-14,649$ & 0,000 & & & & \\
\hline & 2013_Yeung & 0,151 & 0,144 & 0,159 & $-58,772$ & 0,000 & & & & \\
\hline & 2013_Khalid & 0,001 & 0,001 & 0,002 & $-52,542$ & 0,000 & & & & \\
\hline & 2011_Yang & 0,184 & 0,166 & 0,203 & $-23,757$ & 0,000 & & & & \\
\hline & 2010_Al-Mutairi & 0,054 & 0,044 & 0,066 & $-26,354$ & 0,000 & & & & \\
\hline & 2008_Dreiher & 0,057 & 0,053 & 0,061 & $-72,744$ & 0,000 & & & & \\
\hline Fixed & & 0,073 & 0,072 & 0,073 & $-475,759$ & 0,000 & & & 1 & \\
\hline Random & & 0,027 & 0,013 & 0,055 & $-9,433$ & 0,000 & & & & \\
\hline & & & & & & & $-0,25$ & $-0,13$ & 0,00 & 0,25 \\
\hline
\end{tabular}

Figure 4: Prevalence of Asthma/COPD in moderate to severe plaque psoriasis patients

\section{Chronic liver disease}

\begin{tabular}{|c|c|c|c|c|c|c|}
\hline \multirow[t]{2}{*}{ Model } & \multirow[t]{2}{*}{ Study name } & \multirow[b]{2}{*}{$\begin{array}{l}\text { Event } \\
\text { rate }\end{array}$} & \multicolumn{3}{|c|}{ Statistics for each study } & \multirow[b]{2}{*}{ p-Value } \\
\hline & & & $\begin{array}{l}\text { Lower } \\
\text { limit }\end{array}$ & $\begin{array}{l}\text { Upper } \\
\text { limit }\end{array}$ & Z-Value & \\
\hline & 2014_Vanaclocha & 0,042 & 0,028 & 0,062 & $-14,397$ & 0,000 \\
\hline & 2014_Sanchez-Carazo & 0,022 & 0,014 & 0,032 & $-17,708$ & 0,000 \\
\hline & 2013_Yeung & 0,000 & 0,000 & 0,001 & $-15,441$ & 0,000 \\
\hline Fixed & & 0,021 & 0,016 & 0,028 & $-26,240$ & 0,000 \\
\hline Random & & 0,008 & 0,001 & 0,049 & $-5,104$ & 0,000 \\
\hline
\end{tabular}

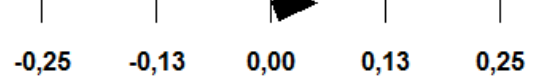

Prevalence

FIGURE 5: Prevalence of chronic liver disease in moderate to severe plaque psoriasis patients 


\section{Recommendations:}

Psychiatric comorbidities, such as depression and anxiety, and the diseases associated to metabolic syndrome, such as obesity, nonalcoholic fatty liver disease, diabetes, systemic hypertension and dyslipidemia stand out among the possible comorbidities associated to psoriasis.

\section{TOPICAL TREATMENT}

The topical treatment modality is used in clinical practice for all patients with plaque psoriasis, regardless of the severity of the disease. With the aim of establishing the recommendations on the topical treatment of plaque psoriasis, a search was carried out in the Medline-PubMed database, and 29 studies were selected to answer the clinical questions. ${ }^{42,89-116}$

\section{Non-alcoholic fatty liver disease}

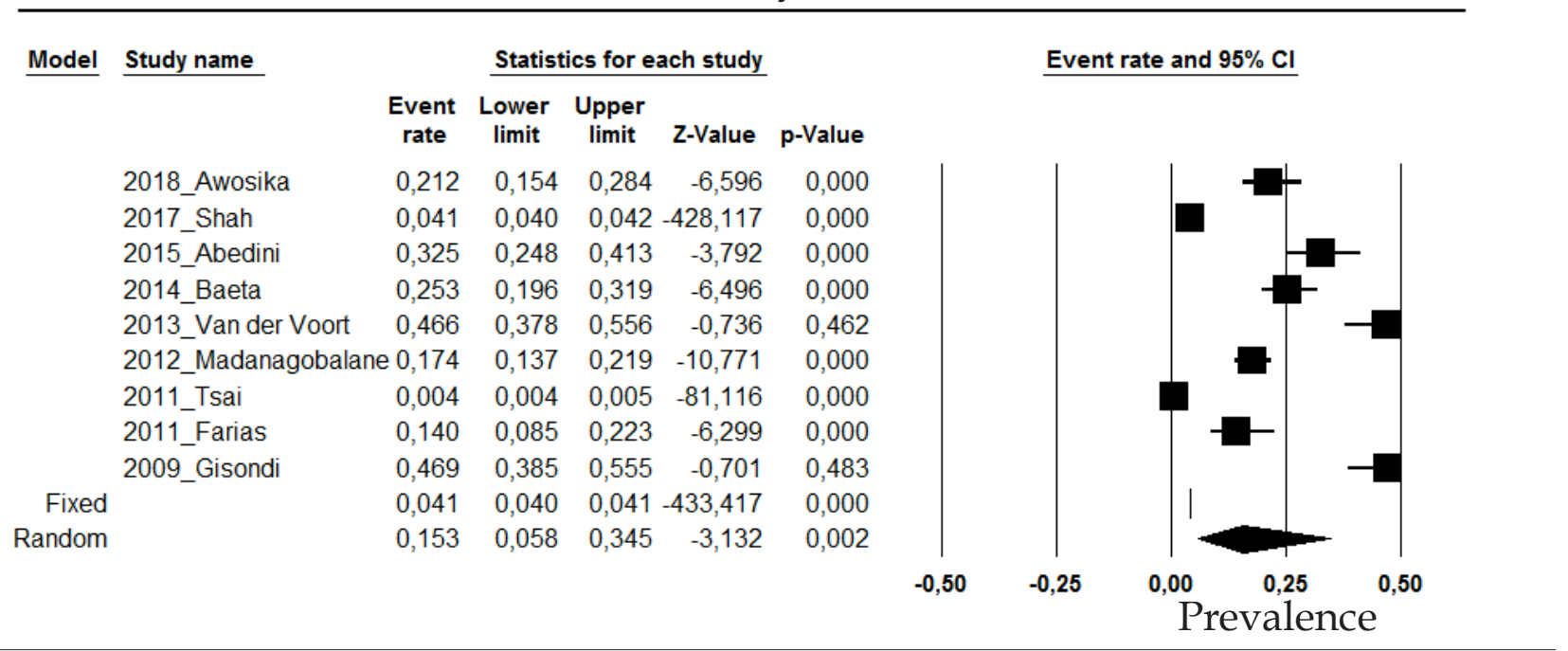

Figure 6: Prevalence of non-alcoholic fatty liver disease in moderate to severe plaque psoriasis patients

\section{Obesity}

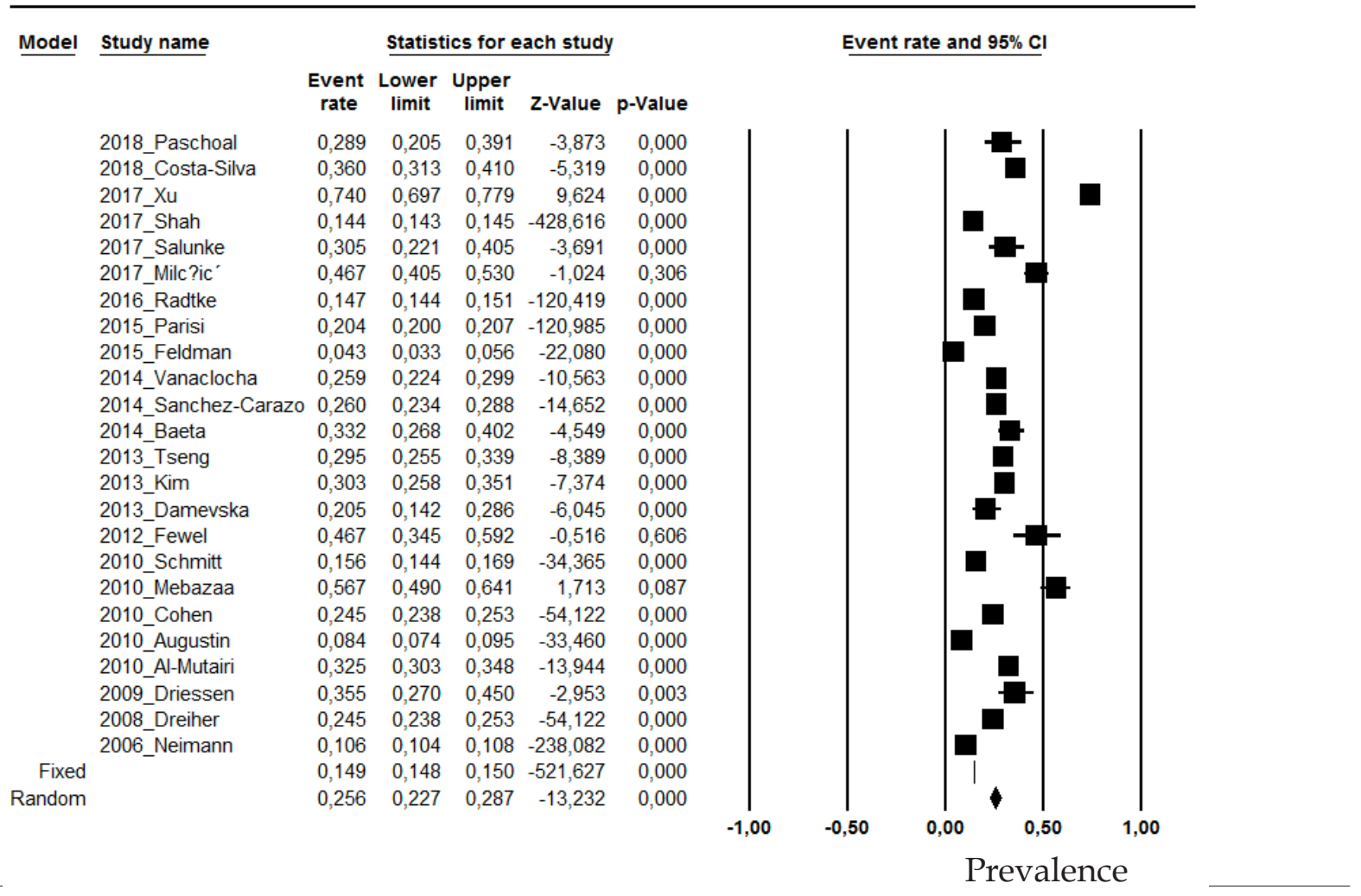

Figure 7: Prevalence of obesity in moderate to severe plaque psoriasis patients 
3.1. What is the efficacy and the risk of topical corticosteroids for the treatment of psoriasis?

Twice-daily application of $0.05 \%$ clobetasol propionate spray or placebo for four weeks, in placebo-controlled studies, showed improvement of psoriasis lesions after four weeks [Number Needed to Treat $(\mathrm{NNT}=2)]$, with significant response in the intervention group already on the first week of treatment $(\mathrm{p}<0.001)$. Local burning sensation was observed in similar rates to the placebo group. No serious adverse event was reported ${ }^{89}(\mathbf{A})^{101}$ (A).

In a study that evaluated clobetasol propionate lotion, cream or its vehicle, the use of lotion and cream showed significant and similar improvement $(\mathrm{p}<0.001)$. There was a reduction of lesions in $55 \%$ of patients using clobetasol propionate in both groups of active treatment $(\mathrm{NNT}=2)$ on the fourth week. Three patients of each treatment group with the active ingredient reported telangiectases, and four patients in the group using clobetasol cream reported mild to moderate skin atrophy (A). ${ }^{92}$

The use of $0.05 \%$ clobetasol propionate foam for two weeks was more effective than placebo (vehicle with no active ingredient), with improvement ranging from $47 \%$ to $22 \%$ (placebo) of patients reaching PGA score 0 or $1(\mathrm{p}<0.0001, \mathrm{NNT}=3)$. The most common adverse event was burning sensation on the area of application $(5 \%$ of the patients in the intervention group and $7 \%$ of the comparison group). There were no severe side effects, (A). $\cdot^{97,108}$

The use of betamethasone valerate (BMV) on one side of the body and placebo on the other side, twice daily for 12 weeks lead to at least $50 \%$ improvement against $24 \%$ in the placebo group (NNT= 4). Adverse events were limited, being burning sensation and pruritus the most common (A). ${ }^{114}$ When the investigator's global assessment is used for completely clear or almost clear lesions, there is a $64 \%$ reduction $(\mathrm{p}<0.0001, \mathrm{NNT}=2)$ for the use of clobetasol propionate foam and $57 \%$ reduction $(\mathrm{p}<0.0001, \mathrm{NNT}=2)$ for the use of clobetasol propionate solution when compared to their corresponding vehicles on the scalp. The percentage of patients that reported adverse events was not significantly different among the comparison groups (A). ${ }^{96}$

The safety and efficacy of $0.005 \%$ fluticasone propionate ointment for four weeks was evaluated, in comparison with its vehicle. There was significantly more improvement in the intervention group $(\mathrm{p}<0.0001)$ measured by PGA $0 / 1$ between $29.4 \% \quad(\mathrm{NNT}=4)$ and $36 \%(\mathrm{NNT}=3)$. The adverse events were mild to moderate, the most common being burning sensation and pruritus on the area of application, which occurred in $6 \%$ of patients, both in the intervention and the comparison group (A). ${ }^{109}$

\section{Dyslipidemia}

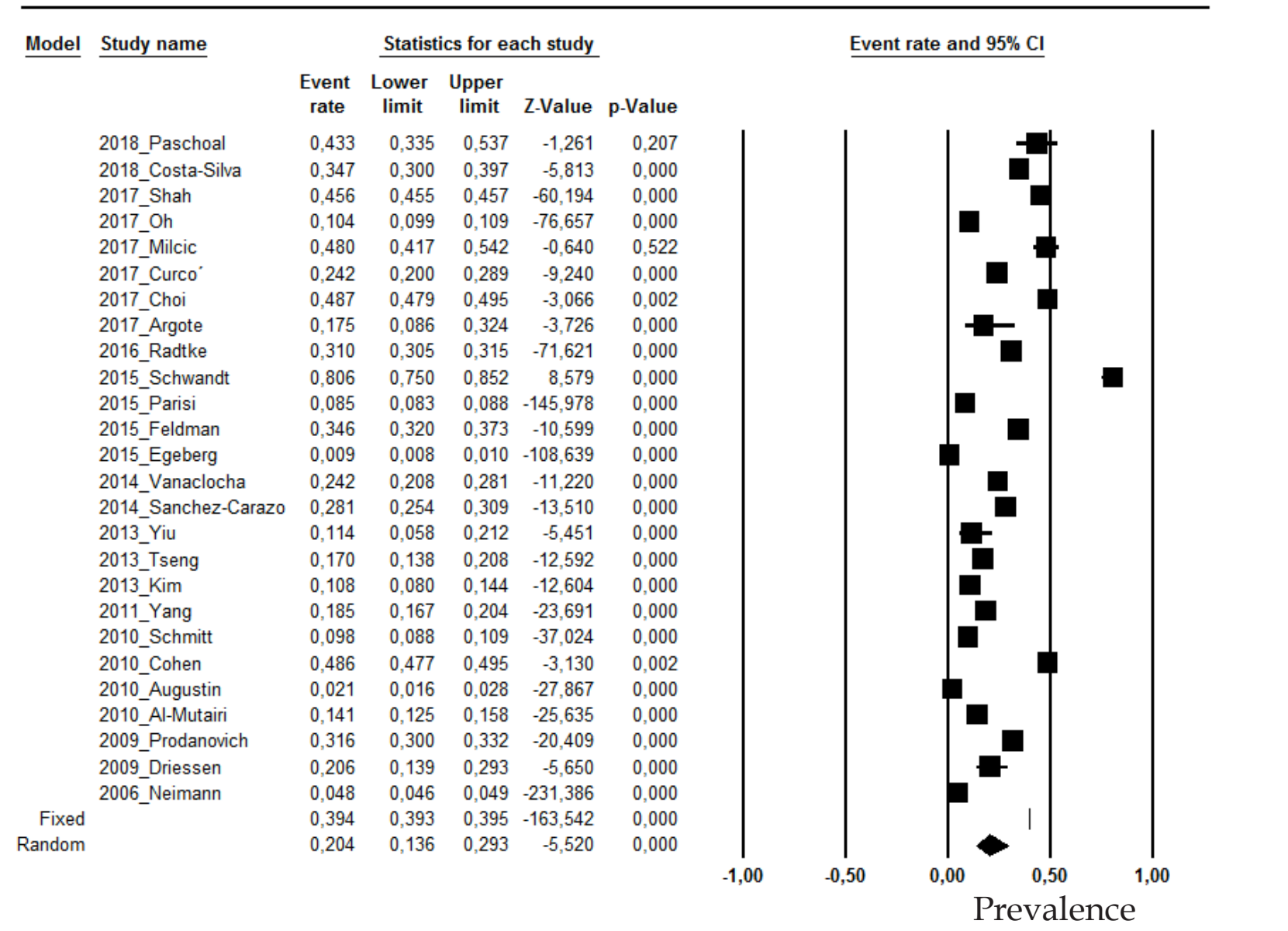

FigURE 8: Prevalence of dyslipidemia in moderate to severe plaque psoriasis patients 
In the comparison between $0.05 \%$ betamethasone propionate ointment, its ointment vehicle and $0.05 \%$ diflorasone diacetate ointment, the group using betamethasone showed a faster improvement, seen already on the first week of treatment, with significant difference in relation to the group using diflorasone or to the control group ( $\mathrm{p}=0.01$ ). The improvement seen was maintained on the third week. The adverse events were minimal (A). ${ }^{105}$

\section{Recommendations:}

In plaque psoriasis, the use of the topical corticosteroids clobetasol propionate, betamethasone valerate and fluticasone propionate, proved to be significantly effective in improving signs and symptoms of erythema, scaling, thickness of the plaque and pruritus, besides the significant improvement in the evaluation of the physician or the patient regarding clearance of the lesions. The most frequent adverse events were burning sensation and stinging on the area of application, both with the active ingredient and the placebo, with no significant difference among the comparison groups.
3.2 What is the efficacy and risk of tar derivatives (coal tar and liquor carbonis detergens - LCD) for the treatment of psoriasis?

The use of $2 \%$ dithranol ointment, for one minute, once daily, associated to UVB phototherapy, resulted in significant clearance measured by the physician and the patient after eight weeks, except for pruritus ( $p=0.004$ ). The adverse event reported during the study was skin irritation on the area of application (A). ${ }^{42}$

\section{Recommendations:}

Of the tar derivatives, only dithranol (associated to phototherapy) showed significant efficacy in the improvement of erythema, scaling and thickness of psoriasis plaques, not being effective for the improvement of pruritus. The adverse event observed with dithranol was local skin irritation.

There are no evidences that allow for the recommendation of coal tar and Liquor Carbonis Detergens for the treatment of Plaque Psoriasis.

\begin{tabular}{|c|c|c|c|c|c|}
\hline 2018_Paschoal & 0.444 & 0,345 & 0,548 & $-1,052$ & 0,293 \\
\hline 2018_Costa-Silva & 0.484 & 0,433 & 0,535 & $-0,622$ & 0,534 \\
\hline 2017 Xu & 0,510 & 0.484 & 0,557 & 0,430 & 0,688 \\
\hline 2017_Shah & 0,422 & 0,421 & 0,423 & $-108,406$ & 0,000 \\
\hline 2017_Salunke & 0,179 & 0,114 & 0,289 & $-5,692$ & 0,000 \\
\hline 2017_Oh & 0,182 & 0,176 & 0,189 & $-67,538$ & 0,000 \\
\hline 2017_Milcic & 0,672 & 0,611 & 0,728 & 5,264 & 0,000 \\
\hline 2017_Eppinga & 0,189 & 0,171 & 0,209 & $-23,098$ & 0,000 \\
\hline $2017^{\prime}$ Curco & 0,303 & 0,258 & 0,353 & $-7,211$ & 0,000 \\
\hline 2017_Choi & 0,519 & 0,511 & 0,527 & 4,489 & 0,000 \\
\hline 2017_Argote & 0,350 & 0,219 & 0,508 & $-1,887$ & 0,062 \\
\hline 2016_Radtke & 0,417 & 0,412 & 0,422 & $-32,050$ & 0,000 \\
\hline 2016_Pietrzak & 0,230 & 0,181 & 0,288 & $-7,858$ & 0,000 \\
\hline 2015_Schwandt & 0,882 & 0,811 & 0,901 & 9,625 & 0,000 \\
\hline 2015 _Parisi & 0,154 & 0,151 & 0,157 & $-135,473$ & 0,000 \\
\hline 2015_Khalid & 0,009 & 0,008 & 0,010 & $-117,685$ & 0,000 \\
\hline 2015 _Feldman & 0,358 & 0,331 & 0,385 & $-9,839$ & 0,000 \\
\hline 2015 _Egeberg & 0,042 & 0,041 & 0,044 & $-153,702$ & 0,000 \\
\hline 2015 _Abedini & 0,106 & 0,062 & 0,174 & $-7,282$ & 0,000 \\
\hline 2014_Vanaclocha & 0,242 & 0,208 & 0,281 & $-11,220$ & 0,000 \\
\hline 2014_Sanchez-Carazo & 0,183 & 0,160 & 0,208 & $-18,495$ & 0,000 \\
\hline 2014_Menegon & 0,577 & 0,525 & 0,628 & 2,875 & 0,004 \\
\hline 2014_Baeta & 0,437 & 0,368 & 0,508 & $-1,736$ & 0,082 \\
\hline 2013_Yiu & 0,143 & 0,079 & 0,246 & $-5,246$ & 0,000 \\
\hline 2013_Tseng & 0,398 & 0,354 & 0,444 & $-4,274$ & 0,000 \\
\hline 2013_Kim & 0,143 & 0,111 & 0,183 & $-12,053$ & 0,000 \\
\hline 2013_Damevska & 0,303 & 0,228 & 0,390 & $-4,223$ & 0,000 \\
\hline 2011_Yang & 0.291 & 0,270 & 0,313 & $-16,684$ & 0,000 \\
\hline 2010_Schmitt & 0,428 & 0,409 & 0,443 & $-8,259$ & 0,000 \\
\hline 2010_Mebazaa & 0,524 & 0,448 & 0,600 & 0,624 & 0,532 \\
\hline 2010_Cohen & 0,388 & 0,380 & 0,397 & $-24,827$ & 0,000 \\
\hline 2010_Augustin & 0,016 & 0,012 & 0,022 & $-28,282$ & 0,000 \\
\hline 2010_Al-Mutairi & 0,320 & 0,298 & 0,343 & $-14,308$ & 0,000 \\
\hline 2009_Prodanovich & 0,601 & 0,584 & 0,618 & 11,417 & 0,000 \\
\hline 2009_Driessen & 0,346 & 0,262 & 0,440 & $-3,137$ & 0,002 \\
\hline 2006_Sommer & 0,102 & 0,079 & 0,129 & $-15,873$ & 0,000 \\
\hline 2005_Pearce & 0,287 & 0,256 & 0,320 & $-11,303$ & 0,000 \\
\hline 2001_Naldi & 0,089 & 0,088 & 0,116 & $-15,672$ & 0,000 \\
\hline 1995_Henseler \& Christophers & 0,114 & 0,103 & 0,126 & $-35,332$ & 0,000 \\
\hline & 0,387 & 0,388 & 0,388 & $-178,010$ & 0,000 \\
\hline & 0,289 & 0,215 & 0,330 & $-6,674$ & 0,000 \\
\hline
\end{tabular}

Model Study name
Statistics for each study

Event Lower Upper

rate limit limit Z-Value p-Value

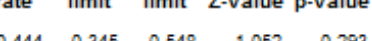

$\begin{array}{lllll}0,484 & 0,433 & 0,535 & -0,622 & 0,534\end{array}$

$\begin{array}{rrrrr}0,510 & 0,464 & 0,557 & 0,430 & 0,688\end{array}$

$\begin{array}{llll}0.421 & 0,423 & -106,400 & 0,000\end{array}$

$\begin{array}{rrrrr}0,672 & 0,811 & 0,728 & 5,264 & 0,000\end{array}$

$\begin{array}{lllll}0,189 & 0,171 & 0,209 & -23,098 & 0,000\end{array}$

$\begin{array}{lll}-7.211 & 0,000\end{array}$

$\begin{array}{lllll}0,350 & 0,219 & 0,508 & -1,887 & 0,062\end{array}$

$\begin{array}{lllll}0,417 & 0,412 & 0,422 & -32,050 & 0,000\end{array}$

$\begin{array}{ll}-858 & 0,000\end{array}$

$\begin{array}{lll}0,901 & 9,625 & 0,000\end{array}$

$\begin{array}{lllll}0.009 & 0,009 & 0,157 & -135,473 & 0,000\end{array}$

$\begin{array}{llllll}0.0095 & 0.331 & 0.395 & -9.839 & 0.000\end{array}$

$\begin{array}{llllll}0,106 & 0,062 & 0,174 & -7,282 & 0,000\end{array}$

$\begin{array}{llllll}0.106 & 0,062 & 0.174 & -7.282 & 0,000 \\ 0.242 & 0.208 & 0.281 & -11.220 & 0,000\end{array}$

$\begin{array}{lllll}0,577 & 0,525 & 0,628 & 2,875 & 0,004\end{array}$

$\begin{array}{llllll}0.143 & 0.079 & 0,248 & -5,248 & 0,000\end{array}$

0,000

0,000

0,532

0,000

0,000

0,000

0,002

0,000

0,000

0,000

0,000 0,000 $\begin{array}{llll}0,5258 & 0,508 & -1,736 & 0,082 \\ 0,079 & 0,248 & -5,249 & 0,000\end{array}$

Systemic hypertension

\section{Event rate and $95 \% \mathrm{Cl}$}

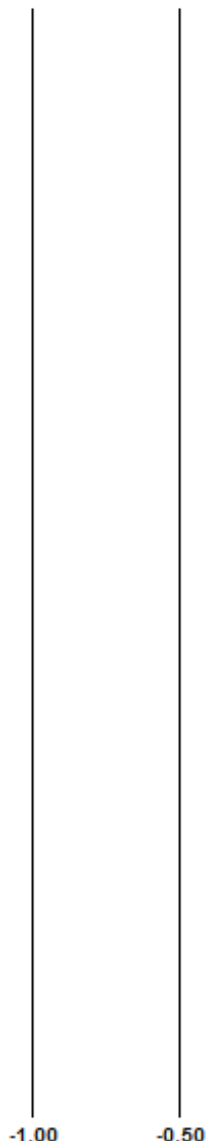

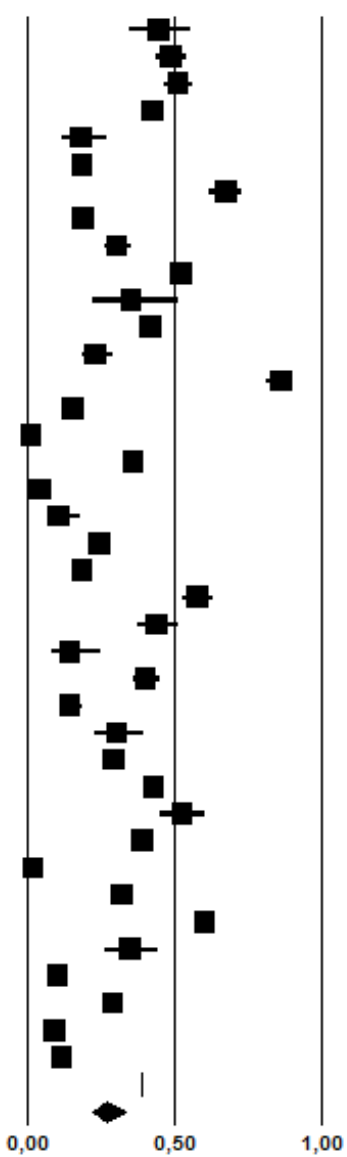

Prevalence

FigURE 9: Prevalence of systemic hypertension in moderate to severe plaque psoriasis patients 


\section{Diabetes}

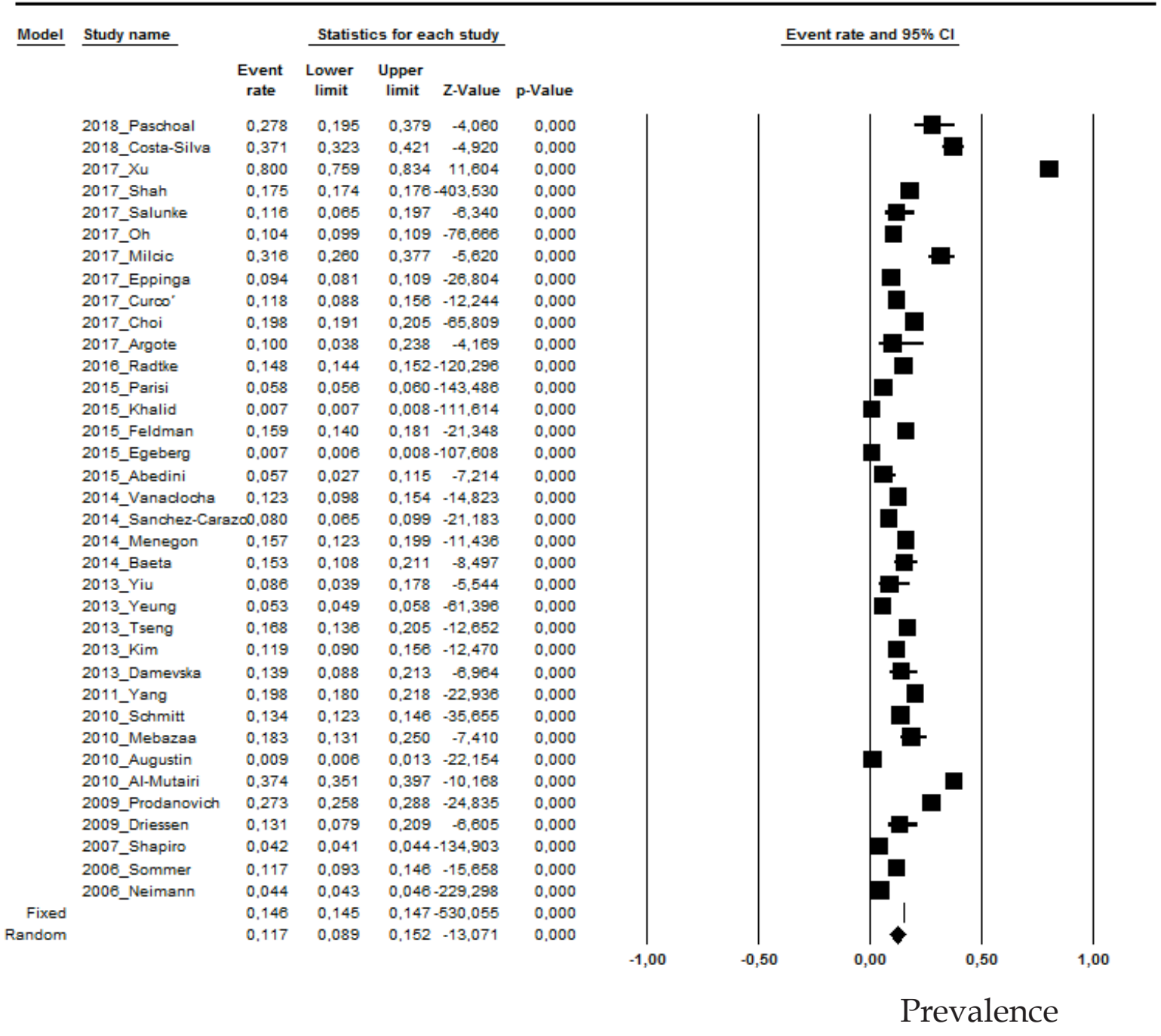

Figure 10: Prevalence of diabetes mellitus in moderate to severe plaque psoriasis patients

3.3 What is the efficacy and risk of topical calcineurin inhibitors for the treatment of psoriasis?

The use of $6 \%$ salicylic acid gel associated to $0.1 \%$ tacrolimus ointment twice daily, on one side of the body, compared to $6 \%$ salicylic acid gel associated to placebo on the other side, lead to an improvement in the pruritus, erythema and scaling on weeks 1,2 and $8(\mathrm{p}<0.05)$, as well as a significant improvement in the global assessment of the disease in week 8 , except for the evaluation of erythema (A) ${ }^{90,90}$ In a study that evaluated twice-daily $0.005 \%$ calcipotriol ointment or once-daily $0.3 \%$ tacrolimus ointment or placebo, there was no significant reduction in PASI with the use of topical tacrolimus in relation to placebo $(p=0.77)(\mathbf{A}) \cdot{ }^{116}$

\section{Recommendations:}

Regarding the topical use of calcineurin inhibitors, tacrolimus does not show significant improvement in PASI reduction. However, in an evaluation eight weeks after starting the application, it proved to be effective for the improvement of pruritus, erythema and scaling of psoriatic plaques. When using the global assessment index from 0 to 5 points, there is no significant improvement in the erythema with the use of tacrolimus. There is no response evaluation after eight weeks of follow-up.

3.4 What is the efficacy and the risk of vitamin D analogues for the treatment of psoriasis?

Calcipotriol ointment at $0.05 \%$ significantly improved lesions compared to the control group $(\mathrm{p}<0.001)(\mathrm{A})$, however, the active ingredient in a cream, in the same concentration did not show improvement when compared to placebo $(p=0.12) .{ }^{112}$

In the physician's global assessment there is also a statistically significant difference between treatments, favoring twice-daily $0.005 \%$ calcipotriol, since the first week $(\mathrm{p}<0.001)$, which was maintained after the eighth week of treatment (A). ${ }^{100}$ 
The use of twice-daily $50 \mu \mathrm{g} / \mathrm{mg}$ calcipotriol ointment for four weeks on one side of the body showed improvement in the efficacy evaluation with PASI at two weeks $(19.8 \%, \mathrm{p}<0.001, \mathrm{NNT}=5)$, as well as at four weeks $(23.2 \%, \mathrm{p}<0.001, \mathrm{NNT}=5) \mathbf{( A )} .^{94}$

In the investigator's global assessment, $56 \%, 22 \%$ and $22 \%$ of patients using twice-daily $50 \mu \mathrm{g} / \mathrm{mg}$ calcipotriol ointment for eight weeks showed moderate or marked improvement or clearance, respectively $(\mathrm{p}<0.004)(\mathrm{A}) .{ }^{104}$

When evaluating the use of $0.005 \%$ calcipotriol foam according to the PGA, between $7 \%(p=0.058, N N T=15)$ and $11 \%(p=0.016$, $\mathrm{NNT}=9$ ) of patients achieved PGA $0 / 1$ for the intervention group in the study. The adverse events were reported in 1 to $2 \%$ of patients

\section{Coronary insufficiency}

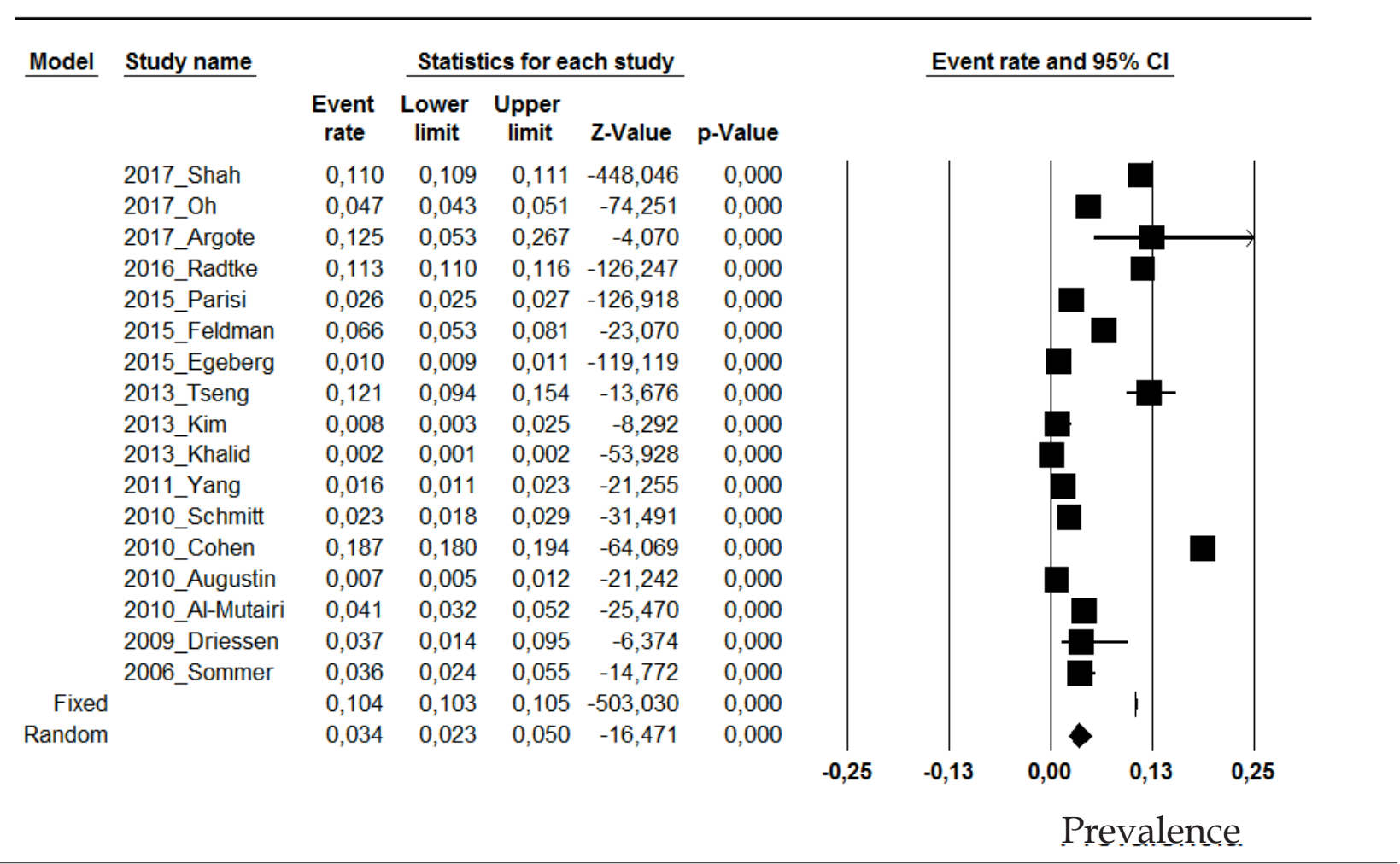

FIGURE 11: Prevalence of coronary insufficiency in moderate to severe plaque psoriasis patients

\section{Inflammatory bowel disease}

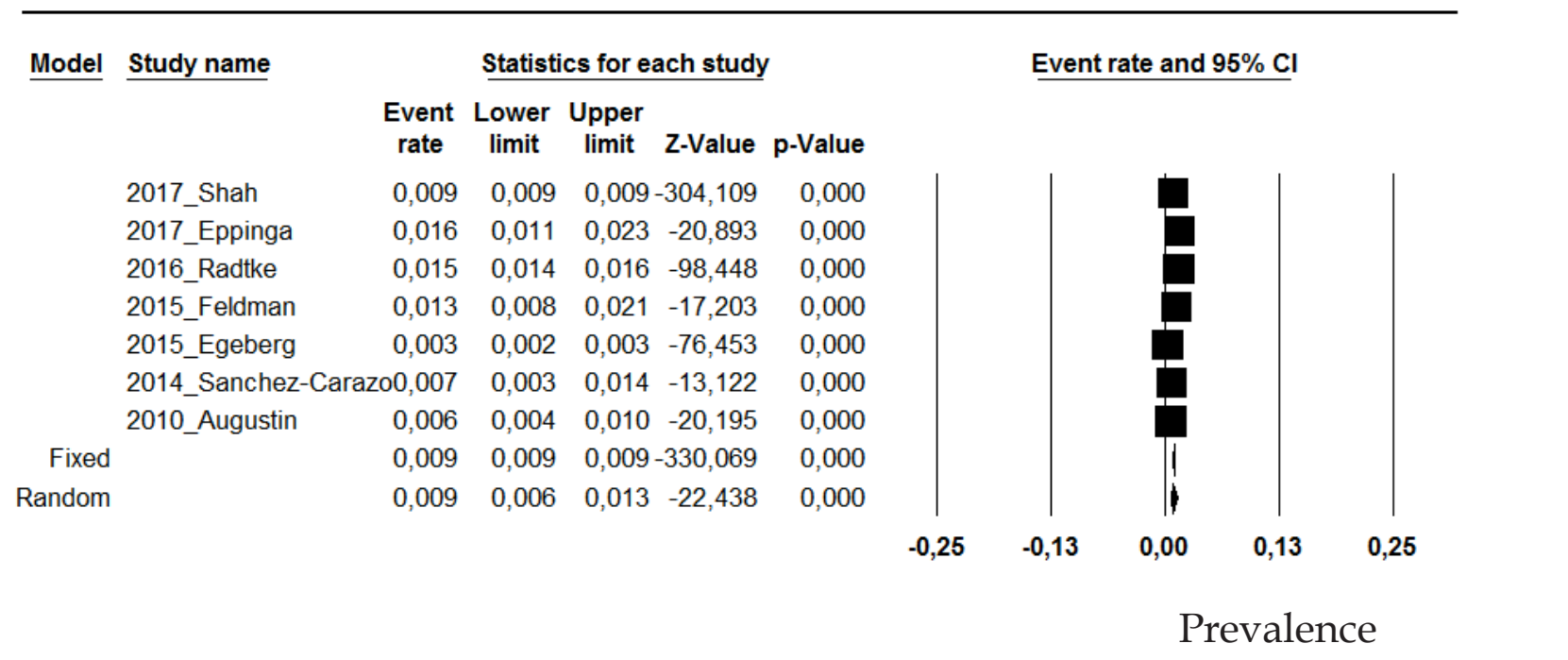

FIGURE 12: Prevalence of inflammatory bowel disease in moderate to severe plaque psoriasis patients 


\section{Migraine}

Model Study name

2017_Capo
2011_Yang
Fixed
Random

Statistics for each study

Event Lower Upper rate limit limit $z$-Value $p$-Value

0,471

0,019

0,069

0,115
0,356

0,013

0,053

0,003

$\begin{array}{lr}0,589 & -0,485 \\ 0,027 & -22,136 \\ 0,089 & -18,127 \\ 0,848 & -1,063\end{array}$

0,628
0,000
0,000
0,288

0,000

0,288

\section{Event rate and $95 \% \mathrm{Cl}$}

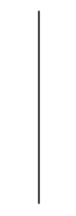

$-1,00$

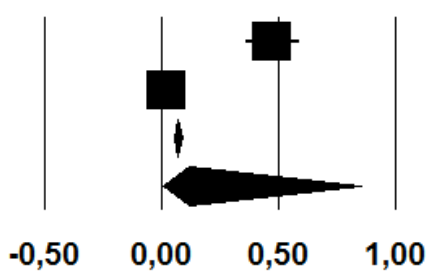

Prevalence

FigurE 13: Prevalence of migraine in moderate to severe plaque psoriasis patients

\begin{tabular}{|c|c|c|c|}
\hline Study & $\mathbf{N}$ & Comorbidity & Prevalence (\%) \\
\hline 2016_Sampogna & 670 & Alexithymia & 24.8 \\
\hline 2014_Vanaclocha & 528 & $\begin{array}{l}\text { Seborrheic } \\
\text { dermatitis }\end{array}$ & 8 \\
\hline 2017_Zander & 2781 & Rosacea & 3.4 \\
\hline 2017_Zander & 2781 & Acne & 2.1 \\
\hline 2017_Choi & 13936 & $\begin{array}{c}\text { Pulmonary } \\
\text { hypertension }\end{array}$ & 1.6 \\
\hline 2008_Birkenfeld & 12502 & Celiac disease & 0.29 \\
\hline
\end{tabular}

(irritation, erythema, or pruritus on the area of application) (A). ${ }^{95}$

When compared to placebo, the use of $3 \mu \mathrm{g} / \mathrm{g}$ calcitriol showed difference between $11.9 \%(p=0.05, \mathrm{NNT}=9)$ and $21 \%(\mathrm{p}<0.01, \mathrm{NNT}=5)$ in the physician's global assessment. The adverse events reported were mild, and included discomfort, pruritus or erythema (A). ${ }^{107}$

The efficacy evaluation of $15 \mu \mathrm{g} / \mathrm{g}$ calcitriol according to the PASI score, showed there was a significant difference of response of $81 \%$ favoring topical treatment with calcitriol after two months of follow-up (NNT=2). Nonetheless, in the control group, $83.3 \%$ did not show any changes in the lesions and $1.2 \%$ had worsening (A). ${ }^{111}$

Regarding PGA, when $15 \mu \mathrm{g} / \mathrm{g}$ calcitriol was evaluated on one side of the body and its vehicle on the other side, there was a significant difference between the treatments on both sides of the body from the first week $(p=0.0004)$, which was maintained after the sixth week $(p=0.002)$, favoring calcitriol use $(\mathrm{NNT}=3)(\mathbf{A}) \cdot{ }^{106}$

\section{Recommendations:}

Vitamin D analogues, $50 \mu \mathrm{g} / \mathrm{g}$ calcipotriol ointment, $0.005 \%$ calcipotriol foam and $6 \mu \mathrm{g} / \mathrm{g}$ calcitriol, were shown to be effective for the topical treatment of plaque psoriasis in a period of 4 to 16 weeks for the analysis of clinical features like erythema, scaling and plaque thickness, and for PASI and the investigator's or patient's global assessment. This class of drugs proved to be safe, since most side effects are mild and related to reactions on the areas of application such as erythema, pruritus and burning sensation.
3.5 What is the advantage of using the combination betamethasone + calcipotriol and the advantage in relation to topical corticosteroids for the treatment of psoriasis?

The comparison between $50 \mu \mathrm{g} / \mathrm{g}$ calcipotriol associated to $0.5 \mathrm{mg} / \mathrm{g}$ betamethasone, or $50 \mu \mathrm{g} / \mathrm{g}$ calcipotriol alone, or $0.5 \mathrm{mg} / \mathrm{g}$ betamethasone alone, when the SUM score is used (it evaluates erythema, thickness and scaling in the lesion), demonstrates that the mean percentage of score reduction in four weeks is of $61 \%$ for the combination of drugs, $32 \%$ for calcipotriol alone and $41 \%$ for betamethasone alone; on the sixth week, this reduction was of $58 \%, 45 \%$ and $56 \%$, respectively (A) ${ }^{115}$

When the difference in PASI change (in percentage) between the combination of drugs compared to betamethasone alone was evaluated, the result was $10.3 \%$ (CI95\% 5.8\% to $14.7 \%$, p $<0.001$, $\mathrm{NNT}=10$ ). (A) ${ }^{110}$ If the mean PASI difference is evaluated in points during the treatment, the result was -13.1 for the intervention group (CI95\% -16.9 to $-9.3, \mathrm{p}<0.001)$ in one study (A) and -14.2 for the intervention group (C195\% -17.6 to $-10.8, \mathrm{p}<0.001)$ in another $(\mathbf{A})$ in up to eight weeks. ${ }^{93,102}$ Side effects were mild and comparable between the groups analyzed (A). ${ }^{93,102}$

\section{Recommendations:}

In plaque psoriasis lesions, the use of calcipotriol associated to topical betamethasone shows statistically significant improvement in comparison to the use of the topical corticosteroid alone, in a period of assessment of 4 to 8 weeks, regarding the evaluation with the PASI score.

3.6. What is the advantage of the use of the combination of betamethasone + calcipotriol and the advantage in relation to calcipotriol alone for the treatment of psoriasis?

When $50 \mu \mathrm{g} / \mathrm{g}$ calcipotriol ointment, $50 \mu \mathrm{g} / \mathrm{g}$ calcipotriol cream, $50 \mu \mathrm{g} / \mathrm{g}$ calcipotriol associated to $0.5 \mathrm{mg} / \mathrm{g}$ betamethasone dipropionate ointment, the same association in gel and $25 \mu \mathrm{g} / \mathrm{g}$ calcipotriol associated to $10 \mathrm{mg} / \mathrm{g}$ hydrocortisone for up to 21 days were evaluated, there was a statistically significant difference bet- 
ween the use of calcipotriol associated to betamethasone compared to the use of calcipotriol alone, considering erythema, scaling and thickness of psoriatic lesions (A). ${ }^{112}$

When evaluated with the SUM score, there is a statistically significant difference in the three variables analyzed on the fourth and sixth weeks $(p<0.001)$ favoring the use of the combination of drugs. The mean percentage of reduction on the fourth week was of $61 \%$ for the use of the combination of drugs, $32 \%$ for calcipotriol alone and $41 \%$ for betamethasone alone; on the sixth week, this reduction was of $58 \%, 45 \%$ and $56 \%$ respectively (A). ${ }^{115}$ In the evaluation of the mean reduction in PASI, this was of 6.99 for the intervention group and 5.04 for the comparison group (A). ${ }^{113}$ The evaluation of the PASI reduction in eight weeks showed $73.3 \%$ reduction of the mean PASI percentage for the compound twice daily, $68.2 \%$ for the combination for four weeks, followed by calcipotriol alone for four more weeks and $64.1 \%$ for calcipotriol alone (A). ${ }^{103}$ The difference in the mean reduction of the thickness of the lesions at the end of the treatment ranged from $16.3 \%$ (CI95\% 11.5 to $21, \mathrm{p}<0.001 \mathrm{NNT}=7$ ) (A) to $25.2 \%$ favoring the combination of drugs (CI95\% 20.1 to 30.1, $\mathrm{p}<0.001, \mathrm{NNT}=4)(110)(\mathrm{A}) .{ }^{93}$ In regards to the number of daily applications, there was no difference between once- or twice-daily application in efficacy measurements, being the combination calcipotriol/betamethasone always superior in comparison to calcipotriol alone. The most common adverse events were local and mild, with pruritus being the most frequent (A)..$^{98}$

\section{Recommendations:}

The use of calcipotriol associated to topical betamethasone demonstrates a statistically significant improvement in relation to the use of topical calcipotriol alone for plaque psoriasis lesions in the period of 2 to 8 weeks of evaluation.

\section{PHOTOTHERAPY}

With the aim of establishing the recommendations on the efficacy and safety of phototherapy for plaque psoriasis, a search was carried out in the Medline-PubMed database, resulting in 436 studies, with 09 selected to answer the clinical questions.

4.1 What is the efficacy and risk of phototherapy for the treatment of psoriasis?

In the evaluation of the treatment of plaque psoriasis with the concurrent use of narrowband ultraviolet B (NB-UVB) phototherapy and fumaric acid esters and the use of fumaric acid esters alone, it was observed that the NB-UVB combined treatment led to a higher median reduction in the PASI score in six weeks of treatment, when compared to the use of fumaric acid alone $(p=0.016)$, therefore, with a higher positive impact in the quality of life $(p=0.031)$ and less side effects (A). ${ }^{117}$

In a study that compared NB-UVB phototherapy, the association of NB-UVB with methotrexate and methotrexate alone, there was no difference in the concurrent use of methotrexate (MTX) regarding clearance of lesions. The rates observed were of $94.74 \%$ with NB-UVB and MTX, 92.11\% with NB-UVB alone, and $89.19 \%$ of those with only MTX, $(\mathrm{p}=0.674))(\mathbf{A}){ }^{118}$
The association of NB-UVB phototherapy and etanercept also showed better results than therapy with etanercept only (best result showing a difference of patients achieving PASI 90 of $39.5 \%$ $(p=0.018, N N T=3))(A) \cdot{ }^{119,120}$ The association of phototherapy to adalimumab also significantly accelerated and improved resolution of lesions, assessed by the PASI adapted for half of the body, with a $33 \%$ reduction of the PASI in the sixth week $(\mathrm{NNT}=3)(\mathrm{B}) .{ }^{121}$

Adding calcipotriol to the NB-UVB phototherapy regime lead to a significant improvement $(\mathrm{p}<0.001)$ in week 12 when compared to NB-UVB alone or twice-daily calcipotriol only (A). ${ }^{122}$ Only one study did not show difference between the application of the topical active ingredient alone and the same application associated to phototherapy (A). ${ }^{123}$

In patients with palmoplantar plaque psoriasis, the use of PUVA (psoralen + ultraviolet A) phototherapy yielded better lesion resolution when evaluated according to complete or partial improvement of lesions ( $>50 \%$ improvement or $<50 \%$ improvement). More people achieved complete response with PUVA (UVB group: $30 \%$; PUVA group: $42 \%$; $<20.001$ ). More people achieved partial response with PUVA and the absence of response was lower for PUVA ( $p<0.001)$, however, more adverse events were observed with PUVA, albeit mild $(\mathrm{p}=0.04)(\mathbf{B}) .{ }^{124}$

\section{Recommendations:}

Phototherapy with PUVA or UVB, associated or not to other treatments such as etanercept, adalimumab, methotrexate, fumaric acid esters and calcipotriol ointment, accelerates the process of improvement of psoriasis, in evaluations with 6 and 16 weeks of follow-up, with significant reduction in PASI compared to these treatments alone.

4.2 What are the advantages and disadvantages of NB-UVB in relation to PUVA?

A study proved NB-UVB to be superior to PUVA for plaque psoriasis, with $75 \%$ of achieving complete resolution in the NB-UVB versus $54 \%$ in the PUVA group. There was no significant difference between the groups regarding time for remission, neither in the number of adverse events (A). ${ }^{125}$ When comparing NB-UVB with the use of UVA associated to trisoralen, there was a median PASI reduction in $32 \%$ favoring UVB phototherapy $(\mathrm{p}<0.001, \mathrm{NNT}=3) \mathbf{( A )} .{ }^{126}$

A study showed that, in patients with skin phototype I to IV, PUVA was significantly more effective than NB-UVB regarding response to resolution ( $84 \%$ vs. $65 \%$, p $=0.02$, NNT=6), but with more side effects and longer treatment time for clearance of lesions (A). ${ }^{127}$ Another similar study showed that clearance of psoriasis lesions was achieved in a significantly higher proportion of patients treated with PUVA (84\%) compared to those treated with NB-UVB (63\%) (CI95\%, 1.18 to $7.84, \mathrm{p}=0.018, \mathrm{NNT}=5)$, but at the expense of more side effects (A). ${ }^{128}$ When PASI median was evaluated, treatment with PUVA showed a significantly higher reduction in PASI median than in the NB-UVB group $(26.72 \%, \mathrm{CI} 95 \%, \mathrm{p}=0.005, \mathrm{NNT}=4) \mathbf{( A )} .{ }^{129}$ The index of resolution with NB-UVB was of $80 \%$ in patients pre-treated with topical retinoids, compared to a $90 \%$ index in patients pre-treated with topical retinoids that were submitted to NB-UVB, and an index of $100 \%$ in patients using PUVA ant topical retinoids 
concomitantly (A). ${ }^{129}$ The association of etretinate and PUVA lead to $100 \%$ of complete improvement in a study, while the association of the medication with NB-UVB improved $80 \%$ of patients. ${ }^{130}$ When the combined treatment of phototherapy and acitretin was analyzed, psoriasis clearance was seen in $56.6 \%$ of patients treated with NB-UVB and in $63.3 \%$ of patients treated with PUVA (A). ${ }^{131}$

In other studies, no difference in improvement as measured by PASI was observed between the use of NB-UVB and PUVA in the treatment of plaque psoriasis, (A), but there seems to be a higher frequency of side effects in patients using PUVA (A). ${ }^{132,133}$

Evaluating a 0 to 4 index similar to PGA for the treatment of palmoplantar psoriasis, a higher percentage in the reduction of the index with PUVA (85.45\%) was observed, rather than with NB-UVB $(61.08 \%-p=0.0001)(A){ }^{134}$

\section{Recommendations:}

In the efficacy comparison between NB-UVB and PUVA, most studies demonstrate a higher efficacy of PUVA in relation to NB-UVB in the evaluation of up to 3 months of treatment, although there is evidence that NB-UVB can occasionally be superior. The mean number of necessary treatments for clearance of the lesions was also significantly lower in patients undergoing PUVA, compared to patients undergoing UVB. The most frequent adverse events in all treatments were mucocutaneous xerosis, erythema, pruritus and nausea, most of the times mild, not interfering with the treatments.

\section{CLASSIC SYSTEMIC TREATMENT}

With the aim of establishing recommendations on the classic treatment for plaque psoriasis (acitretin, methotrexate and cyclosporine), a search was carried out using the Medline-PubMed database and the best scientific evidences were selected to answer the clinical questions.

5.1 What is the efficacy and risk of methotrexate in the systemic treatment of psoriasis?

Patients diagnosed with plaque psoriasis $(n=120)$ were treated with methotrexate $17.5 \mathrm{mg}$ SC once weekly or placebo injections in the first 16 weeks of the study (phase 1). In the second phase of the study (weeks 16 to 52), all patients were treated with methotrexate. In week 16, PASI 75 response was obtained in 37 (41\%) patients of the methotrexate group compared to three (10\%) patients in the placebo group (RR 3.93 CI95\% 1.31-11.81; $\mathrm{p}=0.0026)$. The PGA response 'clear' (0) or 'almost clear' (1) occurred in 25 (27\%) patients treated with methotrexate in the evaluation at 16 weeks compared to two $(7 \%)$ patients receiving placebo; 16 (18\%) versus no patient, respectively, showed PASI 90 response. (A). ${ }^{135}$

A double-blind, randomized study evaluated the efficacy of 7.5 to $25 \mathrm{mg}$ of oral methotrexate (110 patients), compared to adalimumab $80 \mathrm{mg}$ SC as induction and maintenance with 40mg SC fortnightly (108 patients) and placebo (53 patients). After 16 weeks of follow-up, $79.6 \%$ of patients treated with adalimumab reached PASI 75 , compared to $35.5 \%$ for the group of patients treated with methotrexate ( $p<0.001$ vs. adalimumab) and $18.9 \%$ for the group treated with placebo ( $p<0.001 \mathrm{vs}$. adalimumab $-\mathrm{NNT}=2$ and $p<0.05 \mathrm{vs}$. methotrexate $-\mathrm{NNT}=6$ ). There was a statistically significant improve- ment in the complete resolution of lesions (PASI 100) in the patients treated with adalimumab $(16.7 \%)$ in relation to patients treated with methotrexate $(7.3 \%)$ or in patients treated with placebo $(1.9 \%)$. Regarding adverse events, there was no statistically significant difference between the groups for infections, moderate to severe adverse events and adverse events related to the drugs. More adverse events lead to discontinuation of the study in the methotrexate group, mainly due to the events related to liver dysfunction. (A). ${ }^{136,137}$

\section{Recommendations:}

In the treatment of moderate to severe psoriasis with methotrexate, there is significant PASI reduction in relation to baseline at 2, 4 and 6 months of evaluation when compared to placebo, with a number necessary to treat varying from 3 to 6 patients. The most frequent adverse events are nausea, vomiting and abnormalities in transaminases.

5.2 What is the efficacy and risk of acitretin in the systemic treatment of psoriasis?

A randomized, double-blind study evaluated the efficacy and safety of oral acitretin in the treatment of moderate to severe plaque psoriasis, in three treatment groups with different doses: $25 \mathrm{mg}$, 35mg or 50mg/day. Clinical improvement was observed in all groups with PASI 75 response at week 12. The mean PASI dropped $76 \%$ in the $35 \mathrm{mg}$ group after 12 weeks of treatment, this difference was statistically significant compared to the $25 \mathrm{mg}$ and $50 \mathrm{mg}$ groups ( $\mathrm{p}<0.05)$. In the evaluation at 12 weeks of treatment, PASI 75 response was achieved in $47 \%, 69 \%$ and $53 \%$ patients in the 25,35 and $50 \mathrm{mg} /$ day acitretin groups, respectively. Most adverse events were mucocutaneous, mild to moderate and dose-dependent (A). ${ }^{138}$

In another study, patients with moderate to severe plaque psoriasis were randomized to the following doses of acitretin: eight patients using $10 \mathrm{mg}$ to $25 \mathrm{mg}$ per day, or 16 patients using $50 \mathrm{mg}$ to $75 \mathrm{mg}$ per day. Patients treated with acitretin doses of 50 to $75 \mathrm{mg}$ per day showed a significant therapeutical response $(p<0.05)$ in the evaluation at eight weeks. More adverse events occurred in patients receiving the dose of $25 \mathrm{mg}$ per day or more of acitretin, but usually mild and with no need to discontinue the treatment(A). ${ }^{139}$

\section{Recommendations:}

In patients with moderate to severe plaque psoriasis, the use of doses of acitretin of 35 to $75 \mathrm{mg}$ per day showed significant improvement, evaluated by the PASI response. The most frequently observed adverse events are cheilitis, scaling of palmoplantar regions and alopecia, however, the need to discontinue the treatment was rare.

5.3 What is the efficacy and risk of cyclosporine in the systemic treatment of psoriasis?

Patients with moderate to severe plaque psoriasis in remission after treatment with continuous cyclosporine during eight to 16 weeks were evaluated, with 162 receiving oral cyclosporine $5 \mathrm{mg} /$ $\mathrm{kg}$ / day for two consecutive days on the weekend and 81 patients receiving placebo, in the same dosing regimen. The primary end point was a rate of clinical success in 24 weeks, as defined by the absence of relapse or PASI 75 response (in comparison to the PASI pre- 
-cyclosporine treatment). There was no statistically significant difference in the rates of clinical success in the evaluation at 24 weeks between the comparison groups $(66.9 \%$ in the cyclosporine group versus $53.2 \%$ in the placebo group, $\mathrm{p}=0.072$ ). The time frame till the first relapse was significantly longer in the group using cyclosporine $(p=0.023)$. Cyclosporine was well tolerated, with no differences regarding renal function and blood pressure among those receiving the active drug or placebo (A). ${ }^{140}$

A study evaluated the efficacy and safety of cyclosporine for the treatment of severe psoriasis (PASI $\geq 18$ ), in two different dosing regimens: $2.5 \mathrm{mg} / \mathrm{kg} /$ day and $5 \mathrm{mg} / \mathrm{kg} /$ day. The mean PASI score reduction at the end of the induction phase was $69 \%$ in the $2.5 \mathrm{mg} / \mathrm{kg} /$ day group and $89 \%$ in the $5 \mathrm{mg} / \mathrm{kg}$ / day group ( $\mathrm{p}=0.0001, \mathrm{NNT}=5$ ). Eighty-six percent of patients described some adverse event during the treatment period (for up to 21 months), most of them mild to moderate. The most frequent events were systemic hypertension, hirsutism/hypertrichosis, headache, paresthesia, nausea, abdominal discomfort, flu-like symptoms, fatigue, tremor, edema and renal abnormalities. The severe adverse events reported were the development of malignancies in eight patients (of those, four were skin cancers) and two patients had myocardial infarction (A). ${ }^{141}$

In another study, the efficacy and safety of cyclosporine for the treatment of moderate to severe plaque psoriasis was evaluated in two different dosing regimens. One of the groups initially received cyclosporine $1.25 \mathrm{mg} / \mathrm{kg} /$ day, increasing to $2.5 \mathrm{mg} / \mathrm{kg} /$ day or $5 \mathrm{mg} / \mathrm{kg} /$ day in cases where there was no PASI reduction of $10 \%$ in two weeks or $30 \%$ in six weeks. Another group for comparison received cyclosporine $2.5 \mathrm{mg} / \mathrm{kg} /$ day, increasing to $5 \mathrm{mg} / \mathrm{kg} /$ day in the cases where there was no PASI reduction of $10 \%$ in two weeks or $30 \%$ in six weeks. After 12 weeks of treatment, $18 \%$ of patients with the initial dose of $1.25 \mathrm{mg} / \mathrm{kg} /$ day and $56 \%$ of patients with the initial dose of $2.5 \mathrm{mg} / \mathrm{kg} /$ day showed a PASI 75 response. The most frequent adverse events were gastrointestinal abnormalities and viral infections (B). ${ }^{142}$

\section{Recommendations:}

The use of cyclosporine in moderate to severe plaque psoriasis demonstrates significant improvement evaluated by the PASI response, with the best responses obtained with the dose of $5 \mathrm{mg} /$ $\mathrm{kg} /$ day. The most important severe adverse events were reported in long treatments (21 months), encompassing malignancies and systemic hypertension. For those patients who showed an adequate therapeutic response in up to 16 weeks, maintenance treatment with administration of cyclosporine on weekends proved to safely and effectively prolong maintenance of the therapeutic response.

\section{TREATMENT WITH IMMUNOBIOLOGICS}

With the aim of establishing the recommendations on the treatment of psoriasis with immunobiologics, questions regarding indication, efficacy and safety of these medications were structured. A search was carried out in Medline-PubMed database and the best scientific evidences were selected to answer the clinical questions. This search encompassed all immunobiologics approved in Brazil for the treatment of plaque psoriasis: adalimumab, etanercept, in- fliximab, ustekinumab, secukinumab, ixekizumab and guselkumab. 6.1 In which conditions is the treatment with immunobiologics indicated?

The indications for the use of immunobiologics in patients older than 18 years of age, with moderate to severe plaque psoriasis, with PASI score above 10 to 12 or involvement of more than $10 \%$ of body surface area are:

- Patients that did not respond to the treatment or have contraindications or intolerance to the adequate dose and course of at least one of the systemic drugs or phototherapy (A) ${ }^{6,12,136,137,143-173}$

- Less than $50 \%$ improvement in the baseline PASI or less than $75 \%$ improvement in the baseline PASI associated to a significant impact of the disease on the quality of life as measured by the DLQI (Dermatology Life Quality Index) $>=10$ is considered therapeutic failure.

Some groups of patients with moderate to severe plaque psoriasis were not studied for the treatment with immunobiologics (A). ${ }^{6,12,136,137,143-173}$

- Patients with infections associated to the use of antibiotics in the last week prior to the beginning of the study;

- Patients with other associated skin conditions, besides guttate, erythrodermic or pustular psoriasis;

- Patients with hematologic, renal and/or liver abnormalities;

- Patients with history of cancer of any etiology in the last five years;

- $\quad$ Treatment with PUVA in the four previous weeks or topical steroids, vitamin A or D analogues, dithranol or UVB phototherapy in the two previous weeks; or use of any immunobiologic or anti-TNF antibody at any time before the beginning of the study;

- $\quad$ Patients who are pregnant or planning pregnancy.

\section{Recommendations:}

The indications for the use of immunobiologic drugs in patients older than 18 years of age, with moderate to severe plaque psoriasis, with PASI score above 10 or body surface area involvement higher than $10 \%$ are: the lack of response to systemic treatment or phototherapy, contraindications or intolerance to the adequate dose and course of at least one of the systemic treatments.

6.2 What is the efficacy and risk of etanercept for the treatment of psoriasis?

\section{Recommendations:}

The treatment with etanercept for moderate to severe plaque psoriasis, for the period of 12 weeks, was effective and safe with the evaluation of the PASI 75 response (Table 2). The adverse events presented were mild to moderate, mainly of reactions on the site of injection. The best responses occurred in patients using $50 \mathrm{mg}$ twice weekly. PASI 75 response rates in 12 weeks in the different regimens ranged from $10-28 \%$ with the dose of $25 \mathrm{mg}$ once weekly; $26-39 \%$ in the dose of $25 \mathrm{mg}$ twice weekly; and $35-54 \%$, in the dose of $50 \mathrm{mg}$ twice weekly. ${ }^{144,149,151,152,155,158,162,167}$ 
6.3 What is the efficacy and risk of infliximab for the treatment of psoriasis?

\section{Recommendations:}

The induction treatment with infliximab in moderate to severe plaque psoriasis for the period of 10 weeks, was effective with the evaluation of the PASI 75 response (65.8-79.6\%) and improvement in quality of life with the DLQI score (8.9 to $9.9 \%$ ), besides being safe, com few mild to moderate side effects reported, mainly infusion reactions, with the doses of $3 \mathrm{mg} / \mathrm{kg}, 5 \mathrm{mg} / \mathrm{kg}$ or $10 \mathrm{mg} / \mathrm{kg}$, on weeks 0,2 and 6 (Table 3). 6,12,146,148
6.4 What is the efficacy and risk of adalimumab for the treatment of psoriasis?

\section{Recommendations:}

The treatment of moderate to severe plaque psoriasis with adalimumab, during 12 to 16 weeks, was effective with the evaluation of the PASI 75 response and improvement in quality of life with the DLQI score (49-81\%), in the following therapeutic regimen: 40 mg every two weeks (PASI 75 57.9-79.6\%, PASI 90 43\%, PASI 100 $16.7-19 \%$ and PGA $80.5 \%$ ); $80 \mathrm{mg}$ in week 0 followed by $40 \mathrm{mg}$ every two weeks (PASI 75 62.8\%); and 80 mg every two weeks (PASI 75 $81 \%$; besides being safe, with the report of few mild to moderate adverse events (Table 4). ${ }^{136,137,143,145,150,170}$

\begin{tabular}{|c|c|c|c|c|c|c|c|}
\hline Author & Dose (mg/week) & Time of follow-up & PASI $50(\%)$ & PASI $75(\%)$ & PASI 90 (\%) & PGA (\%) & DLQI (\%) \\
\hline Bagel J (144) & 100 & 12 weeks & 78 & 54 & 23 & & \\
\hline Gottlieb AB (151) & 50 & 12 weeks & & 39.6 & & 29.5 & \\
\hline $\begin{array}{l}\text { Van de Kerkhof } \\
\text { PCM (155) }\end{array}$ & 50 & 12 weeks & & 37.5 & & 38.5 & 49.2 \\
\hline Krueger (158) & 50 & 12 weeks & & 46 & & & \\
\hline Feldman ST (149) & 25 & 12 weeks & & 22 & & & \\
\hline Feldman ST (149) & 50 & 12 weeks & & 26 & & & \\
\hline Feldman ST (149) & 100 & 12 weeks & & 35 & & & \\
\hline Papp KA (167) & 50 & 12 weeks & 55 & 29 & 10 & 35 & \\
\hline Papp KA (167) & 100 & 12 weeks & 68 & 43 & 20 & 53 & \\
\hline Gottlieb AB (152) & 25 & 12 weeks & & 28 & & & \\
\hline Leonardi CL (162) & 25 & 12 weeks & 27 & 10 & & & 18 \\
\hline Leonardi CL (162) & 50 & 12 weeks & 44 & 30 & 11 & & 29 \\
\hline Leonardi CL (162) & 100 & 12 weeks & 60 & 45 & 21 & & 44 \\
\hline Author & Dose & Time of follow-up & PASI 50 (\%) & PASI $75(\%)$ & PASI $90(\%)$ & PGA (\%) & DLQI (\%) \\
\hline Feldman ST (148) & $3 \mathrm{mg} / \mathrm{kg}$ & 10 weeks & & & & & 8.9 \\
\hline Feldman ST (148) & $5 \mathrm{mg} / \mathrm{kg}$ & 10 weeks & & & & & 9.9 \\
\hline Reich K (12) & $5 \mathrm{mg} / \mathrm{kg}$ & 10 weeks & & 79.6 & 55.8 & & 9.9 \\
\hline Gottlieb AB (6) & $3 \mathrm{mg} / \mathrm{kg}$ & 10 weeks & 62.2 & 65.8 & 45.5 & 61.9 & \\
\hline Gottlieb AB (6) & $5 \mathrm{mg} / \mathrm{kg}$ & 10 weeks & 75.4 & 82 & 55.6 & 80.1 & \\
\hline Chaudhari U (146) & $5 \mathrm{mg} / \mathrm{kg}$ & 10 weeks & & 63.6 & & & \\
\hline Chaudhari U (146) & $10 \mathrm{mg} / \mathrm{kg}$ & 10 weeks & & 54.5 & & & \\
\hline Author & Dose (mg/sem) & Time of follow-up & PASI $50(\%)$ & PASI $75(\%)$ & PASI $90(\%)$ & PASI 100 (\%) & PGA (\%) \\
\hline Cai L (145) & $40+80$ & 12 weeks & & 77.8 & & & 80.5 \\
\hline Reich K (136) & $80+40$ & 16 weeks & & 79.6 & & 16.7 & \\
\hline Revicki D (170) & $80+40$ & 16 weeks & & 64 & 43 & 19 & \\
\hline Asahina A (143) & $\begin{array}{l}40 \text { every } 2 \\
\text { weeks }\end{array}$ & 16 weeks & & 57.9 & & & \\
\hline Asashina A (143) & $\begin{array}{lr}0 \quad \text { every } & 2 \\
\text { weeks }+ & 40 \\
\text { from week } 2\end{array}$ & 16 weeks & & 62.8 & & & \\
\hline Asashina A (143) & $\begin{array}{l}80 \text { every } 2 \\
\text { weeks }\end{array}$ & 16 weeks & & 81 & & & \\
\hline Gordon KB (150) & $\begin{array}{l}80+40 \text { from } \\
\text { week } 1\end{array}$ & 12 weeks & & 49 & & & \\
\hline Gordon KB (150) & $\begin{array}{l}80+40 \text { from } \\
\text { week } 2\end{array}$ & 12 weeks & & 76 & & & \\
\hline Saurat JH (137) & $\begin{array}{l}80+40 \text { from } \\
\text { week } 2\end{array}$ & 16 weeks & & 79.6 & & & \\
\hline
\end{tabular}


6.5 What is the efficacy and risk of ustekinumab for the treatment of psoriasis?

\section{Recommendations:}

the studies conducted in the evaluation of the efficacy and safety of ustekinumab for moderate to severe plaque psoriasis showed improvement evaluated by the PASI 75 response $52.9-76.5 \%$ for $45 \mathrm{mg}$ and $61.2-78.6 \%$ for $90 \mathrm{mg}$ ) and in the quality of life with the DLQI score (46.4-58.1\%), besides mild to moderate adverse events, upon analysis of a period of 12 weeks (Table 5). ${ }^{157,166,169,174-177}$ When compared to etanercept, ustekinumab in the 45 and $90 \mathrm{mg}$ doses was superior when PASI 75 and PGA 0/1 were evaluated in 12 weeks of follow-up. After this period, although studies have performed a crossover, the treatment with ustekinumab for up to five years was safe and effective after dose adjustment.

6.6 What is the efficacy and risk of guselkumab for the treatment of psoriasis?

\section{Recommendations:}

the studies on the evaluation of efficacy and safety of guselkumab for moderate to severe plaque psoriasis showed improvement in 16 weeks, evaluated by the PASI 90 response (50mg of $70.8 \%$ and $100 \mathrm{mg}$ of $69.8-73.3 \%$ ) and PGA (0/1) (Table 6). ${ }^{178,179}$ Mild to moderate adverse events occurred in the analysis during a period of 36 weeks. When compared to adalimumab, guselkumab (100mg) was superior to adalimumab ( 80 and $40 \mathrm{mg}$ ) in the PGA and PASI 90 response.
6.7 What is the efficacy and risk of ixekizumab for the treatment of psoriasis?

\section{Recommendations:}

the studies performed for the evaluation of the efficacy and safety of ixekizumab for the treatment of moderate to severe plaque psoriasis showed improvement evidenced by the PASI 75 (90-93.4\%), PASI 90 (79.7\%), PASI 100 (56.3\%) and PGA (57-81.9\%) responses (Table 7). ${ }^{180,181}$ When compared to etanercept, the results of ixekizumab used in doses every two or four weeks were significantly better for the outcomes PASI 75, PASI 90, PASI 100 and PGA 0/1. Mild to moderate adverse events were observed in the analysis of a period of 96 weeks, that did not require discontinuation of treatment.

6.8 What is the efficacy and risk of secukinumab for the treatment of psoriasis?

\section{Recommendations:}

the studies conducted in the evaluation of the efficacy and safety of secukinumab for moderate to severe plaque psoriasis showed improvement evaluated by the PASI 75 response $(77.1-81.6 \%$ for $300 \mathrm{mg}$ and $67.0-71.6 \%$ for $150 \mathrm{mg}$ ) and PGA 0 or 1 , and maintenance of quality of life (DLQI) with the use for up to three years, with the best results achieved with the weekly dose of $300 \mathrm{mg}$ in the first four weeks of treatment, followed by $300 \mathrm{mg}$ every four weeks (Table 8).159,182 It was superior when compared to etanercept, evidenced by better results in the response rates for PASI 90 and PASI 100 in 12 weeks ( $54.2 \%$ vs. $20.7 \%$ and 24.1 vs. $4.3 \%$, respectively).

\begin{tabular}{|c|c|c|c|c|c|c|c|c|}
\hline Author & Dose (mg) & $\begin{array}{c}\text { Time of follow-up } \\
\text { (weeks) }\end{array}$ & $\begin{array}{c}\text { PASI } 50 \\
(\%)\end{array}$ & $\begin{array}{c}\text { PASI } 75 \\
(\%)\end{array}$ & $\begin{array}{c}\text { PASI } 90 \\
(\%)\end{array}$ & $\begin{array}{l}\text { PASI } 100 \\
(\%)\end{array}$ & $\begin{array}{c}\text { PGA } \\
(\%)\end{array}$ & $\begin{array}{c}\text { DLQI } \\
(\%)\end{array}$ \\
\hline Langley RG (174) & 45 & 244 weeks & & 76.5 & 50 & & & \\
\hline Langley RG (174) & 90 & 244 weeks & & 78.6 & 55.5 & & & \\
\hline Kimball AB (157) & 45 & 12 weeks & & & & & & 47.2 \\
\hline $\begin{array}{l}\text { Kimball AB (157) } \\
\text { Reich K (169) }\end{array}$ & 90 & 12 weeks & & & & & & 46.4 \\
\hline Рapp KA (175) & 45 & 12 weeks & 73 & 63 & 41.6 & 18.1 & 72.6 & 48.9 \\
\hline Reich K (169) & 90 & 12 weeks & 78.7 & 72 & 50.2 & 18.2 & 71.4 & 54.6 \\
\hline $\begin{array}{l}\text { Nakagawa H (166) } \\
\text { Nakagawa H (166) }\end{array}$ & 45 & 12 weeks & 69.9 & 52.9 & 29.6 & & & 58.1 \\
\hline Igarashi A (176) & 90 & 12 weeks & 71 & 61.2 & 40.3 & & & 54.1 \\
\hline Tsai TF (177) & 45 & 12 weeks & & 62.2 & & & 62.2 & \\
\hline
\end{tabular}

\begin{tabular}{lccccc}
\hline & \multicolumn{5}{c}{ TABLE 6: Evaluation of guselkumab expressed by the benefit estimated in percentage } \\
Author & Dose & Time of follow-up & PASI 75 (\%) & PASI 90 (\%) & PGA (\%) \\
\hline Ohtsuki M (178) & $50 \mathrm{mg}$ & 16 weeks & 89.2 & 70.8 & 92.3 \\
Ohtsuki M (178) & 100mg & 16 weeks & 84.1 & 69.8 & 88.9 \\
Blauvelt A (179) & 100mg & 16 weeks & & 73.3 & 85.1 \\
\hline
\end{tabular}

\begin{tabular}{|c|c|c|c|c|c|c|}
\hline Author & Dose (mg) & Time of follow-up & PASI 75 (\%) & PASI $90(\%)$ & PASI $100(\%)$ & PGA (\%) \\
\hline $\begin{array}{l}\text { Blauvelt A (180) } \\
\text { Leonardi C (181) }\end{array}$ & $\begin{array}{c}80 \text { every } 4 \\
\text { weeks }\end{array}$ & 12 weeks & 93.4 & 79.7 & 56.3 & 57.0 \\
\hline $\begin{array}{l}\text { Blauvelt A (180) } \\
\text { Leonardi C (181) }\end{array}$ & $\begin{array}{c}80 \\
\text { every } 2 \\
\text { weeks }\end{array}$ & 60 weeks & 90 & & & 81.9 \\
\hline
\end{tabular}




\begin{tabular}{|c|c|c|c|c|c|}
\hline Author & Dose (mg) & Time of follow-up & PASI 75 (\%) & PASI 90 (\%) & PASI $100(\%)$ \\
\hline Bissonnette R (182) & $300 / 150$ & 3 years & & 63.8 & 42.6 \\
\hline Langley RG (159) & 300 & 12 weeks & 81.6 & & \\
\hline Langley RG (159) & 150 & 12 weeks & 71.6 & & \\
\hline Langley RG (159) & 300 & 12 weeks & 77.1 & & \\
\hline Langley RG (159) & 150 & 12 weeks & 67.0 & & \\
\hline
\end{tabular}

6.9 Is there a difference of safety and efficacy between immunobiologic treatments?

In the comparison between ustekinumab (UST) and etanercept, there was a significant improvement for PASI 75 for the use of UST $45 \mathrm{mg}$ in relation to etanercept in 10.7\% (CI95\% 2.4 to 19, $\mathrm{p}=0.001, \mathrm{NNT}=10)$ and for the use of UST $90 \mathrm{mg}$ in relation to etanercept in 17\% (CI95\% 10 to 24, p<0.001, NNT=6). For PASI 90, the benefit was of $13.3 \%$ for UST $45 \mathrm{mg}$ in relation to etanercept (CI95\% 5.8 to $20.7, \mathrm{p}<0.001, \mathrm{NNT}=8$ ) and of $21.6 \%$ for the use of UST $90 \mathrm{mg}$ in relation to etanercept (CI95\% 14.6 to $28.5, \mathrm{p}<0.001, \mathrm{NNT}=5)$. In the evaluation with PGA score regarding resolution of the lesions, the benefit was of $16.1 \%$ for UST $45 \mathrm{mg}$ in relation to etanercept (CI95\% 7.6 to $24.2, \mathrm{p}<0.001, \mathrm{NNT}=7$ ) and of $21.6 \%$ for the use of UST $90 \mathrm{mg}$ in relation to etanercept (CI95\% 14.4 to $28.6, \mathrm{p}<0.001, \mathrm{NNT}=5)(\mathbf{A}) .{ }^{183}$

In a comparative study with certolizumab pegol, CZP 400 mg was superior $(\mathrm{NNT}=19, \mathrm{p}<0.0001)$ on week 12 to etanercept for the PASI 75 response rate. (184) (A).

Evaluating the response measured with PGA and PASI90, guselkumab was superior to adalimumab in PGA 0/1 (NNT=6, $\mathrm{p}<0.001)$ and PASI $90(\mathrm{NNT}=5, \mathrm{p}<0.001)$ on week $16(85.1 \%$ vs $65.9 \%$ and $73.3 \%$ vs $49.7 \%)$; on week 24 ( $84.2 \%$ vs $61.7 \%(\mathrm{NNT}=5, \mathrm{p}<0.001)$ and $80.2 \%$ vs $53.0 \%(\mathrm{NNT}=4, \mathrm{p}<0.001))$ and on week $48(80.5 \%$ vs $55.4 \%(\mathrm{NNT}=4, \mathrm{p}<0.001)$ and $76.3 \%$ vs $47.9 \%(\mathrm{NNT}=4, \mathrm{p}<0.001)$ ). The rates of adverse events were similar between treatments (A). ${ }^{179}$

When compared to etanercept $100 \mathrm{mg} /$ week, ixekizumab $160 \mathrm{mg}$ at week 0 followed by $80 \mathrm{mg}$ every two weeks for 12 weeks, demonstrated superior PASI 75, 90 and 100 response rates (41.6\% vs. $89.7 \%, 18.7 \%$ vs. $70.7 \%$ and $5.3 \%$ vs. $40.5 \%$ - p<0.0001). ${ }^{180}$

In a study comparing two doses of brodalumab and ustekinumab, PASI 90 response rates on week 12 were significantly higher with $210 \mathrm{mg}$ brodalumab than with ustekinumab (44\% vs $22 \%$ [AMAGINE-2] and $37 \%$ vs 19\% [AMAGINE-3], (NNT $=5$ and $\mathrm{NNT}=6, \mathrm{p}<0.001$ ). PASI 100 response rates with brodalumab $140 \mathrm{mg}$ were $26 \%$ in AMAGINE-2 ( $p=0.08$ for the comparison with ustekinumab) and $27 \%$ in AMAGINE-3 ( $p=0.007)(\mathbf{A}){ }^{184}$

Secukinumab $300 \mathrm{mg}$ on weeks $0,1,2,3$ and 4 and every four weeks thereafter also demonstrated better PASI 75, 90 and 100 response rates when compared to etanercept $100 \mathrm{mg}$ per week for 12 weeks $(77.1 \%$ vs. $44 \%, 54.2 \%$ vs. $20.7 \%$ and $24.1 \%$ vs. $4.3 \%$, respectively) on week $12(\mathrm{p}<0.001)(\mathbf{A}) .{ }^{185}$

In a study that evaluated the difference between PASI 75 outcomes, comparing briakinumab and etanercept in 12 weeks, the result was $41 \%$ superior for briakinumab in relation to etanercept $(\mathrm{p}<0.001, \mathrm{NNT}=3)(\mathbf{A}) \cdot{ }^{173}$

\section{Recommendations:}

In the evaluation of immunobiologic drugs regarding PASI 75 score, similar benefits were found with: etanercept, infliximab, adalimumab, ustekinumab, guselkumab, ixekizumab, secukinumab. Guselkumab was superior to adalimumab in IGA 0/1 and PASI 90.

There was a significant improvement for PASI 75 and in the evaluation with PGA score for the use of ustekinumab in relation to etanercept. Results of ixekizumab used in doses every two or four weeks were significantly better for the outcomes PASI 75, 90, 100 and IGA $0 / 1$ when compared to etanercept. There was a significant improvement for PASI 75, 90 and 100, as well as for PGA 0/1 for the use of secukinumab in relation to etanercept.

Even though not all drugs have studies assessing the PGA score, the best results were with: ustekinumab, guselkumab, secukinumab and ixekizumab.

6.10 Is there a difference of efficacy and risk when we compare the treatment of psoriasis with the classic drugs (methotrexate, acitretin and cyclosporine) and immunobiologics?

The study that compared the efficacy of adalimumab in relation to methotrexate and placebo showed statistically significant superior therapeutic responses with adalimumab, achieving PASI 75 response in 16 weeks in $79.6 \%$ of patients using adalimumab, $35.5 \%$ of those using methotrexate and $18.9 \%$ of those using placebo (A) ${ }^{137}$ In a study comparing infliximab $(n=653)$ with methotrexate $(n=215)$, here was a significantly better improvement in patients treated with infliximab ( $78 \%$ vs. $42 \%, \mathrm{p}<0.001$, NNT=3) and the proportion of patients achieving PASI 90 was significantly higher $(\mathrm{p}<0.001)$ in patients in the infliximab group (A). ${ }^{186}$

Sixty patients were included in a study, and of these 30 were using etanercept $50 \mathrm{mg}$ twice weekly and the other 30 patients were using acitretin $0.4 \mathrm{mg} / \mathrm{kg} /$ day; $56.7 \%$ of the patients in the etanercept group and $26.7 \%$ of the patients in the acitretin group showed PASI 75 response $(p<0.005$, NNT $=4)(\mathbf{A}){ }^{187}$

Regarding safety, the study comparing adalimumab with methotrexate showed similar rates of adverse events among patients using methotrexate and adalimumab. Regarding the study that compared etanercept with acitretin, safety data between both groups were also very similar.

In the study that evaluated the efficacy and safety of infliximab and methotrexate for the treatment of psoriasis, severe adverse events were reported more frequently in the group using infliximab, encompassing severe infections (tuberculosis, opportunistic infections such as P. carinii pneumonia, listeriosis, atypical mycobacte- 
ria, histoplasmosis, salmonellosis and viral infections) and infusion reactions $\mathbf{( A )} .^{186}$

\section{Recommendations:}

Immunobiologics are more effective in the treatment of moderate to severe plaque psoriasis when compared to the classic treatment. Except for infliximab, immunobiologics are safer and better tolerated when compared to the classic drugs. Studies with infliximab showed higher risk of severe infections and infusion reactions.

6.11 Is there a difference in the efficacy of the treatment with immunobiologics in patients with psoriasis that already used one or more immunobiologics in comparison to those patients who never used an immunobiologic?

In a publication presenting integrated data of efficacy results of 12 weeks of two phase 3 studies, where patients were treated with ixekizumab $80 \mathrm{mg}$ every two weeks $(\mathrm{n}=736)$, ixekizumab $80 \mathrm{mg}$ every four weeks $(\mathrm{n}=733)$ after initial $160 \mathrm{mg}$ dose, or etanercept 50mg twice weekly, patients with and without previous use of immunobiologic were included. Of the total of patients evaluated, $497(19.3 \%)$ had been previously exposed to immunobiologics. In patients being treated with ixekizumab, PASI 75 response rates were very similar among patients with previous use of immunobiologics $(91.5 \%)$ and with no previous use of immunobiologics (87.7\%). For patients being treated with etanercept, PASI 75 response rates were superior in the group that did not previously use immunobiologics $(50.7 \%)$ when compared to those that has used immunobiologics previously (34.6\%) (B). ${ }^{188}$

A study evaluated the efficacy of adalimumab in 30 patients with moderate to severe plaque psoriasis with primary or secondary treatment failure (PASI<50), or intolerance to etanercept. In relation to PASI scores prior to commencement of etanercept, PASI 75 response was obtained in $27 \%(\mathrm{NNT}=4), 36 \%(\mathrm{NNT}=3)$ of patients on weeks 12 and 24 , respectively, of treatment with adalimumab. These response rates are similar to those presented by patients who responded to etanercept. The total rate of adverse events per year with etanercept was of $3.41 \%$ compared to $3.18 \%$ in patients treated with adalimumab. The most frequent events were infections, mainly respiratory, muscular, joint, gastrointestinal complaints, and dermatological abnormalities. The efficacy of treatment with adalimumab was not influenced by previous failure to etanercept (B). ${ }^{189}$

Sixty-nine treated with adalimumab were evaluated, which have already had previous treatment with other immunobiologics and/or TNF-alpha blockers (etanercept, efalizumab, alefacept, infliximab or ustekinumab). The comparison was with 16 patients using adalimumab as the first immunobiologic treatment. In relation to the original baseline (beginning of the study), the difference to PASI 75 in the evaluation at 12 weeks was of $27 \%$ favoring the group that used immunobiologics for the first time $(\mathrm{NNT}=4, \mathrm{p}=0.004)$. There was no significant difference between the comparison groups for PASI 75 response rate in the evaluation at 24 and 48 weeks. Of all patients in the study, $19 \%$ presented adverse events, and only $29 \%$ of these were possibly or probably related to the drug being investigated (B). ${ }^{190}$

The evaluation of 282 patients using adalimumab which had not used TNF-alpha blocker previously, was compared to 448 patients on adalimumab, with previous use of TNF-alpha blockers. In the evaluation at 16 weeks, there was a $22.7 \%$ difference for PASI 75 favoring patients who had not been previously treated with TNF-alpha blockers, compared to the group of patients that had been previously treated with two or more TNF-alpha blockers (NNT=5, $p=0.016$ ). the adverse events were similar in both groups, with the presence of infections being the most common (A). ${ }^{191}$

Another study had 26 patients on etanercept as the intervention group, after treatment failure with a previous immunobiologic drug; and comparison with 98 patients on etanercept as the first immunobiologic drug. After 12 weeks of follow-up, that patients that were not previously treated with immunobiologic had a gain of $11 \%(\mathrm{NNT}=9)$ for PASI 50 and $12.9 \%(\mathrm{NNT}=8)$ for PASI 75; after 24 weeks of follow-up, the patients with no previous treatment with immunobiologics kept the $20.3 \%$ gain $(\mathrm{NNT}=5)$ for PASI 50 and $10.1 \%(\mathrm{NNT}=10)$ for PASI 75. All evaluations at 12 and 24 weeks were significant when the comparison was performed according to baseline $(p<0.001)$, but there was no statistically significant difference in the evaluation of the results between weeks 12 versus week 24 . The adverse events reported were injection site reactions $(n=11)$, asthenia $(n=9)$, cystitis $(n=6)$, headache $(n=5)$, labial herpes $(n=3)$, pharyngitis $(n=2)$, and otitis $(n=1)$. None of these reactions required discontinuation of treatment $(\mathbf{B}){ }^{192}$

\section{Recommendations:}

In the efficacy evaluations at treatment weeks 12 and 16, adalimumab showed better response rates for the patients who were not previously treated with other immunobiologic drugs or tumor necrosis factor blockers; however, in the evaluations at 24 and 48 weeks this benefit was not observed.

In the efficacy evaluations at treatment weeks 12 and 24, etanercept $50 \mathrm{mg}$ demonstrated better response rates in patients that did not receive previous treatment with immunobiologics.

Regarding ixekizumab, there was no difference between those previously treated with other immunobiologics and those not.

\section{7 - COMBINED TREATMENT}

With the aim of establishing the recommendations on the combined treatment of plaque psoriasis with different drugs (immunobiologics, phototherapy and drugs from the classic regimen - Acitretin, Methotrexate and Cyclosporine), a search was carried out using Medline-PubMed database and 24 studies were selected to answer the clinical questions. . $18,119,187-208^{-12}$

7.1 What are the advantages and disadvantages of the combined treatment between drugs of the classic regimen (acitretin, methotrexate and cyclosporine) when compared to isolated treatments?

Thirty-nine male patients with plaque psoriasis, randomly allocated into control group $(n=10)$, acitretin $(n=11)$, methotrexate $(n=9)$ and combination methotrexate + acitretin $(n=9)$ were evaluated. The patients were treated for four weeks, with the following doses: Acitretin 20mg/day; and methotrexate $7.5 \mathrm{mg} /$ week on the first week, followed by $25 \mathrm{mg} /$ week. The combination group had 
better responses (PASI and DLQI) than the acitretin and methotrexate and lower DLQI than the acitretin group ( $\mathrm{p}<0.05)$. PASI 50 and PASI 75 responses were also calculated, showing that the combination group had more patients achieving PASI 50 than the other groups. The patients tolerated well the use of both medications in combinations, in the usual doses (B). ${ }^{193}$

In a retrospective study, 18 patients receiving combined treatment (methotrexate + cyclosporine) were evaluated. The doses of cyclosporine used ranged from 150 to $250 \mathrm{mg}$ / day, with the initial dose of $3 \mathrm{mg} / \mathrm{kg} /$ day. Methotrexate doses ranged from 7.5 to 22.5 $\mathrm{mg} /$ week. Of the total 18 patients, 14 had a short-term treatment ( 3 months) and 4 patients had long-term treatment (mean duration $284.5 \pm 93.2$ days). Twelve patients from the group receiving short-term combined treatment and all patients receiving combined treatment for longer than three months achieved PASI 50 response. PASI 75 response was achieved in five patients in the short-term group and one patient in the long-term group. Nine patients from the first group and all patients from the second group had adverse events, being the main ones increase in creatinine levels, hypertension, hypertriglyceridemia, depression and raised transaminases. The most common adverse event was increased levels of creatinine (higher than 30\%), observed in eight patients (57\%) (B). ${ }^{203}$

Twenty patients received combined treatment with intramuscular methotrexate $10 \mathrm{mg}$ per week associated to cyclosporine $3.5 \mathrm{mg} / \mathrm{kg} /$ day, divided into two doses. The mean combined treatment was 9.5 weeks and median PASI reduction was of $77.4 \%$ (ranging from 51.2 to 90.2) ( $\mathrm{p}<0.001)$. Fourteen patients had some kind of adverse event, being gastrointestinal and renal and hepatic abnormalities the most common (B). ${ }^{195}$

\section{Recommendations:}

Although the treatment combination (methotrexate + cyclosporine and methotrexate + acitretin) show superior efficacy data when compared to efficacy data as monotherapy, the lack of studies proving the safety of these associations limit the recommendations for their use in the management of patients with moderate to severe plaque psoriasis.

7.2 What are the advantages and disadvantages of the combined treatment with phototherapy and drugs from the classic regimen (acitretin, methotrexate and cyclosporine) when compared to the isolated treatments?

One-hundred and twenty patients with plaque psoriasis, allocated into three groups, were evaluated: group 1 with 38 patients receiving the combination of NB-UVB phototherapy associated to methotrexate in the dose of $0.2 \mathrm{mg} / \mathrm{kg}$ per week, with a maximum of $20 \mathrm{mg}$ per week; group 2 with 38 patients receiving NB-UVB phototherapy alone and group 3 with 37 patients receiving methotrexate alone. A minimum $90 \%$ clearance of the lesions was observed in $94.74 \%$ of the patients in the group using the combination of treatments, in $92.11 \%$ of the patients using phototherapy alone and in $89.19 \%$ of the patients receiving methotrexate alone, with no significant difference between the three groups $(p=0.674)$. However, the mean number of weeks to achieve clearance was significantly lower in the combined treatment group (6.11 weeks vs. 11.42 weeks vs. 20.87 weeks, $\mathrm{p}<0.0001$ ). Also, there was no significant difference between the groups for relapse during follow-up period and for the adverse events described (A). ${ }^{119}$

In another study, the efficacy of combined treatment (NB-UVB + oral methotrexate) was compared to NB-UVB phototherapy alone. PASI 75 response was observed in $95 \%$ of patients with the combined treatment and in $70 \%$ of the phototherapy treatment only $(\mathrm{NNT}=4, \mathrm{p}<0.04)$. The mean number of weeks $(\mathrm{p}=0.001)$, the mean cumulative dose of NB-UVB ( $p=0.001)$ and the number of phototherapy treatments $(p=0.0001)$ to achieve PASI 75 were significantly lower in the combined treatment group in relation to phototherapy alone (A). ${ }^{202}$

In another study including 24 patients, the efficacy of phototherapy (NB-UVB) associated to methotrexate $15 \mathrm{mg}$ / week was compared to phototherapy (NB-UVB) associated to placebo. Best results were observed in the combination group of phototherapy + methotrexate, and the difference of the median PASI score reduction between both groups was $5.6(p=0.013)$. The number of adverse events in both comparison groups did not change from four cases of mild erythema, two in each group, and generalized hyperpigmentation in all patients (A). ${ }^{194}$

Another study evaluated the efficacy of the combination of UVB phototherapy + acitretin, compared to the monotherapy with UVB phototherapy and monotherapy with acitretin. Patients were allocated into three groups: 16 patients receiving acitretin 50 mg per day associated to ultraviolet B (UVB), 18 patients receiving UVB only and 16 patients receiving acitretin only. The patients with the combined treatment of acitretin associated to UVB showed superior response rates in comparison to the groups receiving single treatment. There was no significant difference between the adverse events of the three comparative groups (A)..$^{201}$

The association of PUVA + acitretin versus PUVA alone was evaluated in 60 patients with severe psoriasis. Patients were allocated into two groups, with 30 patients using acitretin $1 \mathrm{mg} / \mathrm{kg} /$ day associated to PUVA and 30 treated with PUVA alone. Complete or almost complete improvement (minimum 90\% clearance of lesions) occurred in $96 \%$ patients in the group receiving combined treatment and in $80 \%$ of those treated with PUVA (NNT=7). The most frequent adverse events in both comparison groups were cheilitis, dryness of mucous membranes of the nose and mouth, conjunctivitis, scaling, asteatosis, pruritus and hair loss (A)..$^{206}$

Authors studied nine patients being treated with UVB phototherapy and low dose of acitretin $(0.34$ to $0.44 \mathrm{mg} / \mathrm{kg})$, comparing with 32 patients treated with UVB phototherapy alone. Clearance of lesions occurred significantly more in patients under combined treatment compared to patients using only UVB (89\% vs. $62.5 \%$, $\mathrm{NNT}=4)(\mathrm{A}) .{ }^{200}$

\section{Recommendations:}

The combination of phototherapy (UVB and PUVA) with classic systemic treatments showed higher efficacy than the respective treatments separately, according to evaluation of both PGA 0 or 1 response and PASI 75 response. 
7.3 What are the advantages and disadvantages of the combined treatment with phototherapy and immunobiologics when compared to those treatments separately?

In the first phase of the study ( 8 weeks), 322 patients were treated with phototherapy as the first line treatment option. After eight weeks of phototherapy, patients who did not achieve PASI 75 response joined the second phase of the study, and were treated with conventional systemic therapies or etanercept 50mg twice weekly. After the end of the second phase of the study, those who did not achieve PASI 75 in 12 weeks, joined the third phase of the study, where NB-UVB phototherapy was added. After finishing the first phase of the study, PASI 75 response was obtained in 262 patients $(81.4 \%)$ treated with NB-UVB phototherapy. In the second phase of the study, 24 patients $(7.5 \%)$ were treated with at least one of the conventional systemic treatments for psoriasis and 20 patients $(6.2 \%)$ were treated with etanercept. Of the patients who were treated with etanercept in the second phase of the study, eight $(2.5 \%)$ joined the third phase of the study and NB-UVB was associated. All these patients achieved PASI 75 and three of them had complete remission after 14.6 $\pm 3.3 \mathrm{NV}$-UVB exposures. Combination treatment was well tolerated, with no acute adverse events (B). ${ }^{196}$

In a 2-phase study, 30 patients were treated with etanercept $50 \mathrm{mg}$ once weekly for 12 weeks in the first phase. In the second phase of the study (weeks 12 to 24), patients were randomized into two groups: one group received etanercept alone, and the other group etanercept associated to NB-UVB phototherapy three times per week. At the end of the first phase, $48 \%$ of all patients studied achieved PASI 75 response, $41.7 \%$ of them with BMI above 35 . On week 24 , PASI 75 response rates were similar in the etanercept group and combination etanercept + phototherapy $(46.7 \%$ vs. $53.3 \%$, respectively) (A). ${ }^{205}$

Seventy-five plaque psoriasis patients who did not achieve PASI 90 response in 12 weeks of treatment with etanercept $50 \mathrm{mg}$ twice weekly were assessed. These patients were randomized into two groups: 37 patients treated with NB-UVB phototherapy three times per week for at least four weeks associated to etanercept, and 38 patients using only etanercept in the comparison group. On week 24 , PASI 90 was achieved by $16.2 \%$ of patients with combined treatment of etanercept and NB-UVB, in comparison with $15.8 \%$ of patients who received monotherapy with etanercept (there was no statistically significant difference; $\mathrm{p}=1.000$ ). On week 16 , the proportion of patients that achieved PASI 90 was $39.5 \%$ more in the group with combined treatment $(p=0.018)$. There was no significant difference for treatment safety between the comparison groups (A). ${ }^{119}$

In another study, 10 patients treated with ustekinumab 45 $\mathrm{mg}$ or $90 \mathrm{mg}$ (dose standardized according to the weight), subcutaneous on weeks 0 and 4 , were treated with NB-UVB on one half of the body, three times a week for six weeks. The end point was to compare PASI response of the half of the body that received phototherapy to the half of the body that did not. On week six, PASI 75 was achieved in $78 \%$ of those treated with the combined treatment and in $11 \%$ of those receiving monotherapy $(\mathrm{NNT}=2, \mathrm{p}=0.007)$. On week 12 , the synergistic effect of phototherapy did not show a significant difference (A). ${ }^{207}$

\section{Recommendations:}

In the comparison of etanercept as monotherapy or associated to NB-UVB phototherapy, there was no difference for PASI 75 or PASI 90 in the evaluation at 24 weeks. However, in the evaluation at 12 and 16 weeks after starting the treatment, there are controversies regarding the benefit of the combined treatment for PASI 90.

With ustekinumab, the association with UVB phototherapy speed up the process of improvement of the lesions on week 6 , with a difference of PASI 75 in $67 \%$ for the half of the body receiving the combined therapy $(\mathrm{NNT}=2)$, in relation to the half of the body that was treated with the immunobiologic alone.

7.4 What are the advantages and disadvantages of the combined treatment with drugs from the classic regimen and immunobiologics when compared to their use separately?

In a randomized, double-blind study, 60 patients were randomized into three treatment groups: (a) etanercept 50mg twice weekly every week for 12 weeks, followed by etanercept $25 \mathrm{mg}$ twice weekly every week for 12 more weeks (ETN-ETN); (b) etanercept 25 $\mathrm{mg}$ twice weekly every week and acitretin $20 \mathrm{mg}$ / day for 24 weeks (ETN-ACT); (c) acitretin 20mg/day for 24 weeks. The proportions of patients with PASI 75, PASI 50 and PGA 0 or 1 on week 24 in the groups ETN-ETN $(52.4,71.4$ and 52.4\%, respectively) and ETN-ACT (57.9, 84.2 and $52.6 \%$, respectively) were higher than in the ACT group (22.2; 44.4; and $16.7 \%$, respectively).the incidence of adverse events was similar in all three groups (A). ${ }^{187}$

In a study, 478 patients with moderate to severe plaque psoriasis with normal liver and hematologic functions were included. All patients were treated with etanercept $50 \mathrm{mg}$, subcutaneously, twice weekly for 12 weeks, followed by $50 \mathrm{mg}$ per week. In the intervention group $(n=239)$, weekly oral methotrexate, in doses of $7.5 \mathrm{mg}$ to $15 \mathrm{mg}$ was added from week 12 to 24 . In the comparison group, all patients received etanercept associated to placebo only after the $12^{\text {th }}$ week $(n=211)$. On week 24 , there was a $17 \%$ difference in PASI 75 response, favoring patients treated with the combined therapy (NNT=6, $\mathrm{p}<0.0001$ ); for PASI 50, the difference was of $7 \%$ (NNT=15, $\mathrm{p}=0.01$ ) favoring the group of combined therapy, and for PASI 90, the difference was of $19.6 \%$ (NNT=6, $\mathrm{p}=0.01$ ), also favoring the group receiving the combined therapy. of the patients, $74.9 \%$ of the combined therapy group and $59.8 \%$ of the monotherapy group had adverse events. The most common events were nasopharyngitis, headache, upper respiratory tract infection and nausea (A). ${ }^{199}$

In a double-blind, randomized study, 60 patients with moderate to severe plaque psoriasis allocated into three groups were evaluated: group 1 with 22 patients receiving etanercept $25 \mathrm{mg}$, twice weekly, subcutaneously; group 2 with 20 patients using acitretin $0.4 \mathrm{mg} / \mathrm{kg} /$ day, orally; group 3 with 18 patients using etanercept $25 \mathrm{mg}$ per week, associated to acitretin $0.4 \mathrm{mg} / \mathrm{kg} /$ day. On week 24 , $45 \%$ of the patients in group 1, 30\% of patients in group 2 and $44 \%$ of patients in group 3 achieved PASI 75 ( $\mathrm{p}=0.001$ for both groups receiving etanercept in comparison to the patients who were treated with acitretina only). There was no significant difference regarding the variation of the mean values of ALT, AST, cholesterol and triglycerides between the three groups (A). ${ }^{198}$ 
In another study, with 24 weeks duration, patients with partial response to methotrexate (at least three months of treatment) were included and allocated into two groups: the first group $(n=28)$ received etanercept for 24 weeks associated to a short course of oral methotrexate (four weeks); and the second group $(n=31)$ received subcutaneous etanercept and continuous oral methotrexate for 24 weeks. Etanercept was administered subcutaneously, in the dose of $50 \mathrm{mg}$ twice weekly every week for 12 weeks, followed by $25 \mathrm{mg}$ twice weekly for another 12 weeks. PGA 0 or 1 response was superior in the group using methotrexate continuously (66.7 vs $37.0 \%$, respectively) ( $\mathrm{NNT}=4, \mathrm{p}=0.025)$. Both comparison groups showed PASI improvement compared to baseline. However, the difference was significant for PASI 75 on week $24(p=0.013)$ in the group receiving etanercept associated to continuous methotrexate and there was no significant reduction for PASI $90(\mathrm{p}=0.077)$. regarding adverse events, there was no difference between the comparison groups, with the most common events being infections, pustular psoriasis on the hands, pneumonia, heart failure/atrial fibrillation (A). ${ }^{208}$

\section{Recommendations:}

In the evaluation of the use of etanercept as monotherapy compared to the immunobiologic associated to methotrexate or acitretin, there was improvement to PASI 75 on week 24 in patients treated with the association. Adverse events were reported in $74.9 \%$ of the patients receiving combined therapy and in $59.8 \%$ of the patients receiving monotherapy with immunobiologic or the classic treatment.

\section{TREATMENT OF PREGNANT AND BREASTFEEDING WOMEN}

Psoriasis is a chronic inflammatory condition that is more frequent in adults and the need for therapeutic intervention in women of child-bearing age is common. With the aim of establishing the recommendations for the treatment of plaque psoriasis in pregnant or breastfeeding women, a search was carried out using Medline-PubMed database, retrieving 324 studies, out of which 43 were selected to answer the clinical questions. ${ }^{209-251}$

\subsection{Treatment of plaque psoriasis in pregnant women 8.1.1 Topical Corticosteroids}

The safety of topical glucocorticoids varies according to the strength of the agent and the specific vehicle used. Current evidence suggests that mild/moderate topical corticosteroids are preferred during pregnancy. The risk of high potency applied in large areas of the body surface approach those seen with systemic steroids due to the increased potential of systemic absorption (D). ${ }^{247}$

It was also observed in one study that the use of low and medium potency did not show significant increase of the risk of fetal growth restriction, on the other hand, those of high and very high potency showed increase of the risk (RR 2.08; 95\% CI 1.40-3.10; $\mathrm{p}<0.001, \mathrm{NNH}=168$ ). There was no association between maternal exposure to topical corticosteroids of all potencies and increased risk of fetal death, premature labor or fetal malformations (B). ${ }^{216}$

\subsubsection{Calcineurin inhibitors (Tacrolimus)}

Authors found an association with prematurity and low birth weight. When used topically, calcineurin inhibitors are weakly absorbed systemically (242) (D). Their use is allowed in small areas when there is no other alternative, due to the lack of studies on safety during pregnancy (B). ${ }^{241}$

\subsubsection{Vitamin D analogues (Calcipotriol)}

Calcipotriol or calcipotriene, vitamin D analogue, when applied in small areas and doses $<10,000 \mathrm{IU} /$ day has a small risk of systemic absorption (D). ${ }^{210}$ There are no studies conducted on pregnant women (B)..$^{223}$

In animal studies, calcipotriol resulted in a higher incidence of skeletal abnormalities, including incomplete ossification of the pubic bones and anterior phalanges (D). ${ }^{211,234}$

When there are no alternatives, the topical use of calcipotriol on small surfaces is allowed, but it should be avoided under occlusive dressings, avoiding systemic absorption and reducing the risk of toxicity (D). ${ }^{247}$

8.1.4 Topical retinoids (adapalene, tretinoin and tazarotene)

Some topical retinoids, such as adapalene and tretinoin, are categorized into pregnancy category $\mathrm{C}$ according to the FDA's classification, due to the risk of teratogenesis. On the other hand, tazarotene is currently labeled as pregnancy category $X$, and is totally contraindicated in pregnant women due to the risk of teratogenesis. Its risk is enhanced by the fact that it is applied on large areas of the body surface in cases of moderate to severe psoriasis, therefore increasing its systemic absorption. Topical tazarotene should be avoided in pregnant women (D). ${ }^{227}$

\subsubsection{Salicylates}

There are many concerns regarding the use of topical salicylates during pregnancy. When combined to other drugs, particularly topical corticosteroids, salicylic acid increases percutaneous absorption of other agents. There is also a concern with the systemic absorption of the salicylic acid itself applied topically, in concentrations ranging from $9 \%$ to $25 \%$. Some cases of acute systemic toxicity by salicylates after topical use have been reported, usually with the prolonged use on extensive body surfaces and/or the use of occlusive dressings (D). ${ }^{227}$

\subsubsection{Tar Derivatives}

A retrospective study evaluated 23 pregnant women who used coal tar during pregnancy and no increase in the risk of malformations was observed, when compared to population data (B). ${ }^{220}$

Even though there are animal studies demonstrating that the maternal exposure to high doses resulted in perinatal mortality and increased risk of palate fissures and pulmonary abnormalities in the offspring, literature on human exposure did not reveal any effect (D). ${ }^{234}$

The use of dithranol and coal tar is not recommended during pregnancy $(\mathrm{D}) .{ }^{247}$

\subsubsection{Methotrexate}

Methotrexate was shown to be teratogenic and abortive during pregnancy. There are evidences that methotrexate is found on the liver for up to four months after exposure and a prospective review of nine cases of methotrexate exposure prior to pregnancy 
showed that in four cases, where the exposure took place within six months of the pregnancy, spontaneous abortions occurred (D). ${ }^{211,234,251}$ There are reports of spontaneous abortions after its use on the first trimester of pregnancy (B). ${ }^{231}$

Multiple malformations (craniofacial, skeletal, cardiopulmonary and gastrointestinal) were detected on the $18^{\text {th }}$ week of gestation in a patient who received the drug on the first week of gestation $(\mathbf{C}) .^{219,236}$

\subsubsection{Acitretin}

Acitretin, a synthetic derivative of vitamin A, was shown to be teratogenic in animal studies, supporting it being absolutely contraindicated in pregnant women (D). ${ }^{224}$

The teratogenic effects associated to retinoids and hypervitaminosis A include craniofacial dysmorphia, hip malformations, meningomyelocele, meningoencephalocele, multiple synostoses and limb abnormalities. There are six known cases of fatal outcome after exposure to acitretin, including two with malformations consistent with the teratogenic effects (D), ${ }^{251}$ (B). ${ }^{214}$

Since acitretin can be re-esterified into etretinate, that has a longer elimination half-life (up to 150 weeks), it is necessary to ensure contraception for at least two years after finishing treatment with acitretin (D), ${ }^{251}$ (B). ${ }^{214}$

\subsubsection{Cyclosporine}

The physiologic adaptations and clinical changes that occur in pregnant women can affect cyclosporine absorption, distribution and clearance. Gastric emptying and motility of the small intestine are reduced during pregnancy, what can lead to a higher absorption time and a lower peak serum level of cyclosporine. Therefore, it is paramount that its serum levels be monitored more frequently and, when necessary, dose adjustments be made (B). ${ }^{238}$ High levels of cyclosporine in the placenta and/or umbilical cord blood were found in many studies, with $6 \%$ of the maternal concentration of cyclosporine reaching the fetus albeit no detection of the drug in the maternal or fetal brain (B). ${ }^{238}$

A meta-analysis with 15 studies including 410 pregnant women who underwent a transplant and were exposed to cyclosporine during gestation was conducted to determine if exposure to cyclosporine during pregnancy is associated to an increased risk of congenital malformations, premature labor or low birth rate. The results suggest that the use of cyclosporine during pregnancy is not teratogenic, but can be associated to premature labor and low birth weight in children (2,500g) (B), ${ }^{212}$ (D). ${ }^{211}$

Many studies indicate that a short course of cyclosporine (3 to 4 months), with a low dose (less than $5 \mathrm{mg} / \mathrm{kg} /$ day), results in an $80-90 \%$ improvement in psoriasis, demonstrating the efficacy of cyclosporine use during pregnancy to control severe psoriasis. No incidence of maternal complications was reported, although prematurity and/or low birth weight are common (B). ${ }^{238}$

\subsubsection{Phototherapy}

Phototherapy, narrowband ultraviolet B (NB-UVB) and broadband ultraviolet $\mathrm{V}$ (BB-UVB) are considered safe options during pregnancy (D). ${ }^{238}$
The use of narrowband UVB seems to reduce the serum levels of folate, and can increase the risks of neural tube defects in the fetus/ therefore, the concurrent use of folic acid $5 \mathrm{mg} /$ day is recommended (B)..$^{218}$

In a prospective study that followed 159 pregnant women, psoralen + UVA (PUVA) did not show an increase in the incidence of fetal malformations or fetal deaths (B). ${ }^{225,246}$ Since psoralen is a known mutagen and teratogen, avoidance of treatment with PUVA during pregnancy is recommended (D). ${ }^{234}$

\subsubsection{Immunobiologics}

There are reports that the use of infliximab during pregnancy did not cause abnormalities in fetal development (C). ${ }^{245}$

Adalimumab and infliximab are complete IgG1 antibodies, so its transplacental transport is expected. An international, multicentric, prospective cohort study of 80 pregnant women with inflammatory bowel disease (IBD) that received adalimumab or infliximab, found an inverse correlation between the time since the last exposure to the drug during pregnancy and the concentration in the blood from the cord (B). ${ }^{228}$

A case report found a ratio of concentration of etanercept between maternal blood and blood from the umbilical cord of 14:1 during delivery, in a woman with ankylosing spondylitis receiving $25 \mathrm{mg}$ subcutaneously once a week during the second and third trimester, evidencing the low transplacental transport (B). ${ }^{228}$ Anti-TNF-alpha transplacental transport seems not to occur before the second trimester and, although it increases during the third trimester, etanercept shows considerably less transport than other anti-TNFs (B). ${ }^{215}$

Two ustekinumab studies on fetal development conducted in monkeys did not reveal any evidence of maternal toxicity, embryotoxicity or teratogenicity. There are very limited data on treatment safety, with only two case reports in the literature, all with healthy infants. A report grouped 4-year data of clinical trials with 31 pregnant women, with no incidences of fetal malformations or death. The FDA attributed pregnancy category B to ustekinumab, similar to anti-TNF-alpha; however, due to lack of evidences proving its safety during pregnancy, its use is not recommended (D). ${ }^{211}$

Animal studies with secukinumab, a monoclonal antibody against IL-17A, do not show harmful effects regarding the pregnancy, embryonic/fetal development, labor or post-natal development, including that of the immune system (B). ${ }^{249}$

In a global safety database, the results of pregnancies where there was maternal or paternal exposure to secukinumab were analyzed, and overall rates of spontaneous abortion were 30/292 $(10.3 \%)$, according to the rates observed for the general population. Most of the spontaneous abortions happened within 10 weeks of gestation and there were no stillbirths (> 20 weeks' gestation). Of the 38 cases of exposure in patients with psoriatic arthritis spontaneous abortions occurred in $7.9 \%$ and in $6.7 \%$ of 15 patients with adverse events. Most patients discontinued the treatment in the first trimester, knowing that secukinumab is transferred through the placenta in the third trimester. There are no human data about the effect of secukinumab in the immune system of newborns after in utero exposure (B). ${ }^{249}$ 
Ixekizumab, a humanized monoclonal antibody (IgG4) that binds to IL-17A, has very limited usage data in pregnant women. In the development toxicity studies, ixekizumab crossed the placenta and was present in the blood up to six months of age, but animal studies still do not indicate directly or indirectly harmful effects regarding pregnancy, embryos, or fetal development, labor or post-natal development (D). ${ }^{239}$

\section{Recommendations:}

There are evidences that the use of low and medium potency topical corticosteroids are safe for the treatment of the pregnant woman with psoriasis. There seems to be an association of very high potency topical corticosteroids with low birth weight, and it should be avoided.

Since tazarotene has teratogenic potential, it is contraindicated during pregnancy.

Tacrolimus used topically is very little absorbed, however, due to the lack of safety studies in pregnant women, it is indicated to be used on small areas when there is no other therapeutic alternative.

There are no studies with calcipotriol conducted in pregnant women, and it should be avoided in this population.

The use of topical salicylates should be avoided in pregnant women due to the risk of systemic absorption of the salicylate and subsequent fetal risk.

Ultraviolet B phototherapy is the systemic therapy with best evidence of safety during pregnancy. PUVA phototherapy should be avoided during pregnancy due to the teratogenic potential of psoralen.

Despite being classified as category $\mathrm{C}$ by the FDA (US Food and Drug Administration Agency), cyclosporine has good evidences of safety for use during pregnancy.

Acitretin is absolutely contraindicated in pregnant women because of its teratogenic potential, and effective contraception must be ensured during its use and for at least two years after ceasing the drug.

Methotrexate is contraindicated during pregnancy because it is teratogenic and abortive.

There are reports that the use of infliximab, etanercept and adalimumab do not alter fetal development, being safe to the fetus when used during pregnancy. Nonetheless, there are no sufficient data for recommending these medications for the treatment of psoriasis in the pregnant woman, and effective contraception is recommended during their use in women of childbearing age.

There are very limited data on the safety of the treatment with ustekinumab, secukinumab, ixekizumab and guselkumab during pregnancy, with not enough data yet to recommend their use in pregnant women; effective contraception is recommended during their use in women of childbearing age.

8.2 Treatment of plaque psoriasis in breastfeeding women 8.2.1 Topical Corticosteroids

The first line of treatment for breastfeeding mothers is limited to emollients and low to medium potency topical corticosteroids (D)..$^{232}$

Topical corticosteroids have been proven safe during breastfeeding $(C){ }^{250}$ There is one report of hypertensive crisis in an infant after maternal use of high potency topical corticosteroid (C). ${ }^{244}$

\subsubsection{Calcipotriol}

Regarding calcipotriol, a vitamin D analogue, it presents a low risk of systemic absorption when used in small doses < 10,000 IU/day, however, there are no reports of its use during breastfeeding (D). ${ }^{223}$

\subsubsection{Tar Derivatives}

Coal tar can be transferred to the infant during breastfeeding through skin-to-skin or skin-to-mouth contact (C) ${ }^{243}$ Cases of detection of tar derivatives in breast milk have been reported (D). ${ }^{232}$

\subsubsection{Phototherapy}

Ultraviolet B (UVB) phototherapy is compatible with breastfeeding. Regarding PUVA, topical psoralen has little systemic absorption, however, it is unknown if it is absorbed into breast milk. PUVA phototherapy is contraindicated during breastfeeding (B). ${ }^{210}$

\subsubsection{Acitretin}

Acitretin should be avoided during breastfeeding due to its cumulative toxic effect. Breastfeeding infants are not capable of excreting the drug through the kidneys or liver due to the immaturity of these organs; this would increase the serum levels of the drug and it could reach toxic levels.

It was recently described that there are traces of acitretin (30-40 ng/ ml) excreted in the breast milk; this corresponds to a ratio of concentration milk/serum of 0.18 . the estimated dose for the infant is $1.5 \%$ of the maternal dose. Acitretin is almost exclusively found in the fat component of breast milk, thus, there are no reports of neonatal toxicity after exposure to acitretin in breast milk; however, it should be avoided in breastfeeding women. Recommendations are lacking regarding the time frame after finishing treatment during which breastfeeding should be contraindicated (B). ${ }^{214}$

\subsubsection{Methotrexate}

Methotrexate has reports of transference into breast milk in small concentrations, and can be deposited in the child's tissues for many months. Due to the limited number of studies in breastfeeding women and analysis of its long term effects in infants, its use is not recommended (C). ${ }^{229}$

Two-hourly samples of breast milk from a patient treated with a first dose of $22.5 \mathrm{mg}$ of methotrexate for postpartum choriocarcinoma showed it was excreted in small concentrations in the breast milk. The maximum level of methotrexate measured in the breast milk was around 3\% of the maximum maternal serum level, with the higher ratio milk-serum of 0.08 at 10 hours (D). ${ }^{251}$ The meaning of these measures is uncertain due to limited reports, and its use is contraindicated during breastfeeding (B), ${ }^{210}$ (D). ${ }^{226}$

\subsubsection{Cyclosporine}

There are reports of infants, born from renal transplant recipients using cyclosporine during breastfeeding, who did not develop renal toxicity or other side effects, with undetectable levels of cyclosporine (B), ${ }^{237}$ even though other reports show cytotoxicity and suggest avoiding the drug during breastfeeding $(C) .^{221}$

Data show that the use of calcineurin inhibitors such as cyclosporine during pregnancy does not increase the risk of con- 
genital defects in breastfeeding infants. Besides, it is known that cyclosporine is excreted in breast milk and the American Association of Pediatrics advises against breastfeeding during the use of the drug. Of the 15 cumulative breastfeeding infants in different reports, only one had detectable cyclosporine. The mother ceased breastfeeding and the child was well and developing adequately in the last follow-up. Although any immunosuppressing exposure to the baby can exceed safety limits, the relatively small amount of the drug transferred and the absence of reported adverse events, together with the documented benefits from breastfeeding, can overcome theoretical risks of this exposure (B). ${ }^{238}$

\subsubsection{Immunobiologics}

Data on the use of immunobiologic drugs are still scarce. The absorption of maternal antibodies through breast milk in humans is limited. Small amounts of IgG and other larger immunoglobulins cross mammary acini and, therefore, would hardly reach significant concentrations in the infant's blood. For this reason, the flow of anti-TNF drugs through breast milk is expected to be minimal (D). ${ }^{232}$

Adalimumab and infliximab are complete IgG1-type antibodies, and can cross the placental barrier. The mean clearance time for adalimumab in breastfeeding infants is four months, and for infliximab is 7.3 months. The latter was detected until 12 months of age (B). ${ }^{228}$

Etanercept is only found in small concentrations in breast milk and is undetectable in the blood of breastfeeding infants (C) ${ }^{213,235}$ In all case reports of mothers using etanercept, the breastfeeding infants achieved all development milestones. The authors described the concentration in breast milk of $5 \mathrm{ng} / \mathrm{ml}$ and etanercept was not detected in the infants' blood. Because it is a large protein, oral absorption of etanercept is believed to be minimal or absent (D). ${ }^{232}$ Adalimumab and infliximab had similar results to etanercept and seem to be safe for use during breastfeeding according to some reports (C). ${ }^{213,221,230,245}$

Ixekizumab is excreted in low levels in breast milk from cynomolgus monkeys, but it is unknown if it is excreted in human breast milk or if it is systemically absorbed after ingestion. It is a large protein molecule (molecular weight of $146,000 \mathrm{kDa}$ ), therefore, absorption is unlikely after the first weeks after delivery. The same is described for secukinumab (molecular weight 151,000 kDa) (D). ${ }^{239}$

Data on monoclonal antibodies anti-IL-12/23 are very immature to make any recommendations. Since ustekinumab has a molecular weight of $149,000 \mathrm{kDa}$, the amount in breast milk is likely to be very low and the absorption is unlikely due to its destruction in the infant's gastrointestinal tract (D). ${ }^{239}$

The effects of the use of ustekinumab during breastfeeding were studied in cynomolgus monkeys, in which low levels of ustekinumab (1/1000 of the level found in maternal serum) were found in breast milk. There are no reports of breastfeeding in humans; however, due to the fact that other immunoglobulins and proteins are present in colostrum, it is suggested that ustekinumab is excreted in breast milk (B). ${ }^{214}$

\section{Recommendations:}

Topical corticosteroids have been proven safe during breastfeeding.

There are no reports on the use of calcipotriol during breastfeeding.

Ultraviolet B phototherapy is the safest modality of systemic treatment to be indicated during breastfeeding. PUVA phototherapy should be avoided.

Methotrexate, acitretin, cyclosporine and psoralen (PUVA) are contraindicated during breastfeeding.

Adalimumab, infliximab and etanercept are safe for use during breastfeeding.

The lack of data on ustekinumab, ixekizumab, secukinumab and guselkumab does not allow to recommend their use during breastfeeding.

\section{MEDICATIONS ASSOCIATED TO THE DEVELOPMENT OR AGGRAVA- TION OF PSORIASIS}

With the aim of establishing the recommendations on systemic medications associated to the development or aggravation of psoriasis, a search was carried out using Medline-PubMed database, and the best scientific evidences were selected to answer the clinical questions. This search encompassed drugs that have been historically associated to the development and/or aggravation of psoriasis: angiotensin converting enzyme I inhibitors, angiotensin II receptor antagonists, lithium, beta-blockers, anti-inflammatories, antimalarials and interferon.

9. Which systemic medications are associated to the development or aggravation of psoriasis?

\subsection{TNF-alpha blockers}

Patients with chronic inflammatory conditions being treated with TNF-alpha blockers can progress with psoriasis as a paradoxical effect, also known as reactive psoriasis, most frequently reported in patients with inflammatory bowel disease (C). ${ }^{252-256}$ Many studies evidenced this relationship, with incidence ranging from $1.6 \%$ to $2.5 \%$ (253-256) (C). Smoking (C) ${ }^{252,256}$ and female gender (C) 254,256 were considered significant among the factors possibly related with the development of psoriasis as a paradoxical effect.

\subsection{Interferon Alpha}

During treatment with interferon alpha for the Hepatitis C, 36 cases of patients who developed psoriasis lesions (aggravation in 22 cases and triggering in 14 cases) were reported in 32 publications (C). ${ }^{257}$

\subsection{Angiotensin II Receptor Antagonists}

The use of losartan for the treatment of hypertension in a 49-year-old man lead to the subsequent appearance of psoriasiform lesions (confirmed by biopsy) one week after the medication was commenced. The skin lesions gradually resolved after discontinuation of losartan (C). ${ }^{258}$

\subsection{Nonsteroidal Anti-inflammatories}

Isolated cases of patients with inflammatory arthopathies are reported with the development of psoriasis for using nimesuli- 
$\mathrm{de}^{259}(\mathrm{C})$ and rofecoxib $(\mathrm{C})^{260}$, with subsequent remission of psoriasis after withdrawal of the anti-inflammatory.

The association between many pain killers widely used, including aspirin, nonsteroidal anti-inflammatories (NSAIDs) and acetaminophen (paracetamol) and the risk for psoriasis and psoriatic arthritis (PsA) was evaluated in 95,540 participants during follow-up. During 1,321,280 person-years of follow-up, 646 cases of psoriasis and 165 cases of PsA were documented. Compared to women who did not report their use, regular acetaminophen and NSAIDs users, with longer than 10 years of use, showed multivariate risk rates of 3.60 (CI95\%:2.02-6.41] and 2.10 (CI95\%:1.11-3.96), respectively, for PsA. There was no clear association between aspirin and psoriasis risk or PsA. In conclusion, the prolonged use of acetaminophen and NSAIDs can be associated to an increased risk of psoriasis and PsA(B). ${ }^{261}$

\subsection{Betablockers}

An analysis of 36,702 patients (and the same number of controls) with first-time diagnosis of psoriasis who used cardioselective and non-cardioselective betablocker revealed that according to the number of prescriptions $(1-4,5-19,>20)$ the incidence of psoriasis was, respectively OR 0.93 (0.70 to 1.13 CI95\%), 1.10 (0.97 to 1.24 ) and 1.10 (1.01 to 1.20), not supporting evidences that the use of betablockers increase the incidence of psoriasis (B). ${ }^{262}$

Twenty-three psoriasis patients using betablockers first developed psoriasis after commencing the drug in seven cases, and this number was statistically significant when compared to the control group (psoriasis patients with no previous use of betablocker) - $\mathrm{p}<0.001$. four of these patients had a generalized presentation (severe) of psoriasis and in three the symptoms remitted after discontinuation (B)..$^{263}$

\subsection{Lithium}

The use of lithium in 36,702 patients (and the same number of controls) with first-time diagnosis of psoriasis registered between 1994 and 2005, when compared to non-use prior to development of psoriasis, resulted in an Odds Ratio (OR) of 1.68 (CI95\% 1.18- 2.39, $\mathrm{p}<0.01$ ), demonstrating that the use of lithium was associated to a small risk of an increased incidence of psoriasis (B) ${ }^{264}$
Patients with psychiatric disorders that received lithium for the first time developed psoriasis in $6 \%$ of cases (of the 51 patients receiving lithium, three developed lesions); compared to the control group, $p$ value was not significant $(\mathbf{B}){ }^{265}$

\subsection{Angiotensin I Converting Enzyme Inhibitors}

There are reports that the angiotensin II converting enzyme inhibitors (ACEI) captopril and lisinopril exacerbated or triggered psoriasiform lesions (C). ${ }^{266}$

In a cohort where 16,342 patients received captopril, 25,686 patients received enalapril maleate and 11,235 patients received lisinopril, six developed psoriasiform lesions (one case of exacerbation and five cases of new onset). The rate of association of psoriasiform lesions was 1.3 for 10,000 in total, 2.1 for each 10,000 women and 0.4 for each 10,000 men $(C) .{ }^{267}$

\subsection{Antimalarials}

Six days after starting chloroquine phosphate $500 \mathrm{mg} /$ week and proguanil $200 \mathrm{mg}$ /day for malaria prophylaxis, a 45 -year-old patient with psoriasis presented with worsening of the inflammation and pain in preexisting lesions $(\mathbf{C}) .{ }^{268}$

Another report revealed exacerbation of plaque psoriasis lesions in a patient using chloroquine sulfate $400 \mathrm{mg} /$ week and proguanil $200 \mathrm{mg} /$ day as prophylaxis, requiring hospitalization for systemic treatment with methotrexate $(C){ }^{269}$

\section{Recommendations:}

TNF alpha blockers can paradoxically cause psoriasiform lesions in patients with chronic inflammatory conditions, being more frequent in inflammatory bowel disease, occurring in 1.6-2.5\% of patients.

Results of the largest studies regarding betablockers and lithium are still controversial because they are drugs with considerable evidences, however insufficient, to cause or aggravate psoriasis.

Therapy with interferon alpha, nonsteroidal anti-inflammatories, angiotensin receptor antagonists and ACE inhibitors seem to trigger or exacerbate preexisting psoriasiform lesions, although with weak evidences of causal relationship. $\square$ 


\section{REFERENCES}

1. Diretrizes.amb.org.br [Internet]. Arnone M, AVE Carvalho, Takahashi MDF, Bernardo WM, et al. Projeto Diretrizes AMB: Psoríase [cited 2018 dec 14]. Available from: http://diretrizes.amb.org.br/?s=psoriase.

2. Aktan S, Ilknur T, Akin C, Ozkan S. Interobserver reliability of the Nail Psoriasis Severity Index. Clin Exp Dermatol. Clin Exp Dermatol. 2007;32:141-4.

3. Bronsard V, Paul C, Prey S, Puzenat E, Gourraud PA, Aractingi S, et al. What are the best outcome measures for assessing quality of life in plaque type psoriasis? A systematic review of the literature. JJ Eur Acad Dermatol Venereol. 2010;24 (Suppl 2):S17-22.

4. Chularojanamontri L, Griffiths CE, Chalmers RJ. The Simplified Psoriasis Index (SPI): A Practical Tool for Assessing Psoriasis. J Invest Dermatol. 2013;133:1956-62.

5. Gottlieb AB, Merola JF, Chen R, Levi E, Duffin KC. Assessing clinical response and defining minimal disease activity in plaque psoriasis with the Physician Global Assessment and body surface area (PGA $\times$ BSA) composite tool: An analysis of apremilast phase 3 ESTEEM data. J Am Acad Dermatol. 2017;77:1178-1180.

6. Gottlieb AB, Evans R, Li S, Dooley LT, Guzzo CA, Baker D, et al. Infliximab induction therapy for patients with severe plaque-type psoriasis: a randomized, doubleblind, placebo-controlled trial. J Am Acad Dermatol. 2004;51:534-42.

7. Langley RG, Ellis CN. Evaluating psoriasis with Psoriasis Area and Severity Index, Psoriasis Global Assessment, and Lattice System Physician's Global Assessment. J Am Acad Dermatol. 2004;51:563-9.

8. Ljosaa TM, Mork C, Stubhaug A, Moum T, Wahl AK.. Skin pain and skin discomfort is associated with quality of life in patients with psoriasis. J Eur Acad Dermatol Venereol. 2012;26:29-35.

9. Lubrano E, Scrivo R, Cantini F, Marchesoni A, Mathieu A, Olivieri I, et al. Is the Nail Psoriasis Severity Index reliable in the assessment of nail psoriasis by rheumatologists? Arthritis Care Res (Hoboken). 2012:64:455-8.

10. Lundberg L, Johannesson M, Silverdahl M, Hermansson C, Lindberg M. Healthrelated quality of life in patients with psoriasis and atopic dermatitis measured with SF-36, DLQI and a subjective measure of disease activity. Acta Derm Venereol. 2000;80:430-4.

11. Mattei PL, Corey KC, Kimball AB. Psoriasis Area Severity Index (PASI) and the Dermatology Life Quality Index (DLQI): the correlation between disease severity and psychological burden in patients treated with biological therapies. J Eur Acad Dermatol Venereol. 2014;28:333-7.

12. Reich K, Nestle F0, Papp K, Ortonne JP, Evans R, Guzzo C, et al. Infliximab induction and maintenance therapy for moderate-to-severe psoriasis: a phase III, multicentre, double-blind trial. Lancet. 2005;366:1367-74.

13. Rich P, Scher RK. Nail Psoriasis Severity Index: a useful tool for evaluation of nail psoriasis. J Am Acad Dermatol. 2003:49:206-12.

14. Robinson A, Kardos M, Kimball AB. Physician Global Assessment (PGA) and Psoriasis Area and Severity Index (PASI): why do both? A systematic analysis of randomized controlled trials of biologic agents for moderate to severe plaque psoriasis. J Am Acad Dermatol. 2012;66:369-75.

15. Walsh JA, McFadden M, Woodcock J, Clegg DO, Helliwell P, Dommasch E, et al. Product of the Physician Global Assessment and body surface area: a simple static measure of psoriasis severity in a longitudinal cohort. J Am Acad Dermatol. 2013;69:931-7.

16. Puzenat E, Bronsard V, Prey S, Gourraud PA, Aractingi S, Bagot M, , et al. What are the best outcome measures for assessing plaque psoriasis severity? A systematic review of the literature. J Eur Acad Dermatol Venereol. 2010;24(Suppl 2):10-6

17. Awosika 0, Eleryan MG, Rengifo-Pardo M, Doherty L, Martin LW, Ehrlich A. A Case-control Study to Evaluate the Prevalence of Nonalcoholic Fatty Liver Disease Among Patients with Moderate-to-severe Psoriasis. J Clin Aesthet Dermatol. 2018;11:33-7.

18. Baeta IG, Bittencourt FV, Gontijo B, Goulart EM. Comorbidities and cardiovascular risk factors in patients with psoriasis. An Bras Dermatol. 2014;89:735-44.

19. Birkenfeld S, Dreiher J, Weitzman D, Cohen AD. Coeliac disease associated with psoriasis. Br J Dermatol. 2009;161:1331-4.

20. Capo A, Affaitati G, Giamberardino MA, Amerio P. Psoriasis and migraine. J Eur Acad Dermatol Venereol. 2018:32:57-61.

21. Choi YM, Famenini S, Wu JJ. Incidence of Pulmonary Arterial Hypertension in Patients with Psoriasis: A Retrospective Cohort Study. Perm J. 2017;21.

22. Cohen AD, Dreiher J, Shapiro Y, Vidavsky L, Vardy DA, Davidovici B, et al. Psoriasis and diabetes: a population-based cross-sectional study. J Eur Acad Dermatol Venereol. 2008;22:585-9.

23. Cohen AD, Weitzman D, Dreiher J.. Psoriasis and hypertension: a case-control study. Acta Derm Venereol. 2010;90:23-6.

24. Cohen BE, Martires KJ, Ho RS. Psoriasis and the Risk of Depression in the US Population: National Health and Nutrition Examination Survey 2009-2012. JAMA Dermatol. 2016;152:73-9.

25. Costa-Silva M, Vide J, Lopes S, Azevedo F, Magina S. Psoriasis and comorbidities: general practitioners' awareness. Acta Dermatovenerol Alp Pannonica Adriat.
2018:27:5-7.

26. Curcó N, Barriendos N, Barahona MJ, Arteaga C, García M, Yordanov S, et al. Factors influencing cardiometabolic risk profile in patients with psoriasis. Australas J Dermatol. 2018:59:e93-8

27. Dalgard FJ, Gieler U, Tomas-Aragones L, Lien L, Poot F, Jemec GBE, et al. The psychological burden of skin diseases: a cross-sectional multicenter study among dermatological out-patients in 13 European countries. J Invest Dermatol. 2015;135:984-91

28. Damevska K, Neloska L, Gocev G, Mihova M. Metabolic syndrome in untreated patients with psoriasis: case-control study. J Dtsch Dermatol Ges. 2013;11:1169-75.

29. Dommasch ED, Li T, Okereke OI, Li Y, Qureshi AA, Cho E. Risk of depression in women with psoriasis: a cohort study. Br J Dermatol. 2015;173:975-80.

30. Dreiher J, Weitzman D, Shapiro J, Davidovici B, Cohen AD. Psoriasis and chronic obstructive pulmonary disease: a case-control study. Br J Dermatol. 2008; 159:956-60

31. Driessen RJ, Boezeman JB, Van De Kerkhof PC, De Jong EM. Cardiovascular risk factors in high-need psoriasis patients and its implications for biological therapies. J Dermatolog Treat. 2009;20:42-7.

32. Egeberg A, Khalid U, Gislason GH, Mallbris L, Skov L, Hansen PR. Association between depression and risk of atrial fibrillation and stroke in patients with psoriasis: a Danish nationwide cohort study. Br J Dermatol. 2015;173:471-9.

33. Egeberg A, Mallbris L, Hilmar Gislason G, Skov L, Riis Hansen P. Increased risk of migraine in patients with psoriasis: A Danish nationwide cohort study. J Am Acad Dermatol. 2015;73:829-35.

34. Eppinga H, Poortinga S, Thio HB, Nijsten TEC, Nuij VJAA, van der Woude CJ, et al. Prevalence and Phenotype of Concurrent Psoriasis and Inflammatory Bowe Disease. Inflamm Bowel Dis. 2017;23:1783-9.

35. Feldman SR, Zhao Y, Shi L, Tran MH. Economic and Comorbidity Burden Among Patients with Moderate-to-Severe Psoriasis. J Manag Care Spec Pharm. 2015 ;21:874-88.

36. Gisondi P, Targher G, Zoppini G, Girolomoni G. Non-alcoholic fatty liver disease in patients with chronic plaque psoriasis. J Hepatol. 2009;51:758-64.

37. Goldet G, Howick J. Understanding GRADE: an introduction. J J Evid Based Med 2013;6:50-4.

38. Han C, Lofland JH, Zhao N, Schenkel B. Increased prevalence of psychiatric disorders and health care-associated costs among patients with moderate-tosevere psoriasis. J Drugs Dermatol. 2011;10:843-50.

39. Helmick CG, Lee-Han H, Hirsch SC, Baird TL, Bartlett CL. Prevalence of psoriasis among adults in the U.S.: 2003-2006 and 2009-2010 National Health and Nutrition Examination Surveys. Am J Prev Med. 2014:47:37-45.

40. Henseler T, Christophers E. Disease concomitance in psoriasis. J Am Acad Dermatol. 1995:32:982-6.

41. Jadad AR, Moore RA, Carroll D, Jenkinson C, Reynolds DJ, Gavaghan DJ, et al. Assessing the quality of reports of randomized clinical trials: is blinding necessary? Control Clin Trials. 1996:17:1-12.

42. Jekler J, Swanbeck G. One-minute dithranol therapy in psoriasis: a placebocontrolled paired comparative study. Acta Derm Venereol. 1992;72:449-50.

43. Karia SB, De Sousa A, Shah N, Sonavane S, Bharati A. Psychiatric morbidity and quality of life in skin diseases: A comparison of alopecia areata and psoriasis. Ind Psychiatry J. 2015;24:125-8.

44. Khalid U, Ahlehoff 0 , Gislason GH, Skov L, Torp-Pedersen C, Hansen PR Increased risk of aortic valve stenosis in patients with psoriasis: a nationwide cohort study. Eur Heart J. 2015;36:2177-83.

45. Khalid U, Hansen PR, Gislason GH, Lindhardsen J, Kristensen SL, Winther SA, et al. Psoriasis and new-onset diabetes: a Danish nationwide cohort study. Diabetes Care. 2013:36:2402-7.

46. Kim CR, Lee JH. An observational study on the obesity and metabolic status of psoriasis patients. Ann Dermatol. 2013;25:440-4.

47. Kimball AB, Wu EQ, Guérin A, Yu AP, Tsaneva M, Gupta SR, et al. Risks of developing psychiatric disorders in pediatric patients with psoriasis. J Am Acad Dermatol. 2012;67:651-7.e1-2.

48. Kumar V, Mattoo SK, Handa S. Psychiatric morbidity in pemphigus and psoriasis: a comparative study from India. Asian J Psychiatr. 2013;6:151-6.

49. Kurd SK, Troxel AB, Crits-Christoph P, Gelfand JM. The risk of depression, anxiety, and suicidality in patients with psoriasis: a population-based cohort study. Arch Dermatol. 2010;146:891-5.

50. Lakshmy S, Balasundaram S, Sarkar S, Audhya M, Subramaniam E. A Crosssectional Study of Prevalence and Implications of Depression and Anxiety in Psoriasis. Indian J Psychol Med. 2015;37:434-40.

51. Madanagobalane S, Anandan S. Prevalence of metabolic syndrome in South Indian patients with psoriasis vulgaris and the relation between disease severity and metabolic syndrome: a hospital-based case-control study. Indian J Dermatol. 2012:57:353-7. 
52. Mebazaa A, El Asmi M, Zidi W, Zayani Y, Cheikh Rouhou R, El Ounifi S et al. Metabolic syndrome in Tunisian psoriatic patients: prevalence and determinants. J Eur Acad Dermatol Venereol. 2011;25:705-9.

53. Menegon DB, Pereira AG, Camerin AC, Cestari T. Psoriasis and comorbidities in a southern Brazilian population: a case-control study. Int J Dermatol. 2014;53:e518-25.

54. Milčić D, Janković S, Vesić S, Milinković M, Marinković J, Ćirković A, et al. Prevalence of metabolic syndrome in patients with psoriasis: a hospital-based cross-sectional study. An Bras Dermatol. 2017;92:46-51.

55. Molina-Leyva A, Molina-Leyva I, Almodovar-Real A, Ruiz-Carrascosa JC, NaranjoSintes R5, Jimenez-Moleon JJ. Prevalence and Associated Factors of Erectile Dysfunction in Patients With Moderate to Severe Psoriasis and Healthy Population: A Comparative Study Considering Physical and Psychological Factors. Arch Sex Behav. 2016;45:2047-55.

56. Neimann AL, Shin DB, Wang X, Margolis DJ, Troxel AB, Gelfand JM. Prevalence of cardiovascular risk factors in patients with psoriasis. J Am Acad Dermatol. 2006:55:829-35

57. Oh EH, Ro YS, Kim JE Epidemiology and cardiovascular comorbidities in patients with psoriasis: A Korean nationwide population-based cohort study. J Dermatol. 2017;44:621-9.

58. Parisi R, Rutter MK, Lunt M, Young HS, Symmons DPM, Griffiths CEM, et al. Psoriasis and the Risk of Major Cardiovascular Events: Cohort Study Using the Clinical Practice Research Datalink. J Invest Dermatol. 2015;135:2189-97

59. Paschoal RS, Silva DA, Cardili RN, Souza CDS. Metabolic syndrome, C-reactive protein and cardiovascular risk in psoriasis patients: a cross-sectional study. An Bras Dermatol. 2018:93:222-8

60. Pearce DJ, Morrison AE, Higgins KB, Crane MM, Balkrishnan R, Fleischer AB Jr, et al. The comorbid state of psoriasis patients in a university dermatology practice. $J$ Dermatolog Treat. 2005;16:319-23.

61. Cebm.net [Internet]. Phillips B. Levels of Evidence and Grades of Recommendation Oxford Centre for Evidence-Based Medicine; 2001. [cited 2009 mar 01]. Availabre from: https://www.cebm.net/2009/06/oxford-centre-evidence-based-medicinelevels-evidence-march-2009/

62. Picardi A, Mazzotti E, Pasquini P. Prevalence and correlates of suicidal ideation among patients with skin disease. J Am Acad Dermatol. 2006;54:420-6.

63. Pietrzak D, Pietrzak A, Krasowska D, Makara-Studzińska M, Madej A, Baranowska $\mathrm{M}$, et al. Depressiveness, measured with Beck Depression Inventory, in patients with psoriasis. J Affect Disord. 2017;209:229-34.

64. Pompili M, Innamorati M, Forte A, Erbuto D, Lamis DA, Narcisi A, et al. Psychiatric comorbidity and suicidal ideation in psoriasis, melanoma and allergic disorders. Int J Psychiatry Clin Pract. 2017;21:209-14.

65. Poot F, Antoine E, Gravellier M, Hirtt J, Alfani S, Forchetti G, et al. A case-control study on family dysfunction in patients with alopecia areata, psoriasis and atopic dermatitis. Acta Derm Venereol. 2011;91:415-21.

66. Prodanovich S, Kirsner RS, Kravetz JD, Ma F, Martinez L, Federman DG. Association of psoriasis with coronary artery, cerebrovascular, and peripheral vascular diseases and mortality. Arch Dermatol. 2009;145:700-3.

67. Radtke MA, Schäfer I, Glaeske G, Jacobi A, Augustin M. Prevalence and comorbidities in adults with psoriasis compared to atopic eczema. J Eur Acad Dermatol Venereol. 2017:31:151-7.

68. Roberts KK, Cochet AE, Lamb PB, Brown PJ, Battafarano DF, Brunt EM, et al. The prevalence of NAFLD and NASH among patients with psoriasis in a tertiary care dermatology and rheumatology clinic. Aliment Pharmacol Ther. 2015;41:293-300

69. Salunke AS, Nagargoje MV, Belgaumkar VA, Tolat SN, Chavan RB. Association of Metabolic Syndrome in Chronic Plaque Psoriasis Patients and their Correlation with Disease Severity, Duration and Age: A Case Control Study from Western Maharashtra. J Clin Diagn Res. 2017:11:WC06-WC10.

70. Sampogna F, Puig L, Spuls P, Girolomoni G, Radtke MA, Kirby B, et al. Prevalence of alexithymia in patients with psoriasis and its association with disease burden: a multicentre observational study. Br J Dermatol. 2017;176:1195-203.

71. Sanchez-Carazo JL, López-Estebaranz JL, Guisado C. Comorbidities and healthrelated quality of life in Spanish patients with moderate to severe psoriasis: a cross-sectional study (Arizona study). J Dermatol. 2014;41:673-8.

72. SchmittJ, Ford DE. Psoriasis is independently associated with psychiatric morbidity and adverse cardiovascular risk factors, but not with cardiovascular events in a population-based sample. J Eur Acad Dermatol Venereol. 2010;24:885-92.

73. Schwandt A, Bergis D, Dapp A, Ebner S, Jehle PM, Köppen S, et al. Psoriasis and Diabetes: A Multicenter Study in 222078 Type 2 Diabetes Patients Reveals High Levels of Depression. J Diabetes Res. 2015;2015:792968.

74. Shah K, Mellars L, Changolkar A, Feldman SR. Real-world burden of comorbidities in US patients with psoriasis. J Am Acad Dermatol. 2017;77:287-292.e4

75. Shapiro J, Cohen AD, David M, Hodak E, Chodik G, Viner A, et al. The association between psoriasis, diabetes mellitus, and atherosclerosis in Israel: a case-control study. J Am Acad Dermatol. 2007;56:629-34.
76. Sommer DM, Jenisch S, Suchan M, Christophers E, Weichenthal M. Increased prevalence of the metabolic syndrome in patients with moderate to severe psoriasis. Arch Dermatol Res. 2006;298:321-8.

77. Tsai TF, Wang TS, Hung ST, Tsai PI, Schenkel B, Zhang M, et al. Epidemiology and comorbidities of psoriasis patients in a national database in Taiwan. J Dermatol Sci. 2011;63:40-6

78. Tseng HW, Lin HS, Lam HC. Co-morbidities in psoriasis: a hospital-based casecontrol study. J Eur Acad Dermatol Venereol. 2013;27:1417-25

79. Tsintsadze N, Beridze L, Tsintsadze N, Krichun Y, Tsivadze N, Tsintsadze M. Psychosomatic aspects in patients with dermatologic diseases. Georgian Med News. 2015;243:70-5

80. Vanaclocha F, Crespo-Erchiga V, Jiménez-Puya R, Puig L, Sánchez-Carazo JL, Ferrán M, et al. Immune-mediated inflammatory diseases and other comorbidities in patients with psoriasis: baseline characteristics of patients in the AQUILES study. Actas Dermosifiliogr. 2015;106:35-43.

81. van der Voort EA, Koehler EM, Dowlatshahi EA, Hofman A, Stricker BH, Janssen $\mathrm{HL}$, et al. Psoriasis is independently associated with nonalcoholic fatty liver disease in patients 55 years old or older: Results from a population-based study. J Am Acad Dermatol. 2014;70:517-24.

82. Walter R. Partial purification and characterization of post-proline cleaving enzyme: enzymatic inactivation of neurohypophyseal hormones by kidney preparations of various species. Biochim Biophys Acta. 1976;422:138-58.

83. Ohri.ca [Internet]. Wells G, Shea B, O'Connell D, Robertson J, Peterson J, Welch V, et al. The Newcastle-Ottawa Scale (NOS) for assessing the quality of nonrandomised studies in meta-analyses. [cited 2018 nov 01 ]. Available from: http://www.ohri.ca/programs/clinical epidemiology/oxford.asp

84. Xu X, Su L, Gao Y, Ding Y. The Prevalence of Nonalcoholic Fatty Liver Disease and Related Metabolic Comorbidities Was Associated with Age at Onset of Moderate to Severe Plaque Psoriasis: A Cross-Sectional Study. PLoS One. 2017;12:e0169952.

85. Yang YW, Keller JJ, Lin HC. Medical comorbidity associated with psoriasis in adults: a population-based study. Br J Dermatol. 2011:165:1037-43.

86. Yeung H, Takeshita J, Mehta NN, Kimmel SE, Ogdie A, Margolis DJ, et al. Psoriasis severity and the prevalence of major medical comorbidity: a population-based study. JAMA Dermatol. 2013;149:1173-9.

87. Yiu KH, Yeung CK, Zhao CT, Chan JC, Siu CW, Tam S, et al. Prevalence and extent of subclinical atherosclerosis in patients with psoriasis. J Intern Med. 2013;273:273-82.

88. Zander N, Schäfer I, Radtke M, Jacobi A, Heigel H, Augustin M. Dermatological comorbidity in psoriasis: results from a large-scale cohort of employees. Arch Dermatol Res. 2017:309:349-56

89. Beutner K, Chakrabarty A, Lemke S, Yu K. An intra-individual randomized safety and efficacy comparison of clobetasol propionate $0.05 \%$ spray and its vehicle in the treatment of plaque psoriasis. J Drugs Dermatol. 2006;5:357-60.

90. Carroll CL, Feldman SR, Camacho FT, Balkrishnan R. Better medication adherence results in greater improvement in severity of psoriasis. Br J Dermatol. 2004:151:895-7.

91. Carroll CL, Clarke J, Camacho F, Balkrishnan R, Feldman SR. Topical tacrolimus ointment combined with $6 \%$ salicylic acid gel for plaque psoriasis treatment. Arch Dermatol. 2005;141:43-6.

92. Decroix J, Pres H, Tsankov N, Poncet M, Arsonnaud S. Clobetasol propionate Iotion in the treatment of moderate to severe plaque-type psoriasis. Cutis. 2004; $74: 201-6$

93. Douglas WS, Poulin Y, Decroix J, Ortonne JP, Mrowietz U, Gulliver W, et al. A new calcipotrio//betamethasone formulation with rapid onset of action was superior to monotherapy with betamethasone dipropionate or calcipotriol in psoriasis vulgaris. Acta Derm Venereol. 2002;82:131-5.

94. Dubertret L, Wallach D, Souteyrand P, Perussel M, Kalis B, Meynadier J, et al. Efficacy and safety of calcipotriol (MC 903) ointment in psoriasis vulgaris. A randomized, double-blind, right/left comparative, vehicle-controlled study. J Am Acad Dermatol. 1992;27:983-8.

95. Feldman SR, Matheson R, Bruce S, Grande K, Markowitz 0, Kempers S, et al. Efficacy and safety of calcipotriene $0.005 \%$ foam for the treatment of plaque-type psoriasis: results of two multicenter, randomized, double-blind, vehicle-controlled, phase III clinical trials. Am J Clin Dermatol. 2012;13:261-71.

96. Franz TJ, Parsell DA, Myers JA, Hannigan JF. Clobetasol propionate foam 0.05\%: a novel vehicle with enhanced delivery. Int J Dermatol. 2000;39:535-8.

97. Gottlieb AB, Ford RO, Spellman MC. The efficacy and tolerability of clobetasol propionate foam $0.05 \%$ in the treatment of mild to moderate plaque-type psoriasis of nonscalp regions. J Cutan Med Surg. 2003;7:185-92.

98. Guenther L, Van de Kerkhof PC, Snellman E, Kragballe K, Chu AC, Tegner E, et al. Efficacy and safety of a new combination of calcipotriol and betamethasone dipropionate (once or twice daily) compared to calcipotriol (twice daily) in the treatment of psoriasis vulgaris: a randomized, double-blind, vehicle-controlled clinical trial. Br J Dermatol. 2002;147:316-23. 
99. Helfrich YR, Kang S, Hamilton TA, Voorhees JJ. Topical becocalcidiol for the treatment of psoriasis vulgaris: a randomized, placebo-controlled, double-blind, multicentre study. Br J Dermatol. 2007;157:369-74.

100. Highton A, Quell J. Calcipotriene ointment $0.005 \%$ for psoriasis: a safety and efficacy study. Calcipotriene Study Group. J Am Acad Dermatol. 1995;32:67-72.

101. Jarratt MT, Clark SD, Savin RC, Swinyer LJ, Safley CF, Brodell RT, , et al. Evaluation of the efficacy and safety of clobetasol propionate spray in the treatment of plaque-type psoriasis. Cutis. 2006;78:348-54.

102. Kaufmann R, Bibby AJ, Bissonnette R, Cambazard F, Chu AC, Decroix J, et al. A New Calcipotrio//Betamethasone Dipropionate Formulation (Daivobet $<$ sup $>T M<1$ sup $>$ ) Is an Effective Once-Daily Treatment for Psoriasis vulgaris. Dermatology. 2002;205:389-93

103. Kragballe K, Noerrelund KL, Lui H, Ortonne JP, Wozel G, Uurasmaa T, et al. Efficacy of once-daily treatment regimens with calcipotriol/betamethasone dipropionate ointment and calcipotriol ointment in psoriasis vulgaris. $\mathrm{Br} J$ Dermatol. 2004;150:1167-73

104. Kragballe K. Treatment of psoriasis by the topical application of the novel cholecalciferol analogue calcipotriol (MC 903). Arch Dermatol. 1989;125:1647-52.

105. Lane AT, Wachs GN, Weston WL. Once-daily treatment of psoriasis with topical glucocorticosteroid ointments. J Am Acad Dermatol. 1983;8:523-5.

106. Langner A, Verjans H, Stapór V, Mol M, Fraczykowska M. Topical calcitriol in the treatment of chronic plaque psoriasis: a double-blind study. $\mathrm{Br} \mathrm{J}$ Dermatol. 1993;128:566-71.

107. Lebwohl M, Menter A, Weiss J, Clark SD, Flores J, Powers J, et al. Calcitriol 3 microg $/ \mathrm{g}$ ointment in the management of mild to moderate plaque type psoriasis: results from 2 placebo-controlled, multicenter, randomized double-blind, clinical studies. J Drugs Dermatol. 2007;6:428-35.

108. Lebwohl M, Sherer D, Washenik K, Krueger GG, Menter A, Koo J, et al. A randomized, double-blind, placebo-controlled study of clobetasol propionate $0.05 \%$ foam in the treatment of nonscalp psoriasis. Int J Dermatol. 2002;41:269-74.

109. Olsen EA. Efficacy and safety of fluticasone propionate $0.005 \%$ ointment in the treatment of psoriasis. Cutis. 1996;57(2 Suppl):57-61.

110. Papp KA, Guenther L, Boyden B, Larsen FG, Harvima RJ, Guilhou JJ, et al. Early onset of action and efficacy of a combination of calcipotriene and betamethasone dipropionate in the treatment of psoriasis. J Am Acad Dermatol. 2003:48:48-54.

111. Pèrez A, Chen TC, Turner $A$, Raab R, Bhawan J, Poche P, et al. Efficacy and safety of topical calcitriol (1,25-dihydroxyvitamin $\mathrm{d} 3$ ) for the treatment of psoriasis. Br J Dermatol. 1996;134:238-46.

112. Queille-Roussel C, Hoffmann V, Ganslandt C, Hansen KK. Comparison of the antipsoriatic effect and tolerability of calcipotriol-containing products in the treatment of psoriasis vulgaris using a modified psoriasis plaque test. Clin Drug Investig. 2012;32:613-9.

113. Saraceno R, Andreassi L, Ayala F, Bongiorno MR, Giannetti A, Lisi P, et al. Efficacy, safety and quality of life of calcipotriol/betamethasone dipropionate (Dovobet) versus calcipotriol (Daivonex) in the treatment of psoriasis vulgaris: a randomized, multicentre, clinical trial. J Dermatolog Treat. 2007;18:361-5.

114. Stein LF, Sherr A, Solodkina G, Gottlieb AB, Chaudhari U.. Betamethasone valerate foam for treatment of nonscalp psoriasis. J Cutan Med Surg. 2001;5:303-7.

115. van der Velden HM1, Pasch MC, van Erp PE, van Lingen RG, Otero ME, de Boervan Huizen RT, et al. Treatment of plaque psoriasis with the two-compound product calcipotriol/betamethasone dipropionate versus both monotherapies: an immunohistochemical study. J Dermatolog Treat. 2010;21:13-22.

116. Zonneveld IM, Rubins A, Jablonska S, Dobozy A, Ruzicka T, Kind P, et al. Topical tacrolimus is not effective in chronic plaque psoriasis. A pilot study. Arch Dermatol. 1998:134:1101-2.

117. Tzaneva S, Geroldinger A, Trattner $\mathrm{H}$, Tanew A. Fumaric acid esters in combination with a 6-week course of narrowband ultraviolet B provides an accelerated response compared with fumaric acid esters monotherapy in patients with moderate-to-severe plaque psoriasis: a randomized prospective clinical study. $\mathrm{Br}$ J Dermatol. 2018;178:682-8

118. Al-Hamamy HR, Al-Mashhadani SA, Mustafa IN. Comparative study of the effect of narrowband ultraviolet $B$ phototherapy plus methotrexate vs. narrowband ultraviolet B alone and methotrexate alone in the treatment of plaque-type psoriasis. Int J Dermatol. 2014;53:1531-5.

119. Lynde CW, Gupta AK, Guenther L, Poulin Y, Levesque A, Bissonnette R. A randomized study comparing the combination of nbUVB and etanercept to etanercept monotherapy in patients with psoriasis who do not exhibit an excellent response after 12 weeks of etanercept. J Dermatolog Treat. 2012;23:261-7.

120. Wolf P, Hofer A, Legat FJ, Bretterklieber A, Weger W, Salmhofer W, et al. Treatment with 311-nm ultraviolet $B$ accelerates and improves the clearance of psoriatic lesions in patients treated with etanercept. Br J Dermatol. 2009;160:186-9.

121. Wolf $P$, Hofer A, Weger W, Posch-Fabian T, Gruber-Wackernagel A, Legat FJ. 311 $\mathrm{nm}$ ultraviolet B-accelerated response of psoriatic lesions in adalimumab-treated patients. Photodermatol Photoimmunol Photomed. 2011;27:186-9.
122. Takahashi H, Tsuji H, Ishida-Yamamoto A, lizuka H. Comparison of clinical effects of psoriasis treatment regimens among calcipotriol alone, narrowband ultraviolet B phototherapy alone, combination of calcipotriol and narrowband ultraviolet B phototherapy once a week, and combination of calcipotriol and narrowband ultraviolet B phototherapy more than twice a week. J Dermatol. 2013;40:424-7.

123. Khanna N, Nazli T, Siddiqui KM, Kalaivani M; Rais-ur-Rahman. A non-inferiority randomized controlled clinical trial comparing Unani formulation \& psoralen plus ultraviolet A sol in chronic plaque psoriasis. Indian J Med Res. 2018;147:66-72

124. Lozinski A, Barzilai A, Pavlotsky F. Broad-band UVB versus paint PUVA for palmoplantar psoriasis treatment. J Dermatolog Treat. 2016;27:221-3.

125. Dawe RS, Cameron H, Yule S, Man I, Wainwright NJ, Ibbotson SH, et al. A randomized controlled trial of narrowband ultraviolet $B$ vs bath-psoralen plus ultraviolet A photochemotherapy for psoriasis. Br J Dermatol. 2003;148:1194-204.

126. Snellman E, Klimenko T, Rantanen T. Randomized half-side comparison of narrowband UVB and trimethylpsoralen bath plus UVA treatments for psoriasis. Acta Derm Venereol. 2004;84:132-7.

127. Markham T, Rogers S, Collins P. Narrowband UV-B (TL-01) phototherapy vs ora 8-methoxypsoralen psoralen-UV-A for the treatment of chronic plaque psoriasis. Arch Dermatol. 2003;139:325-8.

128. Gordon PM, Diffey BL, Matthews JN, Farr PM. A randomized comparison of narrow-band TL-01 phototherapy and PUVA photochemotherapy for psoriasis. J Am Acad Dermatol. 1999;41:728-32.

129. Salem SA, Barakat MA, Morcos CM. Bath psoralen+ultraviolet A photochemotherapy vs. narrow band-ultraviolet $B$ in psoriasis: a comparison of clinical outcome and effect on circulating T-helper and T-suppressor/cytotoxic cells. Photodermatol Photoimmunol Photomed. 2010;26:235-42.

130. Green C, Lakshmipathi T, Johnson BE, Ferguson J. A comparison of the efficacy and relapse rates of narrowband UVB (TL-01) monotherapy vs. etretinate (reTL-01) vs. etretinate-PUVA (re-PUVA) in the treatment of psoriasis patients. $\mathrm{Br}$ Dermatol. 1992;127:5-9.

131. Ozdemir M, Engin B, Baysal I, Mevlitoğlu I. A randomized comparison of acitretinnarrow-band TL-01 phototherapy and acitretin-psoralen plus ultraviolet A for psoriasis. Acta Derm Venereol. 2008;88:589-93.

132. Chauhan PS, Kaur I, Dogra S, De D, Kanwar AJ. Narrowband ultraviolet B versus psoralen plus ultraviolet $A$ therapy for severe plaque psoriasis: an Indian perspective. Clin Exp Dermatol. 2011;36:169-73.

133. Dayal S; Mayanka, Jain VK. Comparative evaluation of NBUVB phototherapy and PUVA photochemotherapy in chronic plaque psoriasis. Indian J Dermatol Venereol Leprol. 2010;76:533-7.

134. Sezer E, Erbil AH, Kurumlu Z, Taştan HB, Etikan I. Comparison of the efficacy of local narrowband ultraviolet $B$ (NB-UVB) phototherapy versus psoralen plus ultraviolet $A$ (PUVA) paint for palmoplantar psoriasis. J Dermatol. 2007;34:435-40.

135. Warren RB, Mrowietz U, von Kiedrowski R, Niesmann J, Wilsmann-Theis D, Ghoreschi K, et al. An intensified dosing schedule of subcutaneous methotrexate in patients with moderate to severe plaque-type psoriasis (METOP): a 52 week multicentre, randomised, double-blind, placebo-controlled, phase 3 trial. Lancet. 2017:389:528-37.

136. Reich K, Signorovitch J, Ramakrishnan K, Yu AP, Wu EQ, Gupta SR, et al. Benefitrisk analysis of adalimumab versus methotrexate and placebo in the treatment of moderate to severe psoriasis: comparison of adverse event-free response days in the CHAMPION trial. J Am Acad Dermatol. 2010;63:1011-8.

137. Saurat JH, Stingl G, Dubertret L, Papp K, Langley RG, Ortonne JP, et al. Efficacy and safety results from the randomized controlled comparative study of adalimumab vs. methotrexate vs. placebo in patients with psoriasis (CHAMPION). Br J Dermatol. 2008:158:558-66.

138. Dogra S, Jain A, Kanwar AJ. Efficacy and safety of acitretin in three fixed doses of 25,35 and $50 \mathrm{mg}$ in adult patients with severe plaque type psoriasis: a randomized, double blind, parallel group, dose ranging study. J Eur Acad Dermatol Venereol. 2013;27:e305-11.

139. Gupta AK, Goldfarb MT, Ellis CN, Voorhees JJ. Side-effect profile of acitretin therapy in psoriasis. J Am Acad Dermatol. 1989;20:1088-93.

140. Colombo D, Cassano N, Altomare G, Giannetti A, Vena GA. Psoriasis relapse evaluation with week-end cyclosporine $A$ treatment: results of a randomized, doubleblind, multicenter study. Int J Immunopathol Pharmacol. 2010;23:1143-52.

141. Laburte C, Grossman R, Abi-Rached J, Abeywickrama KH, Dubertret L. Efficacy and safety of oral cyclosporin A (CyA; Sandimmun) for long-term treatment of chronic severe plaque psoriasis. Br J Dermatol. 1994;130:366-75.

142. Christophers E, Mrowietz U, Henneicke HH, Färber L, Welzel D. Cyclosporine in psoriasis: a multicenter dose-finding study in severe plaque psoriasis. The German Multicenter Study. J Am Acad Dermatol. 1992;26:86-90.

143. Asahina A, Nakagawa H, Etoh T, Ohtsuki M; Adalimumab M04-688 Study Group. Adalimumab in Japanese patients with moderate to severe chronic plaque psoriasis: Efficacy and safety results from a Phase II/III randomized controlled study. J Dermatol. 2010;37:299-310. 
144. Bagel J, Lynde C, Tyring S, Kricorian G, Shi Y, Klekotka P. Moderate to severe plaque psoriasis with scalp involvement: a randomized, double-blind, placebocontrolled study of etanercept. J Am Acad Dermatol. 2012;67:86-92.

145. Cai L, Gu J, Zheng J, Zheng M, Wang G, Xi LY, et al. Efficacy and safety of adalimumab in Chinese patients with moderate-to-severe plaque psoriasis: results from a phase 3, randomized, placebo-controlled, double-blind study. J Eur Acad Dermatol Venereol. 2017;31:89-95.

146. Chaudhari U, Romano P, Mulcahy LD, Dooley LT, Baker DG, Gottlieb AB. Efficacy and safety of infliximab monotherapy for plaque-type psoriasis: a randomised trial. Lancet. 2001;357:1842-7.

147. Feldman SR, Gottlieb AB, Bala M, Wu Y, Eisenberg D, Guzzo C, et al. Infliximab improves health-related quality of life in the presence of comorbidities among patients with moderate-to-severe psoriasis. Br J Dermatol. 2008;159:704-10.

148. Feldman SR, Gordon KB, Bala M, Evans R, Li S, Dooley LT, et al. Infliximab treatment results in significant improvement in the quality of life of patients with severe psoriasis: a double-blind placebo-controlled trial. $\mathrm{Br} \mathrm{J}$ Dermatol. 2005;152:954-60

149. Feldman SR, Kimball AB, Krueger GG, Woolley JM, Lalla D, Jahreis A. Etanercept improves the health-related quality of life of patients with psoriasis: Results of a phase III randomized clinical trial. J Am Acad Dermatol. 2005;53:887-9.

150. Gordon KB, Langley RG, Leonardi C, Toth D, Menter MA, Kang S, et al. Clinical response to adalimumab treatment in patients with moderate to severe psoriasis: Double-blind, randomized controlled trial and open-label extension study. J Am Acad Dermatol. 2006;55:598-606.

151. Gottlieb AB, Leonardi C, Kerdel F, Mehlis S, Olds M, Williams DA. Efficacy and safety of briakinumab vs. etanercept and placebo in patients with moderate to severe chronic plaque psoriasis. Br J Dermatol. 2011;165:652-60.

152. Gottlieb AB, Matheson RT, Lowe N, Krueger GG, Kang S, Goffe BS, et al. A randomized trial of etanercept as monotherapy for psoriasis. Arch Dermatol. 2003 Dec;139(12):1627-32.

153. Gottlieb AB, Chaudhari U, Mulcahy LD, Li S, Dooley LT, Baker DG. Infliximab monotherapy provides rapid and sustained benefit for plaque-type psoriasis. J Am Acad Dermatol. 2003;48:829-35.

154. Guenther L, Han C, Szapary P, Schenkel B, Poulin Y, Bourcier M, et al. Impact of ustekinumab on health-related quality of life and sexual difficulties associated with psoriasis: results from two phase III clinical trials. J Eur Acad Dermatol Venereol. $2011 \mathrm{Jul} ; 25(7): 851-7$

155. van de Kerkhof PC, Segaert S, Lahfa M, Luger TA, Karolyi Z, Kaszuba A, et al. Once weekly administration of etanercept $50 \mathrm{mg}$ is efficacious and well tolerated in patients with moderate-to-severe plaque psoriasis: a randomized controlled trial with open-label extension. Br J Dermatol. 2008;159:1177-85.

156. Kimball AB, Papp KA, Wasfi $Y$, Chan D, Bissonnette $R$, Sofen $H$, et al. Longterm efficacy of ustekinumab in patients with moderate-to-severe psoriasis treated for up to 5 years in the PHOENIX 1 study. J Eur Acad Dermatol Venereol. 2013;27:1535-45

157. Kimball AB, Gordon KB, Fakharzadeh S, Yeilding N, Szapary PO, Schenkel B, et al. Long-term efficacy of ustekinumab in patients with moderate-to-severe psoriasis: results from the PHOENIX 1 trial through up to 3 years. Br J Dermatol. 2012;166:861-72.

158. Krueger GG, Langley RG, Finlay AY, Griffiths CE, Woolley JM, Lalla D, et al. Patientreported outcomes of psoriasis improvement with etanercept therapy: results of a randomized phase III trial. Br J Dermatol. 2005;153:1192-9.

159. Langley RG, Elewski BE, Lebwohl M, Reich K, Griffiths CE, Papp K, et al Secukinumab in Plaque Psoriasis - Results of Two Phase 3 Trials. N Engl J Med. 2014:371:326-38.

160. Langley RG, Feldman SR, Han C, Schenkel B, Szapary P, Hsu MC, et al. Ustekinumab significantly improves symptoms of anxiety, depression, and skinrelated quality of life in patients with moderate-to-severe psoriasis: Results from a randomized, double-blind, placebo-controlled phase III trial. J Am Acad Dermatol. 2010;63:457-65

161. Leonardi CL, Kimball AB, Papp KA, Yeilding N, Guzzo C, Wang Y, et al. Efficacy and safety of ustekinumab, a human interleukin-12/23 monoclonal antibody, in patients with psoriasis: 76-week results from a randomised, double-blind, placebo-controlled trial (PHOENIX 1). Lancet. 2008;371:1665-74

162. Leonardi CL, Powers JL, Matheson RT, Goffe BS, Zitnik R, Wang A, et al. Etanercept as monotherapy in patients with psoriasis. N Engl J Med. 2003;349:2014-22.

163. Lebwohl M, Papp K, Han C, Schenkel B, Yeilding N, Wang Y, et al. Ustekinumab improves health-related quality of life in patients with moderate-to-severe psoriasis: results from the PHOENIX 1 trial. Br J Dermatol. 2010;162:137-46.

164. Menter A, Gordon KB, Leonardi CL, Gu Y, Goldblum OM. Efficacy and safety of adalimumab across subgroups of patients with moderate to severe psoriasis. $J$ Am Acad Dermatol. 2010;63:448-56.

165. Menter A, Tyring SK, Gordon K, Kimball AB, Leonardi CL, Langley RG, et al. Adalimumab therapy for moderate to severe psoriasis: $A$ randomized, controlled phase III trial. J Am Acad Dermatol. 2008;58:106-15.

166. Nakagawa $\mathrm{H}$, Schenkel B, Kato M, Kato T, Igarashi A; Japanese Ustekinumab Study Group. Impact of ustekinumab on health-related quality of life in Japanese patients with moderate-to-severe plaque psoriasis: Results from a randomized, double-blind, placebo-controlled phase 2/3 trial. J Dermatol. 2012;39:761-9.

167. Papp KA, Tyring S, Lahfa M, Prinz J, Griffiths CE, Nakanishi AM, et al. A global phase III randomized controlled trial of etanercept in psoriasis: safety, efficacy, and effect of dose reduction. Br J Dermatol. 2005;152:1304-12.

168. Reich K, Nestle F0, Papp K, Ortonne JP, Wu Y, Bala M, et al. Improvement in quality of life with infliximab induction and maintenance therapy in patients with moderate-to-severe psoriasis: a randomized controlled trial. $\mathrm{Br} \mathrm{J}$ Dermatol. 2006;154:1161-8.

169. Reich K, Schenkel B, Zhao N, Szapary P, Augustin M, Bourcier M, et al. Ustekinumab decreases work limitations, improves work productivity, and reduces work days missed in patients with moderate-to-severe psoriasis: results from PHOENIX 2. J Dermatolog Treat. 2011;22:337-47.

170. Revicki D, Willian MK, Saurat JH, Papp KA, Ortonne JP, Sexton C, et al. Impact of adalimumab treatment on health-related quality of life and other patient-reported outcomes: results from a 16-week randomized controlled trial in patients with moderate to severe plaque psoriasis. Br J Dermatol. 2008;158:549-57.

171. Revicki DA, Menter A, Feldman S, Kimel M, Harnam N, Willian MK. Adalimumab improves health-related quality of life in patients with moderate to severe plaque psoriasis compared with the United States general population norms: Results from a randomized, controlled Phase III study. Health Qual Life Outcomes. 2008;6:75.

172. Revicki DA, Willian MK, Menter A, Gordon KB, Kimball AB, Leonardi CL, et al. Impact of adalimumab treatment on patient-reported outcomes: results from a Phase III clinical trial in patients with moderate to severe plaque psoriasis. $J$ Dermatolog Treat. 2007;18:341-50.

173. Strober BE, Crowley JJ, Yamauchi PS, Olds M, Williams DA. Efficacy and safety results from a phase III, randomized controlled trial comparing the safety and efficacy of briakinumab with etanercept and placebo in patients with moderate to severe chronic plaque psoriasis. Br J Dermatol. 2011;165:661-8.

174. Langley RG, Lebwohl M, Krueger GG, Szapary PO, Wasfi Y, Chan D, et al. Longterm efficacy and safety of ustekinumab, with and without dosing adjustment, in patients with moderate-to-severe psoriasis: results from the PHOENIX 2 study through 5 years of follow-up. Br J Dermatol. 2015;172:1371-83.

175. Papp KA, Langley RG, Lebwohl M, Krueger GG, Szapary P, Yeilding N, et al. Efficacy and safety of ustekinumab, a human interleukin-12/23 monoclonal antibody, in patients with psoriasis: 52-week results from a randomised, doubleblind, placebo-controlled trial (PHOENIX 2). Lancet. 2008;371:1675-84.

176. Igarashi A, Kato T, Kato M, Song M, Nakagawa H; Japanese Ustekinumab Study Group. Efficacy and safety of ustekinumab in Japanese patients with moderateto-severe plaque-type psoriasis: long-term results from a phase $2 / 3$ clinical trial. J Dermatol. 2012;39:242-52.

177. Tsai TF Ho JC, Song M, Szapary P, Guzzo C, Shen YK, et al. Efficacy and safety of ustekinumab for the treatment of moderate-to-severe psoriasis: A phase III, randomized, placebo-controlled trial in Taiwanese and Korean patients (PEARL). J Dermatol Sci. 2011;63:154-63.

178. Ohtsuki M, Kubo H, Morishima H, Goto R, Zheng R, Nakagawa H. Guselkumab, an anti-interleukin-23 monoclonal antibody, for the treatment of moderate to severe plaque-type psoriasis in Japanese patients: Efficacy and safety results from a phase 3 , randomized, double-blind, placebo-controlled study. J Dermatol. 2018;45:1053-62.

179. Blauvelt A, Papp KA, Griffiths CE, Randazzo B, Wasfi Y, Shen YK, et al. Efficacy and safety of guselkumab, an anti-interleukin-23 monoclonal antibody, compared with adalimumab for the continuous treatment of patients with moderate to severe psoriasis: Results from the phase III, double-blinded, placebo- and active comparator-controlled VOYAGE 1 trial. J Am Acad Dermatol. 2017;76:405-417

180. Blauvelt A, Gooderham M, Iversen L, Ball S, Zhang L, Agada NO, et al. Efficacy and safety of ixekizumab for the treatment of moderate-to-severe plaque psoriasis: Results through 108 weeks of a randomized, controlled phase 3 clinical trial (UNCOVER-3). J Am Acad Dermatol. 2017;77:855-62.

181. Leonardi C, Maari C, Philipp S, Goldblum O, Zhang L, Burkhardt N, et al. Maintenance of skin clearance with ixekizumab treatment of psoriasis: Three-year results from the UNCOVER-3 study. J Am Acad Dermatol. 2018;79:824-830.e2

182. Bissonnette R, Luger T, Thaçi D, Toth D, Messina I, You R et al. Secukinumab sustains good efficacy and favourable safety in moderate-to-severe psoriasis after up to 3 years of treatment: results from a double-blind extension study. $\mathrm{Br} \mathrm{J}$ Dermatol. 2017:177:1033-42.

183. Griffiths CE, Strober BE, van de Kerkhof P, Ho V, Fidelus-Gort R, Yeilding N, et al. Comparison of ustekinumab and etanercept for moderate-to-severe psoriasis. $\mathrm{N}$ Engl J Med. 2010;362:118-28.

184. Lebwohl M, Strober B, Menter A, Gordon K, Weglowska J, Puig L et al. Phase 3 Studies Comparing Brodalumab with Ustekinumab in Psoriasis. N Engl J Med. 
2015;373:1318-28

185. Griffiths CE, Reich K, Lebwohl M, van de Kerkhof P, Paul C, Menter A, et al. Comparison of ixekizumab with etanercept or placebo in moderate-to-severe psoriasis (UNCOVER-2 and UNCOVER-3): results from two phase 3 randomised trials. Lancet. 2015;386:541-51.

186. Barker J, Hoffmann M, Wozel G, Ortonne JP, Zheng H, van Hoogstraten H, et al. Efficacy and safety of infliximab vs. methotrexate in patients with moderate-tosevere plaque psoriasis: results of an open-label, active-controlled, randomized trial (RESTORE1). Br J Dermatol. 2011;165:1109-17.

187. Lee JH, Youn JI, Kim TY, Choi JH, Park CJ, Choe YB, A multicenter, randomized, open-label pilot trial assessing the efficacy and safety of etanercept $50 \mathrm{mg}$ twice weekly followed by etanercept $25 \mathrm{mg}$ twice weekly, the combination of etanercept $25 \mathrm{mg}$ twice weekly and acitretin, and acitretin alone in patients with moderate to severe psoriasis. BMC Dermatol. 2016;16:11

188. Gottlieb AB, Lacour JP, Korman N, Wilhelm S, Dutronc Y, Schacht A, et al. Treatment outcomes with ixekizumab in patients with moderate-to-severe psoriasis who have or have not received prior biological therapies: an integrated analysis of two Phase III randomized studies. J Eur Acad Dermatol Venereol. 2017;31:679-85.

189. Van Lümig PP, Lecluse LL, Driessen RJ, Spuls PI, Boezeman JB, van de Kerkhof $\mathrm{PC}$, et al. Switching from etanercept to adalimumab is effective and safe: results in 30 patients with psoriasis with primary failure, secondary failure or intolerance to etanercept. Br J Dermatol. 2010;163:838-46.

190. van Lümig PP, van de Kerkhof PC, Boezeman JB, Driessen RJ, de Jong EM. Adalimumab therapy for psoriasis in real-world practice: efficacy, safety and results in biologic-naïve vs. non-naïve patients. J Eur Acad Dermatol Venereol. 2013;27:593-600.

191. Ortonne JP, Chimenti S, Reich K, Gniadecki R, Sprøgel P, Unnebrink K, et al. Efficacy and safety of adalimumab in patients with psoriasis previously treated with anti-tumour necrosis factor agents: subanalysis of BELIEVE. J Eur Acad Dermatol Venereol. 2011;25:1012-20

192. Mazzotta A, Esposito M, Costanzo A, Chimenti S. Efficacy and safety of etanercept in psoriasis after switching from other treatments: an observational study. Am J Clin Dermatol. 2009;10:319-24.

193. An J, Zhang D, Wu J, Li J, Teng X, Gao X, et al. The acitretin and methotrexate combination therapy for psoriasis vulgaris achieves higher effectiveness and less liver fibrosis. Pharmacol Res. 2017;121:158-68.

194. Asawanonda P, Nateetongrungsak Y.. Methotrexate plus narrowband UVB phototherapy versus narrowband UVB phototherapy alone in the treatment of plaque-type psoriasis: a randomized, placebo-controlled study. J Am Acad Dermatol. 2006;54:1013-8.

195. Aydin F, Canturk T, Senturk N, Turanli AY. Methotrexate and ciclosporin combination for the treatment of severe psoriasis. Clin Exp Dermatol. 2006;31:520-4.

196. Calzavara-Pinton PG, Sala R, Arisi M, Rossi MT, Venturini M, Ortel B. Synergism between narrowband ultraviolet $\mathrm{B}$ phototherapy and etanercept for the treatment of plaque-type psoriasis. Br J Dermatol. 2013;169:130-6.

197. Gambichler T, Tigges C, Scola N, Weber J, Skrygan M, Bechara FG, et al. Etanercept plus narrowband ultraviolet $B$ phototherapy of psoriasis is more effective than etanercept monotherapy at 6 weeks. Br J Dermatol. 2011;164:1383-6.

198. Gisondi P, Del Giglio M, Cotena C, Girolomoni G. Combining etanercept and acitretin in the therapy of chronic plaque psoriasis: a 24-week, randomized, controlled, investigator-blinded pilot trial. Br J Dermatol. 2008;158:1345-9.

199. Gottlieb AB, Langley RG, Strober BE, Papp KA, Klekotka P, Creamer K, et al. A randomized, double-blind, placebo-controlled study to evaluate the addition of methotrexate to etanercept in patients with moderate to severe plaque psoriasis. Br J Dermatol. 2012;167:649-57.

200. lest J, Boer J. Combined treatment of psoriasis with acitretin and UVB phototherapy compared with acitretin alone and UVB alone. Br J Dermatol. 1989;120:665-70.

201. Lowe NJ, Prystowsky JH, Bourget T, Edelstein J, Nychay S, Armstrong R. Acitretin plus UVB therapy for psoriasis. Comparisons with placebo plus UVB and acitretin alone. J Am Acad Dermatol. 1991;24:591-4.

202. Mahajan R, Kaur I, Kanwar AJ.. Methotrexate/narrowband UVB phototherapy combination vs. narrowband UVB phototherapy in the treatment of chronic plaquetype psoriasis--a randomized single-blinded placebo-controlled study. J Eur Acad Dermatol Venereol. 2010;24:595-600.

203. Mohanan S, Ramassamy S, Chandrashekar L, Thappa DM. A retrospective analysis of combination methotrexate-cyclosporine therapy in moderate-severe psoriasis. J Dermatolog Treat. 2014;25:50-3.

204. Papp KA, Gordon KB, Langley RG, Lebwohl MG, Gottlieb AB, Rastogi S, et al. Impact of previous biologic use on the efficacy and safety of brodalumab and ustekinumab in patients with moderate-to-severe plaque psoriasis: integrated analysis of the randomized controlled trials AMAGINE-2 and AMAGINE-3. Br J Dermatol. 2018;179:320-328.

205. Park KK, Wu JJ, Koo J. A randomized, "head-to-head" pilot study comparing the effects of etanercept monotherapy vs. etanercept and narrowband ultraviolet
B (NB-UVB) phototherapy in obese psoriasis patients. J Eur Acad Dermatol Venereol. 2013;27:899-906

206. Tanew A, Guggenbichler A, Hönigsmann H, Geiger JM, Fritsch P. Photochemotherapy for severe psoriasis without or in combination with acitretin: a randomized, doubleblind comparison study. J Am Acad Dermatol. $1991 ; 25: 682-4$.

207. Wolf P, Weger W, Legat FJ, Posch-Fabian T, Gruber-Wackernagel A, Inzinger M, Salmhofer W, et al. Treatment with 311-nm ultraviolet B enhanced response of psoriatic lesions in ustekinumab-treated patients: a randomized intraindividual trial. Br J Dermatol. 2012;166:147-53.

208. Zachariae C, Mørk NJ, Reunala T, Lorentzen H, Falk E, Karvonen SL,et al. The Combination of Etanercept and Methotrexate Increases the Effectiveness of Treatment in Active Psoriasis Despite Inadequate Effect of Methotrexate Therapy. Acta Derm Venereol. 2008;88:495-501.

209. Abrouk M, Beroukhim K, Nakamura M, Zhu TH, Farahnik B, Singh R, et al Considerations on biologic agents in psoriasis with the new pregnancy lactation labeling rule. Int J Womens Dermatol. 2016;2:62-4.

210. Bae YS, Van Voorhees AS, Hsu S, Korman NJ, Lebwohl MG, Young M, et al. Review of treatment options for psoriasis in pregnant or lactating women: from the Medical Board of the National Psoriasis Foundation. J Am Acad Dermatol. 2012;67:459-77.

211. Bangsgaard N, Rørbye C, Skov L. Treating Psoriasis During Pregnancy: Safety and Efficacy of Treatments. Am J Clin Dermatol. 2015;16:389-98.

212. Bar Oz B, Hackman R, Einarson T, Koren G. Pregnancy outcome after cyclosporine therapy during pregnancy: a meta-analysis. Transplantation. 2001;71:1051-5.

213. Berthelsen BG, Fjeldsøe-Nielsen H, Nielsen CT, Hellmuth E. Etanercept concentrations in maternal serum, umbilical cord serum, breast milk and child serum during breastfeeding. Rheumatology (Oxford). 2010;49:2225-7.

214. Brown SM, Aljefri K, Waas R, Hampton P. Systemic medications used in treatment of common dermatological conditions: safety profile with respect to pregnancy, breast feeding and content in seminal fluid. J Dermatolog Treat. 2018;13:1-17

215. Carman WJ, Accortt NA, Anthony MS, lles J, Enger C. Pregnancy and infant outcomes including major congenital malformations among women with chronic inflammatory arthritis or psoriasis, with and without etanercept use. Pharmacoepidemiol Drug Saf. 2017;26:1109-18

216. Chi CC, Mayon-White RT, Wojnarowska FT. Safety of topical corticosteroids in pregnancy: a population-based cohort study. J Invest Dermatol. 2011;131:884-91

217. Clowse ME, Feldman SR, Isaacs JD, Kimball AB, Strand V, Warren RB, et al. Pregnancy Outcomes in the Tofacitinib Safety Databases for Rheumatoid Arthritis and Psoriasis. Drug Saf. 2016;39:755-62.

218. El-Saie LT, Rabie AR, Kamel MI, Seddeik AK, Elsaie ML. Effect of narrowband ultraviolet B phototherapy on serum folic acid levels in patients with psoriasis. Lasers Med Sci. 2011;26:481-5.

219. Feldkamp M, Carey JC.. Clinical teratology counseling and consultation case report: low dose methotrexate exposure in the early weeks of pregnancy. Teratology. 1993;47:533-9.

220. Franssen ME, van der Wilt GJ, de Jong PC, Bos RP, Arnold WP. A retrospective study of the teratogenicity of dermatological coal tar products. Acta Derm Venereol. 1999;79:390-1.

221. Fritzsche J, Pilch A, Mury D, Schaefer C, Weber-Schoendorfer C. Infliximab and adalimumab use during breastfeeding. J Clin Gastroenterol. 2012;46:718-9.

222. Ghanem ME, El-Baghdadi LA, Badawy AM, Bakr MA, Sobhe MA, Ghoneim MA Pregnancy outcome after renal allograft transplantation: 15 years experience. Eur J Obstet Gynecol Reprod Biol. 2005;121:178-81.

223. Goldberg LD. Transmission of a vitamin-D metabolite in breast milk. Lancet. 1972:2:1258-9.

224. Guillonneau M, Jacqz-Aigrain E.. Teratogenic effects of vitamin A and its derivates] Arch Pediatr. 1997;4:867-74.

225. Gunnarskog JG, Källén AJ, Lindelöf BG, Sigurgeirsson B. Psoralen photochemotherapy (PUVA) and pregnancy. Arch Dermatol. 1993;129:320-3.

226. Hale EK, Pomeranz MK. Dermatologic agents during pregnancy and lactation: an update and clinical review. Int J Dermatol. 2002;41:197-203.

227. Hoffman MB, Farhangian M, Feldman SR. Psoriasis during pregnancy: characteristics and important management recommendations. Expert Rev Clin Immunol. 2015;11:709-20.

228. Johansen CB, Jimenez-Solem E, Haerskjold A, Sand FL, Thomsen SF. The Use and Safety of TNF Inhibitors during Pregnancy in Women with Psoriasis: A Review. Int J Mol Sci. 2018;19. pii: E1349.

229. Johns DG, Rutherford LD, Leighton PC, Vogel CL. Secretion of methotrexate into human milk. Am J Obstet Gynecol. 1972 Apr 1;112:978-80.

230. Kane $\mathrm{S}$, Ford $\mathrm{J}$, Cohen $\mathrm{R}$, Wagner $\mathrm{C}$. Absence of infliximab in infants and breast milk from nursing mothers receiving therapy for Crohn's disease before and after delivery. J Clin Gastroenterol. 2009;43:613-6.

231. Kozlowski RD, Steinbrunner JV, MacKenzie AH, Clough JD, Wilke WS, Segal AM. Outcome of first-trimester exposure to low-dose methotrexate in eight patients 
with rheumatic disease. Am J Med. 1990;88:589-92.

232. Kurizky PS, Ferreira Cde C, Nogueira LS, Mota LM. Treatment of psoriasis and psoriatic arthritis during pregnancy and breastfeeding. An Bras Dermatol. 2015;90:367-75.

233. Lamarque V, Leleu MF, Monka C, Krupp P. Analysis of 629 pregnancy outcomes in transplant recipients treated with Sandimmun. Transplant Proc. 1997 Aug;29(5):2480.

234. Murase JE, Heller MM, Butler DC. Safety of dermatologic medications in pregnancy and lactation: Part I. Pregnancy. J Am Acad Dermatol. 2014;70:401.e1-14.

235. Murashima A, Watanabe N, Ozawa N, Saito H, Yamaguchi K. Etanercept during pregnancy and lactation in a patient with rheumatoid arthritis: drug levels in maternal serum, cord blood, breast milk and the infant's serum. Ann Rheum Dis. 2009;68:1793-4.

236. Nguyen C, Duhl AJ, Escallon CS, Blakemore KJ.. Multiple anomalies in a fetus exposed to low-dose methotrexate in the first trimester. Obstet Gynecol. 2002;99:599-602.

237. Nyberg G, Haljamäe U, Frisenette-Fich C, Wennergren M, Kjellmer I. Breast-feeding during treatment with cyclosporine. Transplantation. 1998;65:253-5.

238. Paziana K, Del Monaco M, Cardonick E, Moritz M, Keller M, Smith B, et al. Ciclosporin use during pregnancy. Drug Saf. 2013;36:279-94.

239. Rademaker M, Agnew K, Andrews M, Armour K, Baker C, Foley P, et al. Psoriasis in those planning a family, pregnant or breast-feeding. The Australasian Psoriasis Collaboration. Australas J Dermatol. 2018;59:86-100.

240. Rollman 0, Pihl-Lundin I. Acitretin excretion into human breast milk. Acta Derm Venereol. 1990;70:487-90.

241. Ruiz V, Manubens E, Puig L. Psoriasis in pregnancy: a review (II). Actas Dermosifiliogr. 2014;105:813-21.

242. Schaefer C, Peters P, Miller RK. Drugs during pregnancy and lactation: treatment options and risk assessment. 3rd ed. Cambridge: Academic Press; 2014

243. Scheepers PT, van Houtum JL, Anzion RB, Harder R, Bos RP, van der Valk PG. Uptake of pyrene in a breast-fed child of a mother treated with coal tar. Pediatr Dermatol. 2009;26:184-7.

244. De Stefano P, Bongo IG, Borgna-Pignatti C, Severi F. Factitious hypertension with mineralocorticoid excess in an infant. Helv Paediatr Acta. 1983;38:185-9.

245. Stengel JZ, Arnold HL. Is infliximab safe to use while breastfeeding? World J Gastroenterol. 2008;14:3085-7.

246. Stern RS, Lange R. Outcomes of pregnancies among women and partners of men with a history of exposure to methoxsalen photochemotherapy (PUVA) for the treatment of psoriasis. Arch Dermatol. 1991;127:347-50.

247. Vena GA, Cassano N, Bellia G, Colombo D. Psoriasis in pregnancy: challenges and solutions. Psoriasis (Auckl). 2015;5:83-95

248. Vun YY, Jones B, Al-Mudhaffer M, Egan C. Generalized pustular psoriasis of pregnancy treated with narrowband UVB and topical steroids. J Am Acad Dermatol. 2006;54(Suppl):S28-30.

249. Warren RB, Reich K, Langley RG, Strober B, Gladman D, Deodhar A, et al. Secukinumab in pregnancy: outcomes in psoriasis, psoriatic arthritis and ankylosing spondylitis from the global safety database. Br J Dermatol. 2018;179:1205-1207.

250. Westermann L, Hügel R, Meier M, Weichenthal M, Zillikens D, Gläser R,et al Glucocorticosteroid-resistant pemphigoid gestationis: successful treatment with adjuvant immunoadsorption. J Dermatol. 2012;39:168-71.

251. Yiu ZZ, Warren RB, Mrowietz U, Griffiths CE. Safety of conventional systemic therapies for psoriasis on reproductive potential and outcomes. J Dermatolog Treat. 2015;26:329-34
252. Tillack C, Ehmann LM, Friedrich M, Laubender RP, Papay P, Vogelsang H, et al. Anti-TNF antibody-induced psoriasiform skin lesions in patients with inflammatory bowel disease are characterised by interferon- $\gamma$-expressing Th1 cells and IL-17A/ IL-22-expressing Th17 cells and respond to anti-IL-12/IL-23 antibody treatment. Gut. 2014:63:567-77.

253. Guerra I, Algaba A, Pérez-Calle JL, Chaparro M, Marín-Jiménez I, García-Castellanos $\mathrm{R}$, et al. Induction of psoriasis with anti-TNF agents in patients with inflammatory bowel disease: a report of 21 cases. J Crohns Colitis. 2012;6:518-23.

254. Darrigade AS, Milpied B, Truchetet ME, Schaeverbeke T, Laharie D, Zerbib F, et al. Pattern and Severity of Psoriasiform Eruptions in Patients with Inflammatory Bowel Diseases, Arthritis or Skin Inflammatory Disorders Treated with TNF-alpha Inhibitors. Acta Derm Venereol. 2017;97:731-4.

255. Kirthi Jeyarajah S, Tobin AM, Hussey M, Scaldaferri F, McNamara D. Anti-TNF $\alpha$ antibody-induced psoriasiform skin lesions in patients with inflammatory bowe disease: an Irish Cohort Study. QJM. $2017 ; 110: 379-82$.

256. Guerra I1, Pérez-Jeldres T, Iborra M, Algaba A, Monfort D, Calvet X, et al Incidence, Clinical Characteristics, and Management of Psoriasis Induced by AntiTNF Therapy in Patients with Inflammatory Bowel Disease: A Nationwide Cohort Study. Inflamm Bowel Dis. 2016;22:894-901.

257. Afshar M, Martinez AD, Gallo RL, Hata TR. Induction and exacerbation of psoriasis with Interferon-alpha therapy for hepatitis C: a review and analysis of 36 cases. J Eur Acad Dermatol Venereol. 2013;27:771-8.

258. Lamba G, Palaniswamy C, Singh T, Shah D, Lal S, Vinnakota R,Psoriasis induced by losartan therapy: a case report and review of the literature. Am $\mathrm{J}$ Ther 2011;18:e78-80

259. Katoulis AC, Bozi E, Kanelleas A, Makris M, Alevizou A, Panagiotides I, et al. Psoriasiform fixed drug eruption caused by nimesulide. Clin Exp Dermatol. 2009;34:e360-1

260. Clark DW, Coulter DM. Psoriasis associated with rofecoxib. Arch Dermatol. 2003;139:1223

261. Wu S, Han J, Qureshi AA. Use of aspirin, non-steroidal anti-inflammatory drugs, and acetaminophen (paracetamol), and risk of psoriasis and psoriatic arthritis: a cohort study. Acta Derm Venereol. 2015;95:217-23.

262. Brauchli YB, Jick SS, Curtin F, Meier CR. Association between beta-blockers, other antihypertensive drugs and psoriasis: population-based case-control study. $\mathrm{Br}$ Dermatol. 2008;158:1299-307.

263. Arntzen N, Kavli G, Volden G. Psoriasis provoked by beta-blocking agents. Acta Derm Venereol. 1984;64:346-8.

264. Brauchli YB, Jick SS, Curtin F, Meier CR. Lithium, antipsychotics, and risk of psoriasis. J Clin Psychopharmacol. 2009;29:134-40.

265. Chan HH, Wing Y, Su R, Van Krevel C, Lee S. A control study of the cutaneous side effects of chronic lithium therapy. J Affect Disord. 2000;57:107-13.

266. Gilleaudeau P, Vallat VP, Carter DM, Gottlieb AB. Angiotensin-converting enzyme inhibitors as possible exacerbating drugs in psoriasis. J Am Acad Dermatol. 1993:28:490-2

267. Coulter DM, Pillans PI. Angiotensin-converting enzyme inhibitors and psoriasis. N Z Med J. 1993:106:392-3.

268. Vestey JP, Savin JA. Psoriasis worsened by antimalarial prophylaxis. J Infect. 1992;24:211-2.

269. Mallett R, Pye R. Risks and benefits of prophylactic antimalarial drugs. BMJ. $1989 ; 299: 1400$ 


\section{AUTHORS'CONTRIBUTIONS}

Marcelo Arnone $\quad$ (iD) ORCID $\quad 0000-0002-7192-5161$

Approval of the final version of the manuscript; Design and planning of the study; Preparation and writing of the manuscript; Data collection, analysis and interpretation; Critical literature review; Critical manuscript review
Maria Denise Fonseca Takahashi
(iD) ORCID 0000-0001-8671-6680

Approval of the final version of the manuscript; Design and planning of the study; Preparation and writing of the manuscript; Data collection, analysis and interpretation; Critical literature review; Critical manuscript review

André Vicente Esteves de Carvalho

ORCID 0000-0002-0407-538X

Approval of the final version of the manuscript; Preparation and writing of the manuscript; Data collection, analysis and interpretation; Critical literature review; Critical manuscript review

Wanderley Marques Bernardo $\quad$ (iD) ORCID 0000-0002-8597-5207

Statistical analysis; Approval of the final version of the manuscript; Design and planning of the study; Preparation and writing of the manuscript; Data collection, analysis and interpretation; Critical literature review; Critical manuscript review

Aline Lopes Bressan $\quad$ (iD) ORCID

Data collection, analysis and interpretation; Critical literature review

Andrea Machado Coelho Ramos $\quad$ (ID) ORCID 0000-0002-3296-5232

Data collection, analysis and interpretation; Critical literature review Aripuanã Cobério Terena (ID) ORCID

Data collection, analysis and interpretation; Critical literature review Cacilda da Silva Souza $\quad$ (iD) ORCID Data collection, analysis and interpretation; Critical literature review Daniel Holthausen Nunes $\quad$ (ID) ORCID Data collection, analysis and interpretation; Critical literature review Maria Cecília de Carvalho Bortoletto (iD) ORCID Data collection, analysis and interpretation; Critical literature review Maria de Fátima Santos Paim de Oliveira (iD) ORCID Data collection, analysis and interpretation; Critical literature review Jane Marcy Neffá $\quad$ (iD) ORCID Data collection, analysis and interpretation; Critical literature review Luciana Cristina Fieri (iD) ORCID Data collection, analysis and interpretation; Critical literature review Luna Azulay-Abulafia $\quad$ (ID) ORCID Data collection, analysis and interpretation; Critical literature review Paulo Antônio Oldani Felix $\quad$ (iD) ORCID Data collection, analysis and interpretation; Critical literature review Renata Ferreira Magalhaes $\quad$ (iD) ORCID Data collection, analysis and interpretation; Critical literature review Ricardo Romiti $\quad$ (iD) ORCID Data collection, analysis and interpretation; Critical literature review Tatiana Jerez Jaime ID ORCID Data collection, analysis and interpretation; Critical literature review

0000-0001-7414-3395

0000-0002-2550-1341

$0000-0002-8157-7658$

0000-0002-1303-5419

0000-0002-6156-6097

$0000-0002-8594-200 x$

0000-0002-7888-0154

0000-0002-7981-9398

0000-0002-4698-2009

0000-0002-1055-0597

0000-0001-9170-932X

0000-0003-0165-3831

0000-0002-7594-620X

How to cite this article: Arnone M, Takahashi MDF, Carvalho AVE, Bernardo WM, Bressan AL, Ramos AMC, Terena AC, Souza CS, Nunes DH, Bortoletto MCC, Oliveira MFSP, Neffá JM, Fieri LC, Azulay-Abulafia L, Felix PAO, Magalhaes RF, Romiti R, Jaime TJ. Diagnostic and therapeutic guidelines for plaque psoriasis - Brazilian Society of Dermatology. An Bras Dermatol. 2019;94(2): S76-107. 